\title{
Definição das metas regulatórias de inadimplência para as distribuidoras de energia elétrica no Brasil: proposição de um modelo baseado em lógica fuzzy
}

Dissertação de Mestrado

Dissertação apresentada como requisito parcial para obtenção do grau de Mestre pelo Programa de PósGraduação em Metrologia (Área de concentração: Metrologia para Qualidade e Inovação) da PUC-Rio.

Orientador: Rodrigo Flora Calili Coorientador: Daniel Ramos Louzada 
Definição das metas regulatórias de inadimplência para as distribuidoras de energia elétrica no Brasil: proposição de um modelo baseado em lógica fuzzy

\begin{abstract}
Dissertação apresentada como requisito parcial para obtenção do grau de Mestre pelo Programa de PósGraduação em Metrologia (Área de concentração: Metrologia para Qualidade e Inovação) da PUC-Rio. Aprovada pela Comissão Examinadora abaixo:
\end{abstract}

\title{
Prof. Rodrigo Flora Calili
}

Orientador

Programa de Pós-Graduação em Metrologia - PUC-Rio

Prof. Daniel Ramos Louzada

Coorientador

Programa de Pós-Graduação em Metrologia - PUC-Rio

Prof. Reinaldo Castro Souza

Programa de Pós-Graduação em Metrologia - PUC-Rio

José Francisco Moreira Pessanha

Centro de Pesquisas de Energia Elétrica - CEPEL

Guilherme de Azevedo Dantas

Essenz Soluções

Rio de Janeiro, 06 de maio de 2021 
Todos os direitos reservados. A reprodução, total ou parcial, do trabalho é proibida sem autorização da universidade, da autora e do orientador.

\section{Nivia Maria Celestino}

Graduou-se em Ciências Econômicas na Universidade Federal de Juiz de Fora em 2000. Possui Pós-Graduação em Métodos Estatísticos Computacionais pela UFJF e em Gestão Financeira pela Fundação Getúlio Vargas. Atua no setor elétrico como especialista de regulação.

Ficha Catalográfica

Celestino, Nivia Maria

Definição das metas regulatórias de inadimplência para as distribuidoras de energia elétrica no Brasil: proposição de um modelo baseado em lógica fuzzy / Nivia Maria Celestino ; orientador: Rodrigo Flora Calili ; coorientador: Daniel Ramos Louzada. - 2021. 105 f. : il. color. ; $30 \mathrm{~cm}$

Dissertação (mestrado)-Pontifícia Universidade Católica do Rio de Janeiro, Centro Técnico Científico, Programa de Pós-Graduação em Metrologia, 2021.

Inclui bibliografia

1. Metrologia - Teses. 2. Metrologia para Qualidade e Inovação - Teses. 3. Inadimplência de energia. 4. Regulação por incentivo. 5. Metas regulatórias de inadimplência. 6. Inferência fuzzy. I. Calili, Rodrigo Flora. II. Louzada, Daniel Ramos. III. Pontifícia Universidade Católica do Rio de Janeiro. Centro Técnico Científico. Programa de Pós-Graduação em Metrologia. IV. Título.

CDD: 389.1 


\section{Agradecimentos}

Ao meu orientador Prof. Rodrigo Flora Calili e ao meu co-orientador Prof. Daniel Ramos Louzada pelo estímulo e parceria para a realização deste trabalho.

À PUC-Rio, pelos auxílios concedidos, sem os quais este trabalho não poderia ter sido realizado.

A todos os professores e funcionários do Programa de Pós-Graduação em Metrologia pela dedicação, ensinamentos e por toda ajuda ao longo da minha jornada.

Aos professores e amigos que participaram do Projeto de Pesquisa e

Desenvolvimento no qual esse tema teve origem.

Aos professores que participaram da Comissão examinadora.

Ao Conselho Nacional de Desenvolvimento Científico e Tecnológico (CNPq), pela bolsa de estudos durante o curso de mestrado.

O presente trabalho foi realizado com apoio da Coordenação de Aperfeiçoamento de Pessoal de Nível Superior - Brasil (CAPES) - Código de Financiamento 001. 


\section{Resumo}

Celestino, Nivia Maria; Calili, Rodrigo Flora (orientador); Louzada, Daniel (coorientador). Definição das metas regulatórias de inadimplência para as distribuidoras de energia elétrica no Brasil: proposição de um modelo baseado em lógica fuzzy. Rio de Janeiro, 2021. 105p. Dissertação de Mestrado - Programa de Pós-Graduação em Metrologia (Área de concentração: Metrologia para Qualidade e Inovação), Pontifícia Universidade Católica do Rio de Janeiro.

A definição de metas regulatórias de inadimplência é um tema de extrema importância para as distribuidoras de energia elétrica, para a agência reguladora e para todos os consumidores, visto que tem forte impacto sobre as tarifas de energia. Encontrar uma metodologia de simples implantação e que atenda, simultaneamente, às necessidades de todos os envolvidos, é um grande desafio. A presente dissertação se propõe a testar a metodologia de inferência fuzzy, conforme proposta de ZADEH (1965), com vistas a propor um modelo para a definição das metas regulatórias de inadimplência de energia. No Brasil a atual metodologia proposta pela ANEEL para a definição de metas regulatórias de inadimplência está atrelada à metodologia de perdas não técnicas, a qual, por sua vez, tem sido alvo de críticas pelas distribuidoras e pelo meio acadêmico. Dessa forma, uma metodologia independente para a definição das metas regulatórias de inadimplência tende a beneficiar todos os agentes envolvidos. A metodologia de Inferência fuzzy trouxe resultados diretos, que ficaram muito próximos aos obtidos pela metodologia da ANEEL. Os resultados da utilização da Inferência fuzzy para a obtenção das metas regulatórias da inadimplência mostraram que é possível persistir nesse caminho, uma vez que a metodologia proposta se desvincula da metodologia de perdas não técnicas, mantendo os princípios da regulação por incentivo e captando a heterogeneidade das diversas áreas de concessão.

\section{Palavras-chave}

Inadimplência de Energia; Regulação por incentivo; Metas regulatórias de inadimplência; Inferência fuzzy 


\section{Abstract}

Celestino, Nivia Maria; Calili, Rodrigo Flora (Advisor). Louzada, Daniel Ramos (Co-advisor). Defining regulatory default targets for electricity distributors in Brazil: proposing a model based on fuzzy logic. Rio de Janeiro, 2021. 105p. Dissertação de Mestrado - Programa de Pós-Graduação em Metrologia (Área de concentração: Metrologia para Qualidade e Inovação), Pontifícia Universidade Católica do Rio de Janeiro.

Defining regulatory default targets is an extremely important issue for electricity distributors, the regulatory agency and all consumers, as it has a strong impact on energy tariffs. Finding a methodology that is easy to implement and that simultaneously meets the needs of everyone involved is a major challenge. This dissertation proposes to test the fuzzy inference methodology, as proposed by ZADEH (1965), with a view to proposing a model for the definition of regulatory energy default targets. In Brazil, the current methodology proposed by ANEEL for the definition of regulatory default targets is linked to the methodology of nontechnical losses, which, in turn, has been the target of criticism by the distributors and the academic environment. Thus, an independent methodology for defining regulatory default targets tends to benefit all agents involved. The fuzzy Inference methodology brought direct results, which were very close to those obtained by the ANEEL methodology. The results of using fuzzy inference to achieve the regulatory goals of default showed that it is possible to persist in this path, since the proposed methodology is detached from the non-technical losses methodology, maintaining the principles of regulation by incentive and capturing the heterogeneity of the several concession areas.

\section{Keywords}

Energy Default; Regulation by incentive; Default regulatory targets model; Fuzzy inference. 


\section{Sumário}

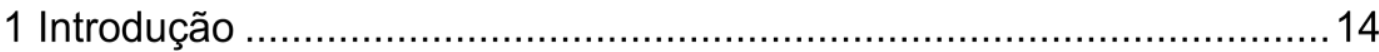

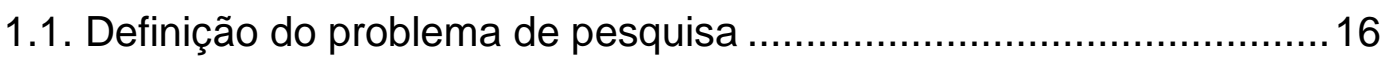

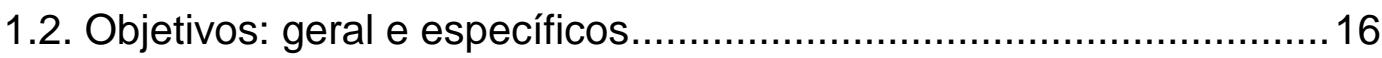

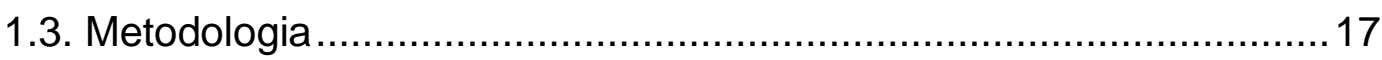

1.3.1. Fase exploratória e descritiva.................................................... 19

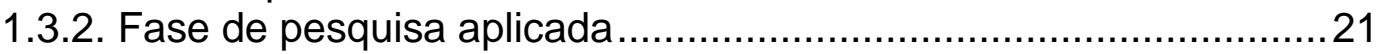

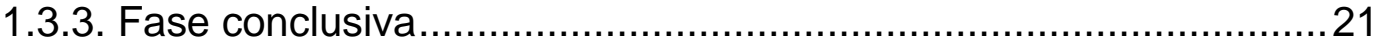

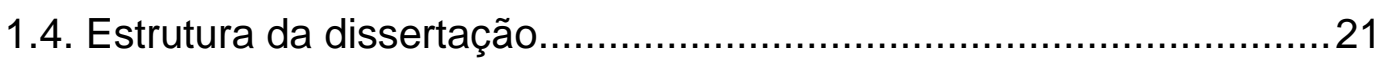

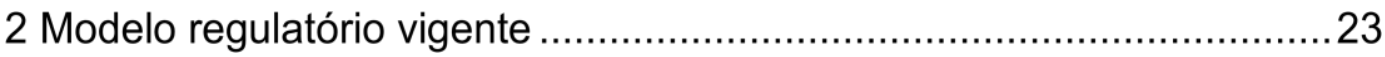

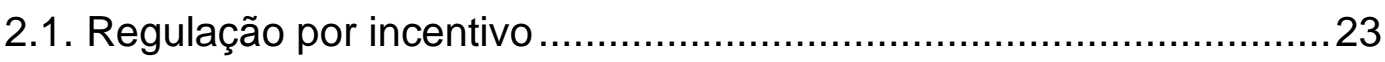

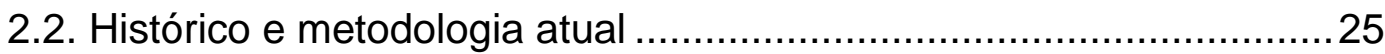

2.3. Análise crítica da metodologia aplicada atualmente..........................27

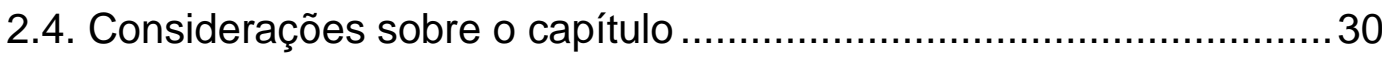

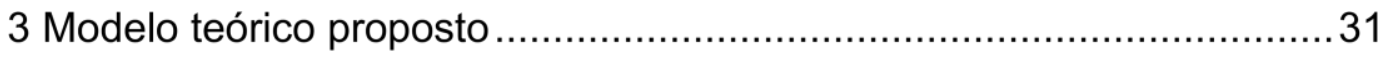

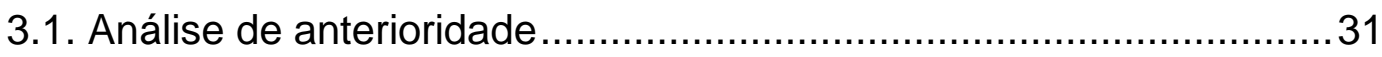

3.2. Modelo proposto com base em inferência fuzzy ..............................36

3.2.1. Fase 1: pesquisa documental e bibliográfica................................37

3.2.2. Fase 2: preparação base de dados e inputs para o Matlab.............39

3.2.3. Fase 3: desenvolvimento/validação do modelo ..............................41

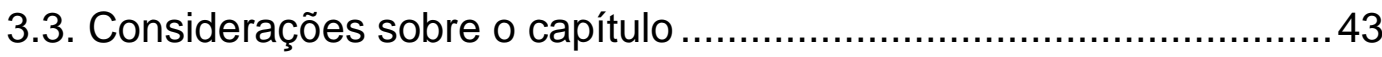

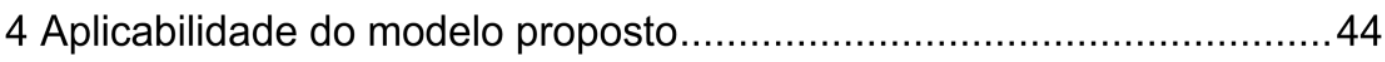

4.1. Fase 1: pesquisa documental e bibliográfica................................... 44

4.2. Fase 2: preparação base de dados e inputs para o Matlab...............47

4.2.1. Definição dos agrupamentos fuzzy ...........................................47

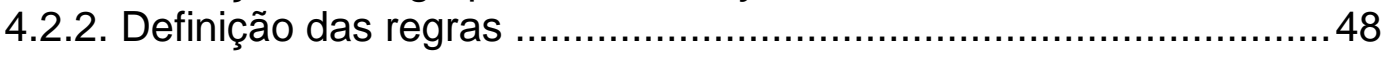

4.3. Fase 3: desenvolvimento/validação do modelo................................52

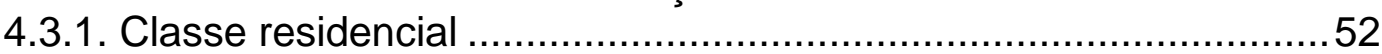

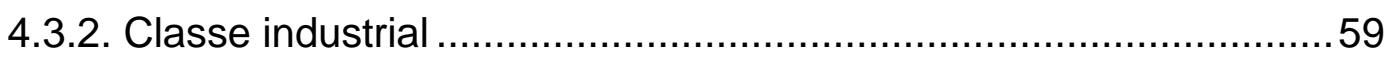

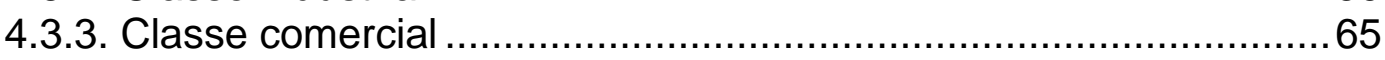

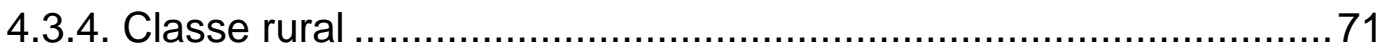

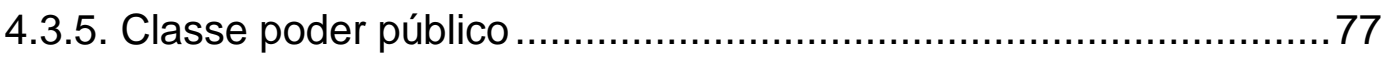

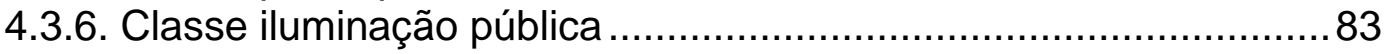

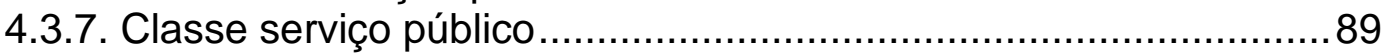

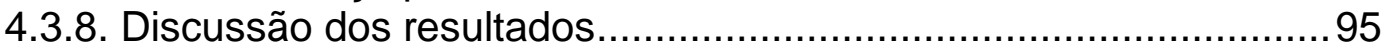

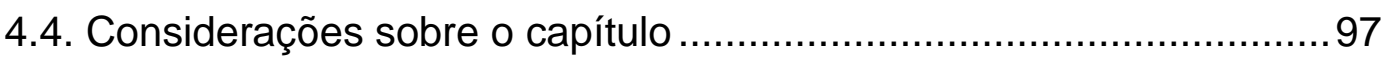

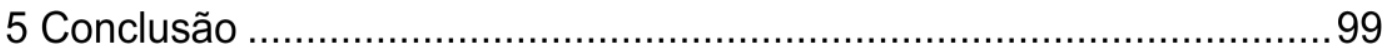

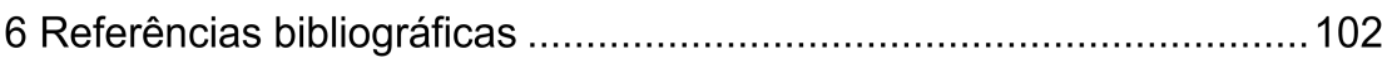




\section{Lista de Figuras}

Figura 1.1 - Desenho da pesquisa, seus componentes e métodos ...........18

Figura 1.2 - Mapa conceitual da pesquisa............................................20

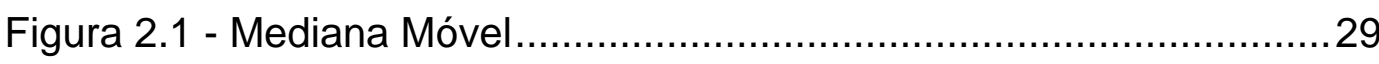

Figura 3.1 - Fases de um Sistema de Inferência Fuzzy - SIF...................34

Figura 3.2 - Esquema global do modelo proposto ...................................37

Figura 3.3 - Grupos fuzzy considerados na modelagem .........................40

Figura 3.4 - Representação dos métodos de defuzzyficação.....................42

Figura 4.1 - Agrupamentos fuzzy para Vulnerabilidade e Porte ................48

Figura 4.2 - Diagrama de formação de regras........................................50

Figura 4.3 -Regras fuzzy - Residencial - curva de aging de 49 a 60

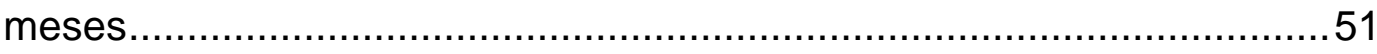

Figura 4.4 - Regras fuzzy - Residencial - curva de aging de 25 a 36 meses.

Figura 4.5 - Escolha do método de defuzzyficação para o residencial curvas de aging de 49 a 60 meses e de 25 a 36 meses

Figura 4.6 - Metas de inadimplência (\%): reais, estimativas modelo fuzzy, estimativas metodologia ANEEL. Em (a) aging de 60 meses e em (b) aging de 36 meses.

Figura 4.7 - Comparação das metas obtidas com curva de aging de 49 a 60 meses e de 25 a 36 meses

Figura 4.8 - Desvios \% Inadimplência real x fuzzy x ANEEL. Em (a) aging de 60 meses e em (b) aging de 36 meses

Figura 4.9 - Comparação da meta ANELL, com a meta estabelecida no modelo fuzzy e a inadimplência real declarada pelas distribuidoras de energia elétrica do Brasil - curva de aging de 49 a 60 meses 58

Figura 4.10 - Comparação da meta ANELL, com a meta estabelecida no modelo fuzzy e a inadimplência real declarada pelas distribuidoras de energia elétrica do Brasil - curva de aging de 25 a 36 meses

Figura 4.11 - Escolha do método de defuzzyficação para o industrial curvas de aging de 49 a 60 meses e de 25 a 36 meses 
Figura 4.12 - Metas de inadimplência (\%): reais, estimativas modelo fuzzy, estimativas metodologia ANEEL. Em (a) aging de 60 meses e em (b) aging de 36 meses

Figura 4.13 - Comparação das metas obtidas com curva de aging de 49 a 60 meses e de 25 a 36 meses 62

Figura 4.14 - Desvios \% Inadimplência real x fuzzy x ANEEL. Em (a) aging de 60 meses e em (b) aging de 36 meses 64

Figura 4.15 - Comparação da meta ANELL, com a meta estabelecida no modelo fuzzy e a inadimplência real declarada pelas distribuidoras de energia elétrica do Brasil - curva de aging de 49 a 60 meses

Figura 4.16 - Comparação da meta ANELL, com a meta estabelecida no modelo fuzzy e a inadimplência real declarada pelas distribuidoras de energia elétrica do Brasil - curva de aging de 25 a 36 meses

Figura 4.17 - Escolha do método de defuzzyficação para o comercial curvas de aging de 49 a 60 meses e de 25 a 36 meses

Figura 4.18 - Metas de inadimplência (\%): reais, estimativas modelo fuzzy, estimativas metodologia ANEEL . Em (a) aging de 60 meses e em (b) aging de 36 meses.

Figura 4.19 - Comparação das metas obtidas com curva de aging de 49 a 60 meses e de 25 a 36 meses

Figura 4.20 - Desvios \% Inadimplência real x fuzzy x ANEEL. Em (a) aging de 60 meses e em (b) aging de 36 meses 70 Figura 4.21 - Comparação da meta ANELL, com a meta estabelecida no modelo fuzzy e a inadimplência real declarada pelas distribuidoras de energia elétrica do Brasil - curva de aging de 49 a 60 meses

Figura 4.22 - Comparação da meta ANELL, com a meta estabelecida no modelo fuzzy e a inadimplência real declarada pelas distribuidoras de energia elétrica do Brasil - curva de aging de 25 a 36 meses .71

Figura 4.23 - Escolha do método de defuzzyficação para o rural - curvas de aging de 49 a 60 meses e de 25 a 36 meses. 72

Figura 4.24 - Metas de inadimplência (\%): reais, estimativas modelo fuzzy, estimativas metodologia ANEEL. Em (a) aging de 60 meses e em (b) aging de 36 meses 
Figura 4.25 - Comparação das metas obtidas com curva de aging de 49 a 60 meses e de 25 a 36 meses

Figura 4.26 - Desvios \% Inadimplência real x fuzzy x ANEEL. Em (a) aging de 60 meses e em (b) aging de 36 meses 76 Figura 4.27 - Comparação da meta ANELL, com a meta estabelecida no modelo fuzzy e a inadimplência real declarada pelas distribuidoras de energia elétrica do Brasil - curva de aging de 49 a 60 meses .77

Figura 4.28 - Comparação da meta ANELL, com a meta estabelecida no modelo fuzzy e a inadimplência real declarada pelas distribuidoras de energia elétrica do Brasil - curva de aging de 25 a 36 meses

Figura 4.29 - Escolha do método de defuzzyficação para o poder público curvas de aging de 49 a 60 meses e de 25 a 36 meses 78

Figura 4.30 - Metas de inadimplência (\%): reais, estimativas modelo fuzzy, estimativas metodologia ANEEL. Em (a) aging de 60 meses e em (b) aging de 36 meses .80

Figura 4.31 - Comparação das metas obtidas com curva de aging de 49 a 60 meses e de 25 a 36

Figura 4.32 - Desvios \% Inadimplência real x fuzzy x ANEEL. Em (a) aging de 60 meses e em (b) aging de 36 meses

Figura 4.33 - Comparação da meta ANELL, com a meta estabelecida no modelo fuzzy e a inadimplência real declarada pelas distribuidoras de energia elétrica do Brasil - curva de aging de 49 a 60 meses

Figura 4.34 - Comparação da meta ANELL, com a meta estabelecida no modelo fuzzy e a inadimplência real declarada pelas distribuidoras de energia elétrica do Brasil - curva de aging de 25 a 36 meses

Figura 4.35 - Escolha do método de defuzzificação para a iluminação

pública - curvas de aging de 49 a 60 meses e de 25 a 36 meses

Figura 4.36 - Metas de inadimplência (\%): reais, estimativas modelo fuzzy, estimativas metodologia ANEEL. Em (a) aging de 60 meses e em (b) aging de 36 meses .86

Figura 4.37 - Comparação das metas obtidas com curva de aging de 49 a 60 meses e de 25 a 36 meses

Figura 4.38 - Desvios \% Inadimplência real x fuzzy x ANEEL. Em (a) aging de 60 meses e em (b) aging de 36 meses .88 
Figura 4.39 - Comparação da meta ANELL, com a meta estabelecida no modelo fuzzy e a inadimplência real declarada pelas distribuidoras de energia elétrica do Brasil - curva de aging de 49 a 60 meses

Figura 4.40 - Comparação da meta ANELL, com a meta estabelecida no modelo fuzzy e a inadimplência real declarada pelas distribuidoras de energia elétrica do Brasil - curva de aging de 25 a 36 meses 89

Figura 4.41 - Escolha do método de defuzzyficação para o serviço público - curvas de aging de 49 a 60 meses e de 25 a 36 meses .90

Figura 4.42 - Metas de inadimplência (\%): reais, estimativas modelo fuzzy, estimativas metodologia ANEEL. Em (a) aging de 60 meses e em (b) aging de 36 meses 92

Figura 4.43 - Comparação das metas obtidas com curva de aging de 49 a 60 meses e de 25 a 36 meses 93

Figura 4.44 - Desvios \% Inadimplência real x fuzzy x ANEEL. Em (a) aging de 60 meses e em (b) aging de 36 meses 94 Figura 4.45 - Comparação da meta ANELL, com a meta estabelecida no modelo fuzzy e a inadimplência real declarada pelas distribuidoras de energia elétrica do Brasil - curva de aging de 49 a 60 meses .95 Figura 4.46 - Comparação da meta ANELL, com a meta estabelecida no modelo fuzzy e a inadimplência real declarada pelas distribuidoras de energia elétrica do Brasil - curva de aging de 25 a 36 meses .95 


\section{Lista de Tabelas}

Tabela 4.1 - Resultado modelo para a classe residencial - valores \% ....54

Tabela 4.2 - Quantidade percentual de desvios entre $-0,5 \%$ e $+0,5 \%$.....56

Tabela 4.3 - Resultado modelo para a classe industrial - valores $\%$.......60

Tabela 4.4 - quantidade percentual de desvios entre $-0,5 \%$ e $+0,5 \% \ldots \ldots .62$

Tabela 4.5 - Resultado modelo para a classe comercial - valores \% ......67

Tabela 4.6 - quantidade percentual de desvios entre $-0,5 \%$ e $+0,5 \% \ldots \ldots .69$

Tabela 4.7 Resultado modelo para a classe rural - valores \% ..................73

Tabela 4.8 - Resultado modelo para a classe poder público - valores \% 79 Tabela 4.9 - Resultado modelo para a classe iluminação pública - valores $\%$ .85

Tabela 4.10 - Resultado modelo para a classe serviço público - valores \% 


\section{Lista de quadros}

Quadro 3.1 - Variáveis avaliadas para a construção do modelo proposto37

Quadro 4.1 - Variáveis utilizadas para a construção das variáveis fuzzy. 46

Quadro 4.2 - Exemplo de formação de regra para o segmento residencial, considerando curva de aging de 25 a 36 meses 


\section{Introdução}

O nível elevado de perdas não técnicas e inadimplência de energia se constitui em um dos grandes desafios para as distribuidoras de energia elétrica do Brasil, bem como para o Órgão Regulador - ANEEL (Agência Nacional de Energia Elétrica).

Em 2013, por meio da abertura da Consulta Pública - CP n 11/2013, a ANEEL deu início à discussão do processo de aprimoramento da metodologia de revisão tarifária aplicada às distribuidoras de energia elétrica. Seguindo os trâmites regulatórios, em 2014, esse mesmo tema foi alvo da Audiência Pública AP no 023/2014. Dentre os módulos em discussão, constou o estabelecimento das metas regulatórias de inadimplência para as distribuidoras de energia elétrica. A metodologia atual adotada para o estabelecimento das metas de inadimplência regulatória das distribuidoras foi definida com base nas discussões realizadas nesse período. Posteriormente, em 2019 e 2020, a ANEEL abriu novas consultas públicas (CP nำ18/2019 e CP nํ29/2020) para obter subsídios para avaliação da necessidade de revisão da metodologia e atualização dos parâmetros dos Procedimentos de Regulação Tarifária - PRORET referentes às receitas irrecuperáveis e perdas de energia.

Conforme consta na Nota Técnica no 107/2015 - SGT / SRM / ANEEL, as distribuidoras convivem com uma receita irrecuperável, que representa uma parcela esperada da receita total faturada que possui baixa expectativa de arrecadação em função da inadimplência dos consumidores de energia. Essa parcela vem sendo considerada pela ANEEL nos itens de custo que formam a tarifa de energia elétrica. No entanto, o repasse feito à tarifa de energia, paga por todos os consumidores, considera apenas parte dessa parcela, cabendo à ANEEL definir qual o percentual de inadimplência deve ser reconhecido nas tarifas.

As metodologias adotadas pelo Órgão Regulador devem seguir os princípios da regulação por incentivo, cujo principal objetivo é estimular a produtividade, recompensando a empresa regulada quando seu desempenho superar as metas de benchmark pré-estabelecidas pelo regulador. Quando o desempenho de produtividade supera as metas, as empresas podem se apropriar da diferença, obtendo ganhos econômicos, o que gera um incentivo à maior produtividade a partir de um processo contínuo de concorrência (ACENDE BRASIL, 2007). 
A revisão das tarifas de forma regulada é o principal instrumento da regulação por incentivos. No Brasil, os contratos de concessão das distribuidoras de energia estabelecem três mecanismos de atualização das tarifas:

- Reajuste tarifário anual: ajuste da tarifa pela inflação ponderada por um índice de ganho/perda de produtividade;

- Revisões tarifárias periódicas: ocorrem normalmente a cada 4 (quatro) anos, em que são estabelecidos os benchmarks a serem perseguidos, sendo necessárias para garantir os repasses adequados aos consumidores e corrigir desvios que possam comprometer o equilíbrio econômico-financeiro das distribuidoras;

- Revisões tarifárias extraordinárias: confere à ANEEL a opção de promover um ajuste extraordinário da tarifa nos casos de custos adicionais imprevistos que comprometam o equilíbrio econômico-financeiro das distribuidoras e repasses adequados aos consumidores.

A metodologia empregada para a obtenção das metas (percentuais) regulatórias de inadimplência aplicada às distribuidoras vem evoluindo ao longo dos ciclos de revisão tarifária, mas ainda carece de aperfeiçoamentos que permitam o estabelecimento de níveis justos para as distribuidoras, uma vez que esse tema é de fundamental importância para as mesmas, que podem perder receita em função de um benchmark muito apertado, bem como para os consumidores que, por outro lado, podem acabar sendo onerados em suas tarifas em função do não gerenciamento de forma eficaz do nível de inadimplência por parte das distribuidoras.

Além disso, não há uma metodologia exclusiva para a obtenção das metas regulatórias de inadimplência, estando a metodologia empregada diretamente atrelada à metodologia para a obtenção das metas regulatórias de Perdas Não Técnicas - PNT.

Tal fato é ressaltado quando se analisa a questão com base na literatura científica. Não há na literatura modelos específicos para a determinação de metas de inadimplência das distribuidoras de energia elétrica. Em alguns casos, a inadimplência é tratada em conjunto com as perdas não técnicas, tema que apresenta similaridade, mas possui determinantes distintos daqueles que dão origem à inadimplência. A inadimplência dos consumidores de energia é predominantemente relacionada à renda, o que nem sempre se verifica para perdas não técnicas.

Diante desse contexto, o presente trabalho, terá como objetivo fornecer um modelo alternativo para a definição das metas regulatórias de inadimplência das 
distribuidoras de energia elétrica do Brasil, que equilibre seus interesses e de seus consumidores, por meio de uma metodologia desatrelada da apuração de metas de PNT e de fácil implementação.

Para atender a esse objetivo, será testada a metodologia de inferência fuzzy, conforme proposta de ZADEH (1965), para obtenção das metas regulatórias de inadimplência das distribuidoras, segmentadas pelas principais classes de consumo.

Esta dissertação insere-se na linha de pesquisa "Redes Inteligentes de Energia (Smart Grid)" do Programa de Pós-graduação em Metrologia (PósMQI) da Pontifícia Universidade Católica do Rio de Janeiro (PUC-Rio).

\section{1. \\ Definição do problema de pesquisa}

Considerando a necessidade de estabelecimento de metas regulatórias de inadimplência que atendam aos requisitos fundamentais da regulação por incentivo, bem como garantam o equilíbrio econômico-financeiro das distribuidoras de energia em consonância com os interesses dos consumidores, definiu-se a seguinte questão principal a ser respondida ao longo do presente trabalho:

"Como estabelecer metas regulatórias de inadimplência para as distribuidoras de energia elétrica do Brasil que atendam aos requisitos fundamentais da regulação por incentivo?"

\section{2.}

Objetivos: geral e específicos

Buscando contribuir para o estabelecimento de uma metodologia que leve em consideração as características específicas de cada distribuidora, o objetivo geral da dissertação é propor um modelo específico para definição das metas regulatórias de inadimplência das distribuidoras de energia elétrica do Brasil que atenda aos requisitos fundamentais da regulação por incentivo.

Para alcançar tal propósito, o objetivo geral será desdobrado nos seguintes objetivos específicos:

- Identificar os principais pontos de atenção no modelo atual para a definição das metas regulatórias de inadimplência das distribuidoras de energia elétrica no Brasil; 
- Estabelecer as premissas fundamentais para determinação de um modelo para a definição das metas regulatórias de inadimplência nas distribuidoras de energia elétrica do Brasil;

- Desenvolver um modelo alternativo ao utilizado pela ANEEL para definição das metas regulatórias de inadimplência das distribuidoras de energia elétrica do país;

- Demonstrar a aplicabilidade do modelo alternativo no setor de distribuição elétrica no Brasil, explicitando seus diferenciais em relação ao modelo atualmente adotado pela ANEEL.

\section{3. \\ Metodologia}

Segundo a taxonomia proposta por VERGARA (2002), a pesquisa pode ser considerada aplicada, descritiva e metodológica (quanto aos fins). Quanto aos meios de investigação, a metodologia compreende:

- Pesquisa bibliográfica, documental e experimental sobre os temas centrais da pesquisa, como indicado na fase exploratória e descritiva da figura 1;

- Desenvolvimento de um modelo baseado em inferência fuzzy para a definição das metas regulatórias de inadimplência das distribuidoras de energia elétrica;

- Estudo empírico visando demonstrar a aplicabilidade do modelo no contexto brasileiro.

A figura 1.1 apresenta o desenho da pesquisa, destacando-se seus componentes e métodos, de acordo com três fases principais: (i) exploratória e descritiva; (ii) pesquisa aplicada; e (iii) conclusiva. 


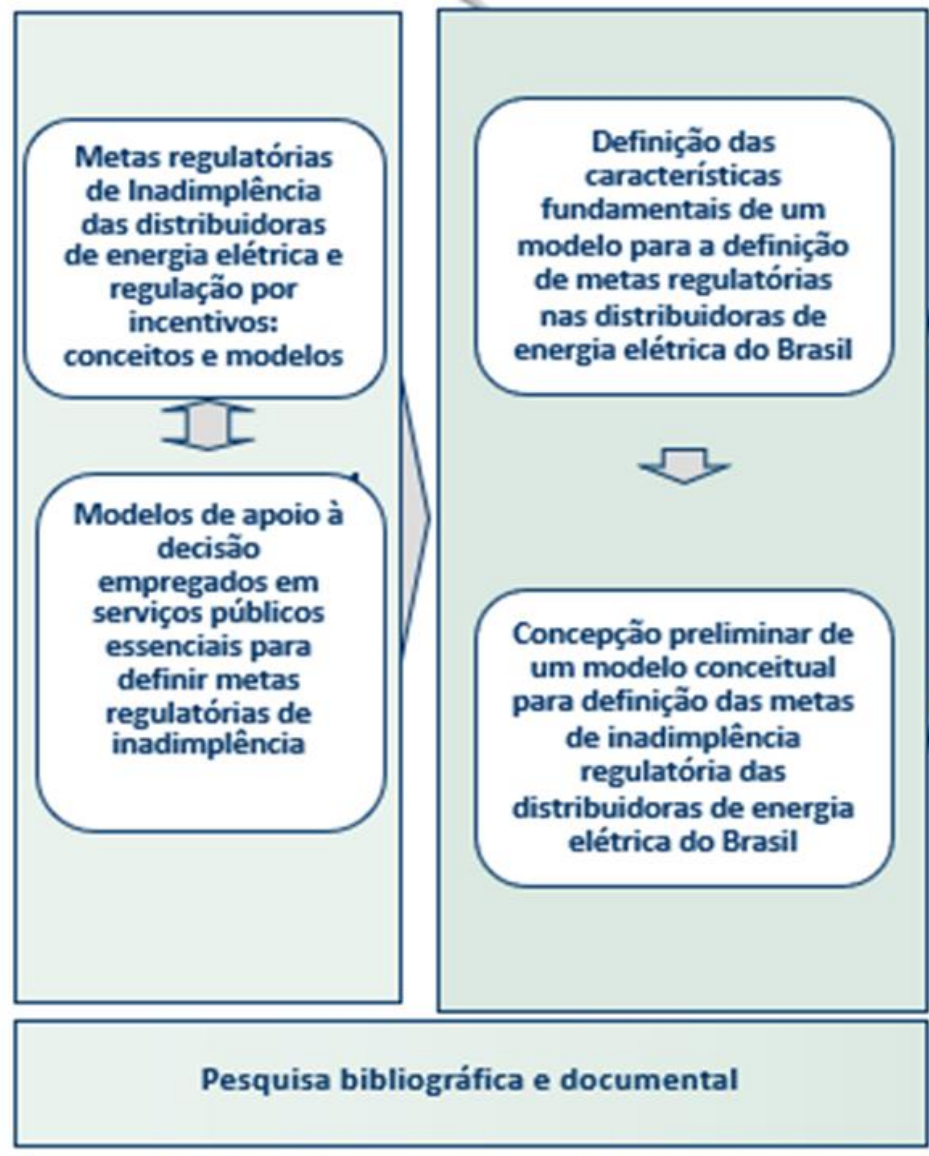

Fase 1 - Pesquisa exploratória e descritiva

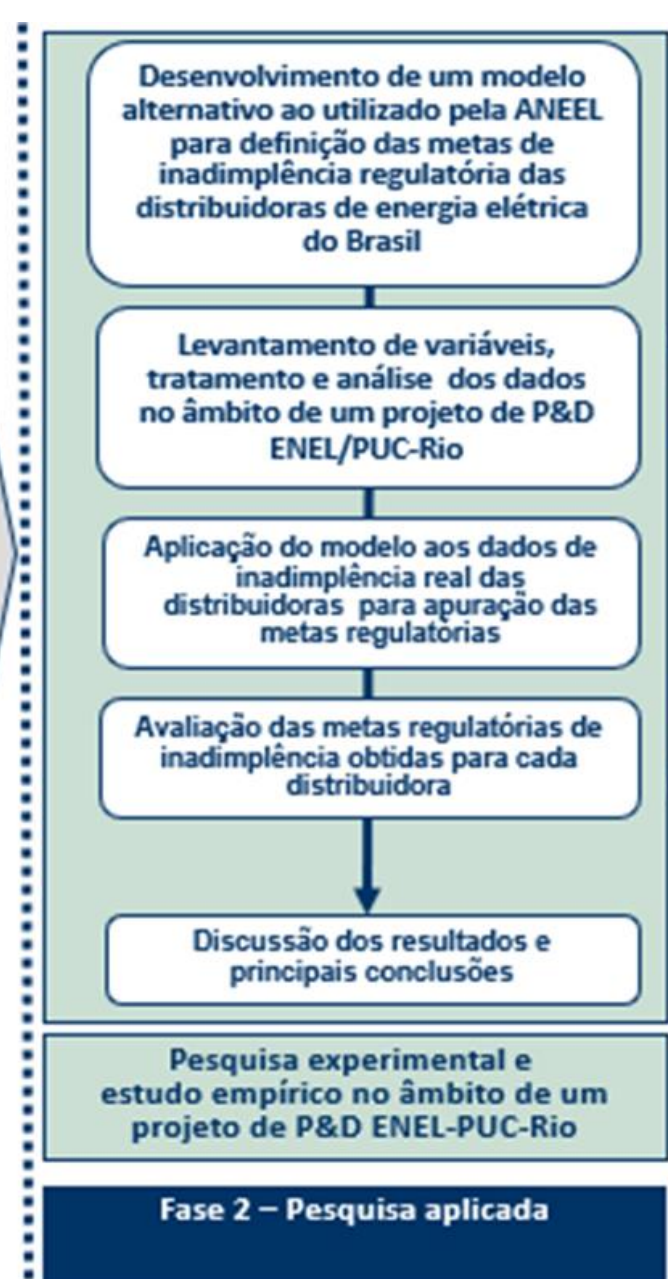

Figura 0.1 - Desenho da pesquisa, seus componentes e métodos

Fonte: Elaboração própria

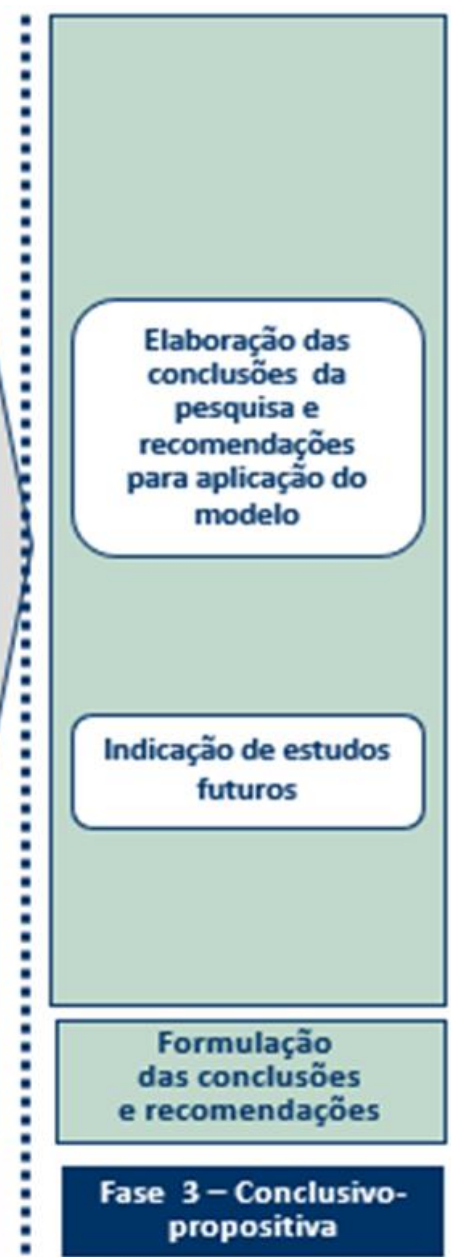




\subsection{1.}

\section{Fase exploratória e descritiva}

Iniciou-se essa fase com a pesquisa bibliográfica e documental, sobretudo com a análise da regulamentação pertinente, disponibilizada especialmente por meio da Consulta Pública no 11/2013, Audiência Pública no 23/2014, realizadas pela ANEEL.

$\mathrm{Na}$ sequência, buscou-se encontrar na literatura os principais modelos desenvolvidos no contexto de aplicação da regulação por incentivos e reunir informações que permitissem a identificação das principais características necessárias à formulação de um modelo que atendesse ao objetivo proposto para o trabalho.

Com base nas informações coletadas, foi testado, primeiramente, o modelo de clusterização dinâmica, tal como definido por TANURE (2004). No entanto, tal metodologia não apresentou mudanças significativas em relação às metas de inadimplência regulatórias estabelecidas pela ANEEL, mostrando não ser a mais adequada para a resolução da questão proposta. Foram analisadas também metodologias com base na homogeneização de fatores, outros tipos de clusterização e dados em painel, mas nenhuma delas teve viabilidade e aderência para a solução do problema. Posteriormente, foram analisados modelos de inferência fuzzy que se mostraram propícios para o atendimento do objetivo almejado.

Desta forma, optou-se pelo desenvolvimento de um modelo baseado em inferência fuzzy, conforme proposta de ZADEH (1965), por ser uma metodologia robusta, considerada de fácil aplicação e eficácia comprovada nos mais diversos temas de aplicação.

A figura 1.2 apresenta uma visão geral e esquemática dos resultados da pesquisa dessa primeira fase: 


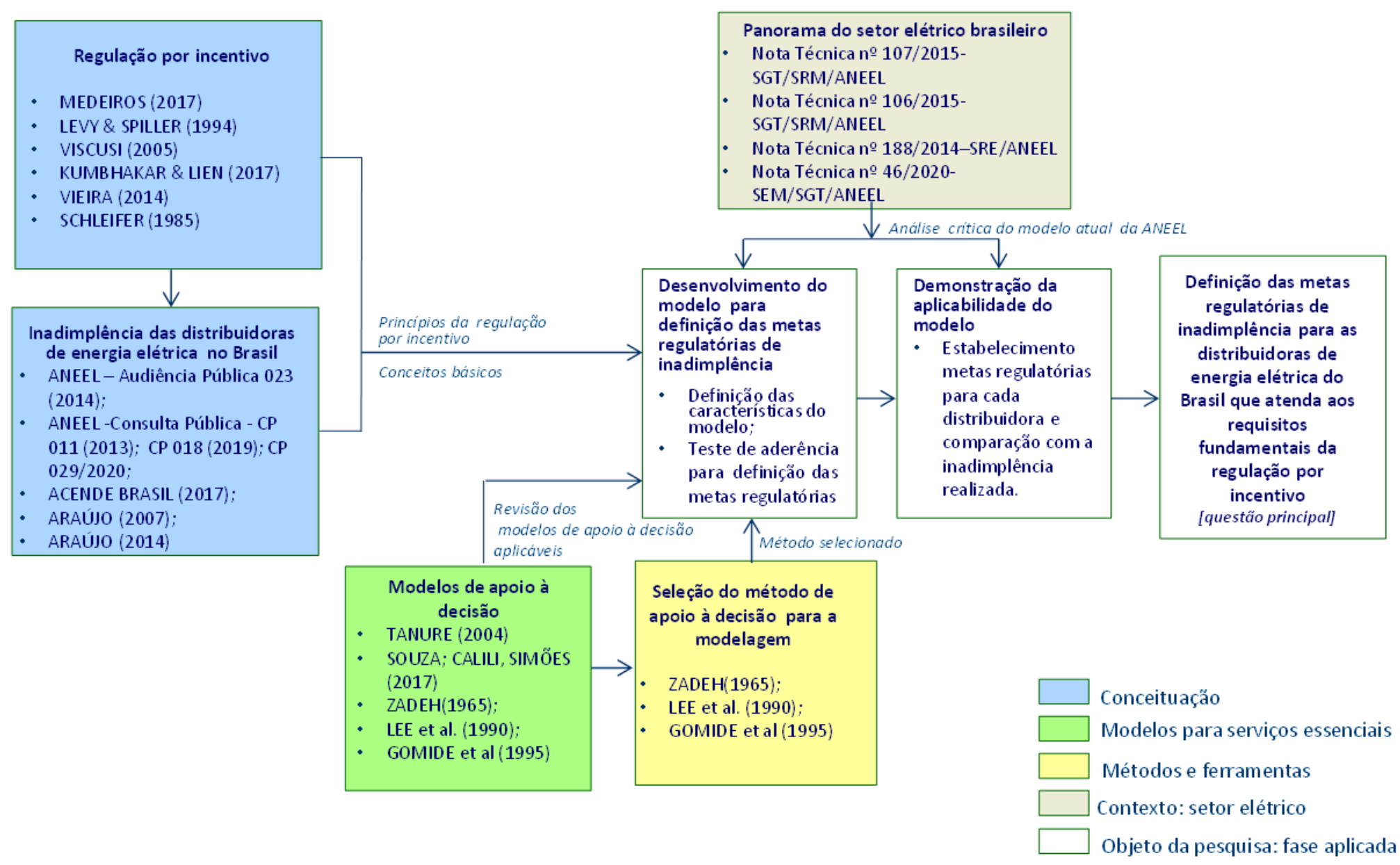

Figura 0.2 - Mapa conceitual da pesquisa

Fonte: Elaboração própria 
O referencial teórico constituiu uma orientação conceitual para a pesquisa, ao compor o vocabulário especializado e organizar o conhecimento sobre modelos de apoio à decisão que possuem características desejáveis para a obtenção das metas de inadimplência regulatória, dentro do contexto de regulação por incentivo.

\subsection{2.}

\section{Fase de pesquisa aplicada}

Com base no referencial teórico mostrado na seção anterior, desenvolveuse a fase de pesquisa aplicada, que consistiu na formulação do modelo e sua aplicação sobre a base de inadimplência real das distribuidoras, disponibilizada pela ANEEL, para a apuração das metas regulatórias.

Nessa fase foram avaliadas as variáveis que deveriam ser utilizadas na proposição do modelo, bem como propostas de como tratar essas variáveis para a elaboração de um modelo que fosse de simples aplicação.

Adicionalmente, foram realizadas análises da base de dados numéricos referentes aos valores de inadimplência de cada uma das distribuidoras e das últimas metas estabelecidas pelo modelo adotado pela ANEEL.

Por fim, pôde ser construído o modelo de inferência fuzzy, com base na proposição de ZADEH (1965), para cada uma das classes de consumo das distribuidoras.

\subsection{3.}

\section{Fase conclusiva}

Na terceira fase, chegou-se à conclusão geral e às específicas em relação a cada um dos objetivos enunciados na seção 1.2, bem como formulou-se um conjunto de recomendações aos diversos atores interessados na aplicação do modelo alternativo proposto para a definição das metas regulatórias de inadimplência para as distribuidoras de energia elétrica.

\section{4.}

\section{Estrutura da dissertação}

A presente dissertação conta com cinco capítulos, incluindo essa introdução. O Capítulo 2 apresenta, inicialmente, os principais conceitos sobre inadimplência de energia e regulação por incentivo. Em seguida, faz-se um resumo da metodologia atualmente utilizada pela ANEEL para a definição de 
metas regulatórias de inadimplência de energia para as distribuidoras brasileiras e uma análise crítica dessa metodologia.

O Capítulo 3 contempla a análise de anterioridade dos modelos e métodos aplicáveis e descreve como se chegou à metodologia proposta, trazendo o embasamento teórico da metodologia desenvolvida para a construção do modelo proposto.

$\mathrm{Na}$ sequência, o Capítulo 4, aplica o modelo proposto para ao caso específico das distribuidoras brasileiras. Mostra o passo a passo da construção e aplicação do modelo e discute os resultados apurados. A aplicabilidade do modelo proposto é detalhada por meio da análise de aderência dos resultados à realidade das distribuidoras brasileiras de energia elétrica e comparação com as metas regulatórias de inadimplência definidas a partir da aplicação da metodologia atual da ANEEL.

Por fim, o Capítulo 5 apresenta a conclusão do estudo e recomendações para trabalhos posteriores. 


\section{2 \\ Modelo regulatório vigente}

\section{1. \\ Regulação por incentivo}

Entre os anos de 1995 e 2000 houve uma maior liberalização do mercado afetando a dinâmica dos serviços públicos de infraestrutura no Brasil, culminando na criação das agências federais de regulação. Em 1996, por meio da Lei 9.427, foi criada a Agência Nacional de Energia Elétrica - ANEEL, que teve suas atribuições regulamentadas pelo Decreto $n^{2}$ 2.335/1997. Dessa forma, coube à ANEEL, dentre outras atividades: i) regular e fiscalizar a geração, transmissão, distribuição e comercialização de energia e ii) orientar a execução de suas atividades finais de modo a proporcionar condições favoráveis para que o desenvolvimento do mercado de energia elétrica ocorra com equilíbrio entre os agentes e em benefício da sociedade.

De acordo com MEDEIROS (2017), a implantação do modelo regulatório brasileiro se estruturou ao redor de agências regulatórias independentes e altamente especializadas, como é o caso da ANEEL. Tal formato permitiria blindar suas ações de influências políticas e possibilitar um tratamento técnico especializado para cada problema, ganhando a credibilidade da sociedade e dos agentes do setor. Ocorre que, a assimetria de informações entre o regulado e o regulador pode distanciar esse último de atingir os objetivos almejados.

LEVY e SPILLER (1994, p.202 apud VIEIRA, 2014, p.10), diz que a credibilidade e eficácia de um modelo regulatório varia de acordo com as instituições políticas e sociais do país e, para ter um desempenho satisfatório em uma gama de procedimentos regulatórios, a arbitrariedade administrativa deve ser contida pelas seguintes restrições: i) restrições substantivas em relação à discricionariedade do regulador; ii) restrições formais ou informais sobre a alteração do sistema regulatório e iii) instituições que imponham as duas anteriores.

Depreende-se desse contexto que, tanto a assimetria de informações fomentada pelo regulado, quanto o excesso de arbitrariedade empregado pelo regulador, podem afetar negativamente o desempenho do modelo regulatório.

Dessa forma, faz-se importante a adoção de um modelo regulatório que procure minimizar as condições de informações assimétricas, permitindo ao regulador auferir informações complementares, de fontes distintas e, assim, 
avaliar com maior precisão o desempenho de seus regulados. Por outro lado, é importante que o regulador adote modelos com fundamentos e princípios claros, de forma a garantir a transparência nas suas decisões, proporcionando segurança aos regulados e a constante busca por melhor desempenho e eficiência.

Nesse contexto, o modelo regulatório adotado pela ANEEL no setor elétrico, assim como em grande parte do mundo, está baseado nos princípios da regulação por incentivos. Esta forma de regulação, de acordo com VISCUSI et al. (2005, p.436 apud VIEIRA, 2014, p.66), é "projetada para criar incentivos para que a empresa regulada reduza custos, inove, adote práticas eficientes de preços, melhore a qualidade, entre outros".

Conceitualmente, a regulação por incentivo pode se desdobrar em 3 tipos: earnings sharings, yardstick e price cap. De acordo com VIEIRA (2014) na regulação conhecida por earnings sharings, ou por taxa de retorno, não há incentivos suficientes para que a empresa regulada reduza seus custos e promova a eficiência. A regulação por yardstick, ou regulação por desempenho, foi desenvolvida por SHLEIFER (1985) e utiliza empresas similares ou idênticas para analisar o potencial da empresa em foco, o que reduz a necessidade da obtenção de informações necessárias para o cálculo da tarifa de remuneração do serviço. A regulação conhecida como price cap, ou preço teto, permite que a empresa estabeleça sua taxa de retorno com base no preço máximo estabelecido pelo órgão regulador. O preço teto terá reajuste anual com base na inflação, deduzido um índice de produtividade X (fator X). O índice de produtividade é dependente das informações da regulada, aumentando a possibilidade de assimetria de informações.

Ressalta-se que, no setor elétrico brasileiro, de um modo geral, assim como em diversos outros países, os modelos de regulação por incentivo, adotados pela ANEEL, procuram mesclar conceitos da regulação por desempenho (yardstick) e da regulação pelo preço teto (price cap).

Posto esse arcabouço geral, cabe destacar que, especificamente no que se refere à metodologia empregada para a determinação das metas regulatórias de inadimplência de energia, desde o segundo ciclo de revisão tarifária, a base teórica tem sido a regulação por desempenho (yardstick), como será exposto na seção a seguir. 


\section{2.}

\section{Histórico e metodologia atual}

A metodologia empregada para a obtenção das metas regulatórias de inadimplência aplicadas às distribuidoras vem evoluindo ao longo dos ciclos de revisão tarifária, mas ainda carece de aperfeiçoamentos que permitam o estabelecimento de níveis justos para as distribuidoras, uma vez que esse tema é de fundamental importância para as concessionárias de distribuição de energia, que podem perder receita em função dos valores de inadimplência reais acima dos reconhecidos pela ANEEL e também para os consumidores que, por outro lado, podem acabar sendo onerados em suas tarifas em função do não gerenciamento de forma eficaz do nível de inadimplência por parte das distribuidoras.

Nesse cenário, há que se levar em conta que, o reconhecimento da integralidade de custos na tarifa dos consumidores finais tende a reduzir os estímulos para a busca da eficiência. Por outro lado, o não reconhecimento dos custos de forma correta pode reduzir a atratividade do setor e afetar os investimentos, culminando em perda da qualidade dos serviços prestados pelas empresas (SHLEIFER, 1985; KUMBHAKAR \& LIEN, 2017).

A ANEEL entende que a inadimplência das faturas de energia elétrica dependem tanto das características socioeconômicas das áreas de concessão de cada distribuidoras como também dos mecanismos de gestão empregados pelas mesmas, que consistem, basicamente, em: i) execução de cobranças domiciliares e por mensagens de voz (Unidade de Resposta Audível - URA); ii) atuação conjunta com empresas de cobrança; iii) suspensão por inadimplemento pelo não pagamento da fatura, prevista atualmente pelo inciso I do artigo 172 da Resolução Normativa no 414/2010 (AIR nำ5/2019-SRM/SGT/ANEEL).

Nesse contexto, como mostra o histórico das metodologias adotadas para cada um dos ciclos tarifários a seguir, a ANEEL tem buscado aplicar a regulação por incentivos (yardstick competition), com o objetivo de estimular a eficiência das distribuidoras ao mesmo passo em que procura captar as particularidades de cada uma. Segue um resumo da evolução dos ciclos tarifários ao longo dos anos:

- 1ํ Ciclo de Revisão Tarifária Periódica (1ํCRTP) - 2005 a 2006: aplicação de uma metodologia simplificada para o tratamento de inadimplência de energia para fins de repasse na tarifa, adotando percentuais fixos de $0,5 \%$ sobre 0 faturamento bruto (sem ICMS nas tarifas de energia elétrica) para todas as distribuidoras. 
- $2^{\circ}$ CRTP (2007 - 2010): a partir deste ciclo de revisão tarifária, o modelo proposto se baseou na metodologia de regulação por incentivos, em que o regulador se utiliza de observações de parâmetros de outras empresas para definir o valor de cada uma. As concessionárias foram subdivididas em 3 grupos (clusters), definidos a partir do índice socioeconômico de cada área de concessão, estabelecido conforme Nota Técnica no 342/2008-SRE/ANEEL, que tratou da metodologia de perdas não técnicas ${ }^{1}$. Para o $2^{\circ}$ CRTP, de acordo com a Resolução Normativa no 338 , de 25/11/2008, foram estabelecidos os percentuais de receitas irrecuperáveis de 0,9\%, 0,6\% e 0,2\% para as empresas dos grupos 1 , 2 e 3, respectivamente. Ou seja, no segundo ciclo, ainda foram adotados percentuais fixos sobre o faturamento das distribuidoras. No entanto, o agrupamento segundo o índice sócio econômico passou a fazer uma diferenciação entre as empresas. Os percentuais de inadimplência realizados foram obtidos com base em uma curva de aging que representa o ponto de estabilização de envelhecimento da fatura, sendo utilizada uma mediana dos meses 18, 21 e 24 do faturamento não recebido até o mês de referência (dezembro do ano anterior ao início do ciclo).

- 3ํㅡㄹ CRTP (2011 - 2014): foi proposta a manutenção da metodologia do 2CRTP, inclusive a clusterização e a curva de aging, levando em consideração alguns ajustes, tais como a segmentação dos percentuais da inadimplência por classe de consumo e a consideração da "neutralidade" dos encargos setoriais. Os indicadores regulatórios foram definidos com base na mediana de cada classe em cada cluster (excluindo outliers).

- 4ํㅡㄹ CRTP (2015 - 2018): houve a separação das distribuidoras em 2 clusters, sendo as empresas de maior porte (Grupo 1) aquelas com mais de 500 mil unidades consumidoras e mercado de baixa tensão acima de $1.000 \mathrm{GWh}$ ou que possuem mais do que $15.000 \mathrm{~km}$ de rede elétrica. As demais empresas, consideradas de pequeno porte, ficaram no Grupo 2. Neste ciclo, foi considerada a metodologia de "mediana móvel" dos faturamentos não recebidos, isto é, considerou-se a curva de envelhecimento da dívida (aging) como uma mediana móvel do período de 49 a 60 meses anteriores ao mês de referência. Com base nessa mediana móvel foi definido o percentual regulatório de receitas irrecuperáveis de cada empresa, calculado a partir da mediana de um conjunto de empresas, formado por 10 concessionárias situadas acima e abaixo no ranking de

1 Índice criado para cada uma das distribuidoras com base em um conjunto de variáveis socioeconômicas relacionados com o fenômeno das Perdas Não Técnicas de Energia Elétrica. 
complexidade social, obtido por meio dos modelos econométricos escolhidos para a obtenção de PNT.

- 5 CRTP (2019 - 2022): manutenção da regulamentação vigente, contemplando as alterações do ranking de complexidade ${ }^{2}$ e atualização dos percentuais regulatórios de receitas irrecuperáveis com base nos dados dos últimos 4 anos.

As seções 4.2 e 4.1 dos Submódulos 2.2 e 2.2 A do PRORET, respectivamente, estabelecem que o recálculo dos percentuais de receitas irrecuperáveis deve ocorrer a cada quatro anos e que a revisão geral da metodologia deverá ser efetuada após oito anos (em 2023).

Conforme apresentado nas seções anteriores do presente trabalho, a metodologia de determinação das metas regulatórias de inadimplência vem evoluindo ao longo dos ciclos tarifários. No entanto, cabe analisar criticamente o que ainda pode ser considerado pontos de atenção e melhoria na metodologia atual, visando manter os avanços alcançados e atender ao objetivo geral proposto pela dissertação, qual seja, propor um modelo específico para definição das metas regulatórias de inadimplência das distribuidoras de energia elétrica do Brasil que atenda aos requisitos fundamentais da regulação por incentivo.

\section{3. \\ Análise crítica da metodologia aplicada atualmente}

Como se depreende do disposto anteriormente, a disposição de cada uma das distribuidoras dentro dos dois grupos criados (clusters) é fundamental para a definição dos percentuais regulatórios das receitas irrecuperáveis. A simples troca de posicionamento de uma distribuidora dentro do grupo pode afetar consideravelmente a mediana das demais. Nesse sentido, a principal crítica à metodologia empregada atualmente se refere à utilização do índice de complexidade (IC) social obtido por meio de modelos econométricos elaborados para a obtenção de perdas não técnicas (PNT) para o ranqueamento das distribuidoras. Destaca-se aqui, que os próprios modelos de PNT são temas de críticas levantadas por SOUZA et al (2016), que fazem uma proposta alternativa para PNT, o que denota uma fragilidade em se estabelecer a metodologia de metas de inadimplência regulatória atrelada à metodologia atual de determinação de PNT.

${ }^{2}$ Foi revisto o critério para definição do porte das distribuidoras, sendo consideradas de grande porte as distribuidoras com mercado acima de $700 \mathrm{GWh} /$ ano e não mais $1.000 \mathrm{GWh} / \mathrm{ano}$. 
Dentre as principais críticas à metodologia de PNT, destaca-se a complexidade envolta no seu desenvolvimento, com inúmeras etapas ad hoc, a baixa habilidade explicativa dos modelos econométricos, com uma possível omissão de variáveis, a apuração do cálculo do Índice de Complexidade Social sem levar em consideração heterogeneidade ou especificidade da empresa (componente $\mu_{i}$ estimada dos modelos de PNT) ${ }^{3}$, não utilização da variável tempo de forma explícita no modelo adotado e não tratamento de outliers, LEITE (2020).

O Índice de Complexidade Social é construído com base na estimação dos coeficientes de correlação entre o percentual de Perdas Não Técnicas sobre o mercado de baixa tensão das distribuidoras e um conjunto de variáveis socioeconômicas das áreas de concessão, utilizando-se um modelo de dados em painel com efeitos aleatórios. ${ }^{4}$

A premissa de utilização do mesmo ranking de complexidade social, cuja obtenção é fonte de crítica na metodologia de PNT, se baseia no princípio de que tanto as perdas não técnicas como as receitas irrecuperáveis são impactadas pelas variáveis socioeconômicas das áreas de concessão. No entanto, cabe ressaltar que, os modelos econométricos utilizados para a obtenção das metas regulatórias de PNT, bem como o índice de complexidade, deixaram de considerar algumas variáveis importantes para a explicação dos índices de inadimplência como, por exemplo, a taxa de desemprego, emprego informal e índice de endividamento das famílias.

${ }^{3} \mathrm{O}$ argumento da ANEEL para ignorar essa componente $\mu_{i}$ estimada se baseia no fato de que essa componente representaria em sua maior parte a ineficiência das distribuidoras. Deve-se esclarecer que a componente $\mu_{i}$ visa capturar as especificidades da empresa não explicadas pelas demais variáveis do modelo, incluindo possíveis ineficiências, mas também eventuais problemas decorrentes da omissão de variáveis relevantes no modelo.

${ }^{4}$ Um maior nível de detalhamento pode ser encontrado em LEITE; D. A. Definição das metas regulatórias de perdas não técnicas para as distribuidoras de energia elétrica no Brasil: proposição de um modelo baseado na Análise de Fronteira Estocástica (SFA). Rio de Janeiro, 2014, p.147. Dissertação (mestrado). Dissertação de Mestrado - Departamento de Metrologia, Pontifícia Universidade Católica do Rio de Janeiro. 
Adicionalmente, o uso da mediana das 10 empresas acima e abaixo no ranking de complexidade social gera diferença entre o número de empresas comparadas para a determinação dos valores regulatórios, visto que a primeira no ranking será comparada apenas com as 10 inferiores e a última no ranking, apenas com as 10 superiores, podendo ser considerado um método ad-hoc, não permitindo generalizações. Somente as empresas posicionadas mais ao centro serão comparadas com outras 20 distribuidoras. O grupo das menores empresas, por exemplo, só possui 28 distribuidoras, o que reduz ainda mais o número de distribuidoras comparáveis nessa metodologia de mediana móvel proposta pela ANEEL. Por meio da figura 2.1, pode-se ver graficamente como é feita essa comparação no ranking de complexidade social.

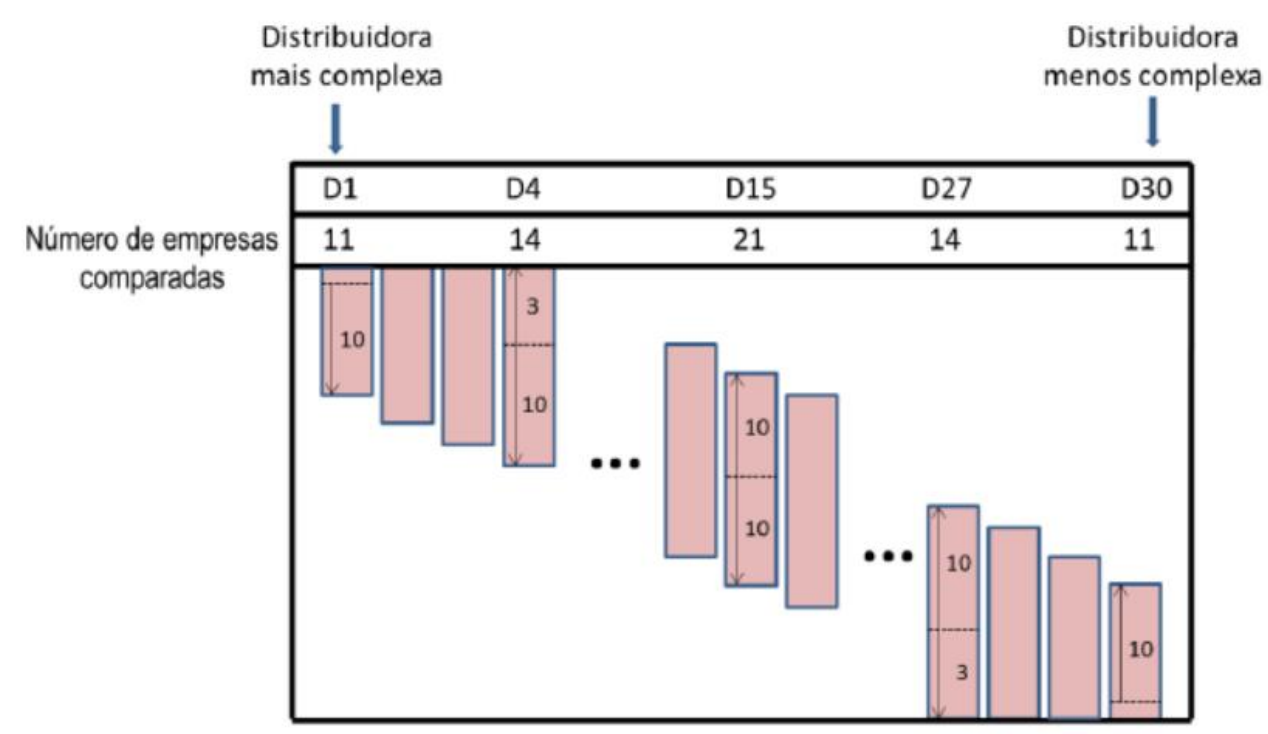

Figura 0.1 - Mediana Móvel

Fonte: ANEEL (2015)

Ainda no que se refere à metodologia adotada, há críticas levantadas por parte dos agentes do setor quanto ao período de 49 a 60 meses da curva de aging utilizada, visto que, por hipótese, a inadimplência do setor é afetada, normalmente, por fatores externos e cuja dinâmica mais recente afeta diretamente os percentuais de inadimplência. Assim, as contribuições da ABRADEE (Associação Brasileira de Distribuidores de Energia Elétrica) na Consulta Pública n 18 de 2019 foram no sentido de propor a utilização de uma curva de aging de 25 a 36 meses de histórico.

Diante do exposto, atendendo ao primeiro dos objetivos específicos propostos para esse trabalho, destaca-se os principais pontos de atenção do modelo de apuração das metas de inadimplência regulatórias: 
- Metodologia atrelada aos modelos de apuração das metas de perdas não técnicas, que não consideram algumas variáveis importantes para se modelar 0 problema de inadimplência das distribuidoras de energia elétrica;

- Utilização de uma única base de indicadores socioeconômicos para perdas e inadimplência, deixando de considerar algumas variáveis que estão mais propriamente ligadas à inadimplência das faturas de energia;

- Utilização de mediana móvel para a determinação da meta de inadimplência, fazendo com que tenha uma diferenciação entre o número de distribuidoras que é utilizado na composição das metas individuais de cada distribuidora.

- Utilização de aging de 60 meses para a determinação do percentual de receitas irrecuperáveis, deixando de considerar o histórico mais recente.

\section{4 .}

\section{Considerações sobre o capítulo}

Como demonstrado nesse capítulo, a metodologia aplicada para a definição das metas regulatórias de inadimplência das distribuidoras vem sendo aperfeiçoada ao longo dos ciclos tarifários de forma a se tornar coerente com os princípios da regulação por incentivo, em que a busca por eficiência deve ser constante e estimulada por meio da constante comparação com outras empresas que, dentro de contextos semelhantes, conseguem melhores resultados.

Apesar dos avanços observados, a metodologia atualmente empregada continua atrelada à metodologia de PNT, cuja obtenção do Índice de Complexidade Social passa por inúmeras etapas, consideradas ad hoc, e deixa de considerar, conforme exposto anteriormente, justamente a componente que visa capturar as especificidades e heterogeneidade das empresas.

No capítulo 3 será demonstrado o passo a passo na busca e na construção de um modelo para determinação das metas regulatórias de inadimplência que mantenha os princípios da regulação por incentivo, seja robusto, de fácil implementação e não dependa da metodologia estabelecida para PNT. 


\section{3 \\ Modelo teórico proposto}

O presente capítulo procura evidenciar os trabalhos que influenciaram a decisão para a proposição de uma metodologia baseada em inferência fuzzy para o estabelecimento de metas regulatórias de inadimplência de energia, dentro de um contexto da regulação por incentivo.

\section{1.}

\section{Análise de anterioridade}

A revisão da literatura foi concentrada, inicialmente, no tema de inadimplência, eixo conceitual e empírico. Como estratégia de busca foi adotada primeiramente a pesquisa documental, por meio do site da Agência Nacional de Energia Elétrica - ANEEL (a Agência Reguladora do setor elétrico brasileiro) e demais regulamentações vigentes, o que se enquadra em grey literature. Em seguida foi realizada uma pesquisa no Google acadêmico e base de teses e dissertações em português, visando ter uma visão mais ampla do que já foi publicado nacionalmente. Posteriormente, foram realizadas buscas nas bases de Teses e Dissertações Internacionais, Web of Science, ScienceDiret e Scopus.

Foram encontrados diversos artigos que abordaram o tema de perdas não técnicas de energia elétrica. Com relação à inadimplência das faturas de energia, as publicações são menos frequentes, tendo sido encontradas, principalmente, publicações da África do Sul, Índia e Rússia. A maioria dos artigos apresentaram estudos de casos bem específicos que não tiveram correlação direta com a abordagem do presente estudo. Dessa forma, serão citados, a seguir, apenas os trabalhos que influenciaram diretamente na concepção das premissas e fundamentos desse trabalho.

Assim sendo, destaca-se o trabalho realizado por ARAUJO (2007), em que foi feita uma análise estatística de PNT e inadimplência (energia elétrica) nas distribuidoras do Brasil propondo um modelo de regressão para caracterizar a inadimplência. Tal modelo conseguiu explicar em mais de $50 \%$ a variação da inadimplência observada pelas distribuidoras, utilizando como variáveis explicativas a tarifa média da concessionária, a intensidade da indigência e a taxa de urbanização. Utilizou-se uma análise fatorial para a criação de um índice conjunto para perdas e inadimplência, constituído por meio da tarifa média das concessionárias, posse de ar condicionado, área de concessão e intensidade de 
indigência, além de segmentar as análises por regiões de maior homogeneidade entre as distribuidoras. Entre as conclusões desse estudo, infere-se que a inadimplência está fortemente relacionada à perda da capacidade de pagamento das contas de uma população e que, quanto maior a urbanização de um local, menor a inadimplência.

ARAÚJO et al (2014), através de um estudo de caso, buscou identificar quais as variáveis apresentavam alta correlação com a inadimplência residencial. O seu estudo testou variáveis como:

- parcela de energia em débito;

- $\quad$ número de clientes baixa renda;

- status da instalação do cliente;

- forma de pagamento das faturas;

- tensão de fornecimento da energia;

- número de faturas vencidas; e

- ações de cobrança.

Neste trabalho o autor concluiu que a correlação das variáveis era muito baixa em alguns casos. A escolha das variáveis é sempre um desafio e conseguir bases de dados seguras é fundamental. Outro fator que complica para adoção das variáveis é que algumas áreas de concessão são segmentadas, compostas por diversos municípios, mas nem sempre constituídas pela totalidade dos estados brasileiros.

Um estudo realizado pelo Instituto ACENDE BRASIL (2017), afirma que a informalidade é uma das características sócio econômica relacionadas ao aumento tanto de perdas comerciais quanto de inadimplência de energia elétrica no Brasil. Dessa forma, o estudo condiciona o aumento da inadimplência à informalidade e a ocupação irregular/clandestina nas áreas de concessão das distribuidoras. Observa ainda que o nível de comprometimento da renda para o pagamento da conta de energia é outro fator importante na análise da inadimplência. Nesse sentido, o rendimento salarial, a taxa de desemprego e o nível de inadimplência de crédito seriam variáveis extremamente importantes para explicar a inadimplência de energia elétrica. Entretanto, não são usadas nos modelos definidos pela agência reguladora brasileira, a ANEEL.

A ANEEL utiliza para definição das metas regulatórias de inadimplência as mesmas variáveis utilizadas nos modelos de PNT, sendo as mais relevantes:

- nível de violência em cada área de concessão;

- percentual de chefes de família com renda de até 3 salários mínimos;

- coeficiente de desigualdade social (índice de Gini); 
- precariedade dos domicílios;

- percentual de domicílios com cobertura do sistema de água e esgoto;

- percentual de domicílios com coleta de lixo;

- inadimplência do setor de crédito;

- participação do mercado baixa renda de energia elétrica.

O modelo regulatório adotado pela ANEEL no setor elétrico, assim como em grande parte do mundo, está baseado nos princípios da regulação por incentivos. A regulação por incentivo, de acordo com VISCUSI et al. (2005, p.436 apud VIEIRA, 2014, p.66), é propícia, entre outros fatores, para incentivar a empresa regulada a reduzir custos, inovar, adotar práticas eficientes de preços e melhorar a qualidade do serviço oferecido.

Em seus modelos, a ANEEL busca, por meio da comparação equânime entre as distribuidoras, criar mecanismos de incentivo que garantam a redução de custos, a inovação e a eficiência das empresas. Como já mencionado na seção 2.2, a metodologia empregada para a determinação das metas regulatórias vigentes de inadimplência de energia, desde o segundo ciclo de revisão tarifária, tem como base a regulação por Yardstick Competition.

A principal crítica à metodologia empregada atualmente pela ANEEL se refere à utilização do índice de complexidade (IC) social obtido por meio de modelos econométricos elaborados para a obtenção de PNT, como um dos pilares para a obtenção das metas de inadimplência regulatórias.

A escolha de um modelo alternativo ao adotado pela ANEEL para a definição de metas regulatórias de inadimplência deve preservar os objetivos da regulação por incentivo. Além disso, deve levar em conta a heterogeneidade das áreas de concessão das distribuidoras num país de tantas desigualdades como o Brasil, bem como ser baseada em metodologia robusta, de simples aplicação e de eficácia comprovada. Nesse sentido, um sistema inteligente, que se alimente de informações reais e seja capaz de modelar cenários com base em incerteza, como um Sistema de Inferência fuzzy - SIF, pode ser uma alternativa viável, o que procura evidenciar-se nesse trabalho.

O SIF se tornou popular a partir de 1965 com a publicação de ZADEH (1965). Este autor observou que a automatização de sistemas relacionados às atividades de natureza industrial, biológica ou humana, as quais compreendem situações ambíguas (não passíveis de processamento através da lógica booleana), era impossível de ser realizada. Dessa forma, procurou fornecer um ferramental matemático para o tratamento de informações imprecisas ou incertas, 
dando origem à lógica fuzzy e aos sistemas que usam esta nova forma de lógica (LEE et al, 1990).

Um sistema de inferência fuzzy, concebido de acordo com o método de Mamdani ${ }^{5}$, pode ser descrito por três processos distintos (figura 3.1): fuzzyficação das variáveis, Inferência e defuzzyficação.

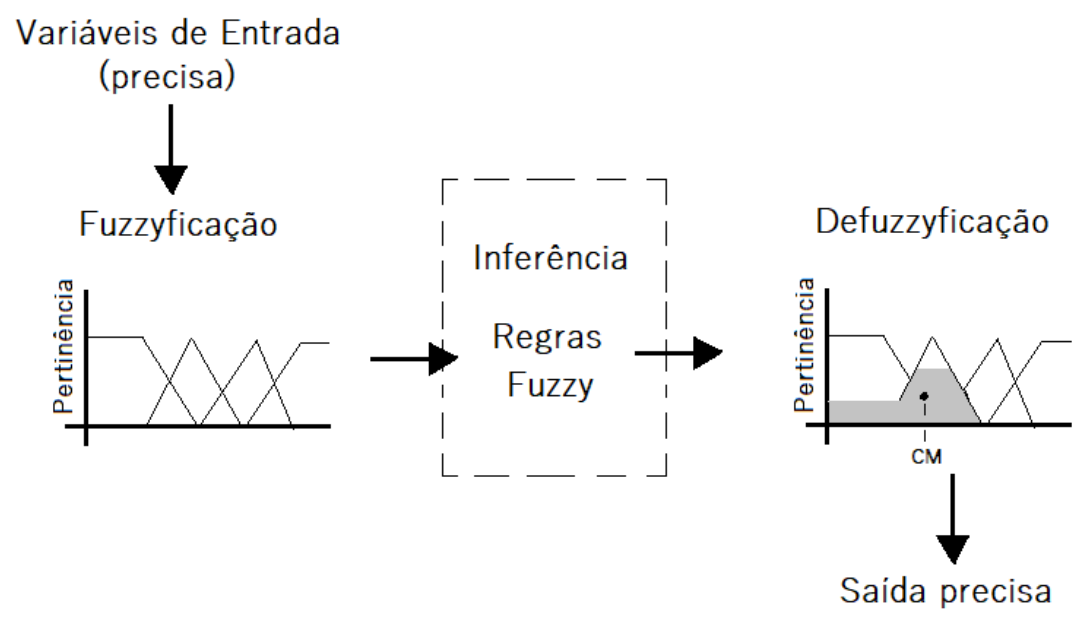

Figura 0.1 - Fases de um Sistema de Inferência Fuzzy - SIF

Fonte: Elaboração própria

Antes de explicar cada uma das fases de um SIF, faz-se importante definir os conceitos de conjunto e subconjunto fuzzy, base para as etapas de fuzzyficação e criação de regras. Um subconjunto $A$ de um conjunto $U$ é considerado subconjunto fuzzy de $U$ se for descrito como um conjunto de pares ordenados conforme descrição a seguir:

$$
A=\left\{\left(x, \mu_{A}(x)\right) ; \quad x \in U \quad \mu_{A}(x) \in[0,1]\right)
$$

onde

$\mu_{\mathrm{A}}(\mathrm{x})$ é uma função de pertinência que determina com que grau $\mathrm{x}$ está em $\mathrm{A}$ :

$\mu_{\mathrm{A}}(\mathrm{x})=1 \rightarrow \mathrm{x}$ pertence totalmente ao conjunto $\mathrm{A}$

$0>\mu_{\mathrm{A}}(\mathrm{x})>1 \rightarrow \mathrm{x}$ pertence parcialmente ao conjunto $\mathrm{A}$

$\mu_{\mathrm{A}}(\mathrm{x})=0 \rightarrow \mathrm{x}$ não pertence ao conjunto $\mathrm{A}$

${ }^{5} \mathrm{~A}$ formulação completa do método Mamdani pode ser consultada em AMENDOLA et al (2005), Manual do uso da teoria dos conjuntos Fuzzy no MATLAB 6.5. 
Feita a conceituação geral, de acordo com a Figura 3.1, na primeira etapa, chamada de fuzzyficação, são criadas variáveis linguísticas, as quais são associadas às variáveis de entrada (exatas). Dessa forma, uma determinada variável pode ser classificada com diferentes graus de pertencimento a uma variável linguística, ou conjunto/grupo fuzzy (boa, ruim, alta, baixa).

Assim sendo, a inferência fuzzy, transforma uma variável numérica absoluta (crisp) em um conceito linguístico.

Na segunda etapa, são encadeadas diferentes associações através de uma série de sentenças linguísticas, estabelecidas por meio de regras (regras fuzzy). De uma forma simplificada, pode-se dizer que tais regras descrevem as relações entre as variáveis de entrada (antecedentes) e as variáveis de saída (consequente). Nelas, cada valor de entrada (antecedente de uma regra) ativa um ou mais grupos fuzzy com determinada função de pertinência. Na lógica fuzzy os dados podem pertencer mais ou menos a um determinado grupo, as fronteiras dos conjuntos são flexíveis, permitindo trazer o elemento de incerteza para o modelo.

Uma regra pode ser determinada por algum especialista ou obtida diretamente através da análise de uma base de dados, como a de inadimplência real, por exemplo. Assim, pode-se definir uma regra do tipo Se/Então, como se segue:

Se preço é 'alto' e quantidade é 'baixa' então risco é 'alto'

Toda a base de conhecimento de um sistema de inferência fuzzy fica retida nas suas regras. Elas caracterizam a estratégia de controle e/ou metas a serem alcançadas.

A terceira e última etapa de um sistema de inferência fuzzy é caracterizada pela transformação das variáveis linguísticas obtidas, em variáveis exatas (crisps). Esse processo é denominado de defuzzyficação, e permite que o SIF gere uma saída (valor numérico) que pode ser avaliada. Existem algumas métricas as quais podem ser utilizadas na defuzzyficação, sendo as mais comuns, cálculo do centro de massa (centroid), média dos máximos, maior dos máximos, menor dos máximos e bissetriz.

O uso de sistemas de inferência fuzzy permite que se resolva processos complexos e com muitas incertezas, de modo que os sistemas resultantes sejam mais precisos, estáveis e robustos. Tais características, aliadas à sua grande simplicidade de implementação, podem reduzir a complexidade de um projeto, permitindo a resolução de problemas anteriormente intratáveis (GOMIDE et al. 1995). 
Nesse contexto, a aplicação de um sistema de inferência fuzzy para a determinação das metas regulatórias de inadimplência, metodologia ainda não empregada na literatura com esse determinado fim, poderá trazer ganhos metodológicos, sendo de simples implementação, podendo ser aplicada de forma coerente com os princípios da regulação por incentivo.

Por todo exposto, permite-se chegar ao segundo objetivo específico a que se propõe o presente trabalho. Estabelecer as premissas fundamentais para a especificação e escolha do modelo proposto:

- Manter os princípios da regulação por incentivo, que podem ser considerados como um ganho proveniente da evolução das metodologias propostas pela ANEEL;

- Captar a heterogeneidade das áreas de concessão das distribuidoras;

- Fornecer tratamento isonômico para todas as distribuidoras;

- Basear-se em metodologia robusta e de eficácia comprovada;

- Utilizar-se da base de dados de inadimplência das próprias distribuidoras, extraindo aprendizado e padrões observados;

- Ser de fácil implementação.

O próximo item deste capítulo traz as especificações teóricas para a implementação de um modelo de inferência fuzzy para a determinação das metas de inadimplência regulatórias.

\section{2.}

\section{Modelo proposto com base em inferência fuzzy}

Para atender às premissas fundamentais de uma proposta de modelo para a apuração das metas de inadimplência regulatórias, foi desenvolvido um algoritmo em linguagem MatLab de forma a gerar um sistema de inferência fuzzy que fosse capaz de modelar a inadimplência de 59 distribuidoras de energia elétrica brasileiras. 
Por meio da figura 3.2, pode-se observar a forma global do modelo proposto:

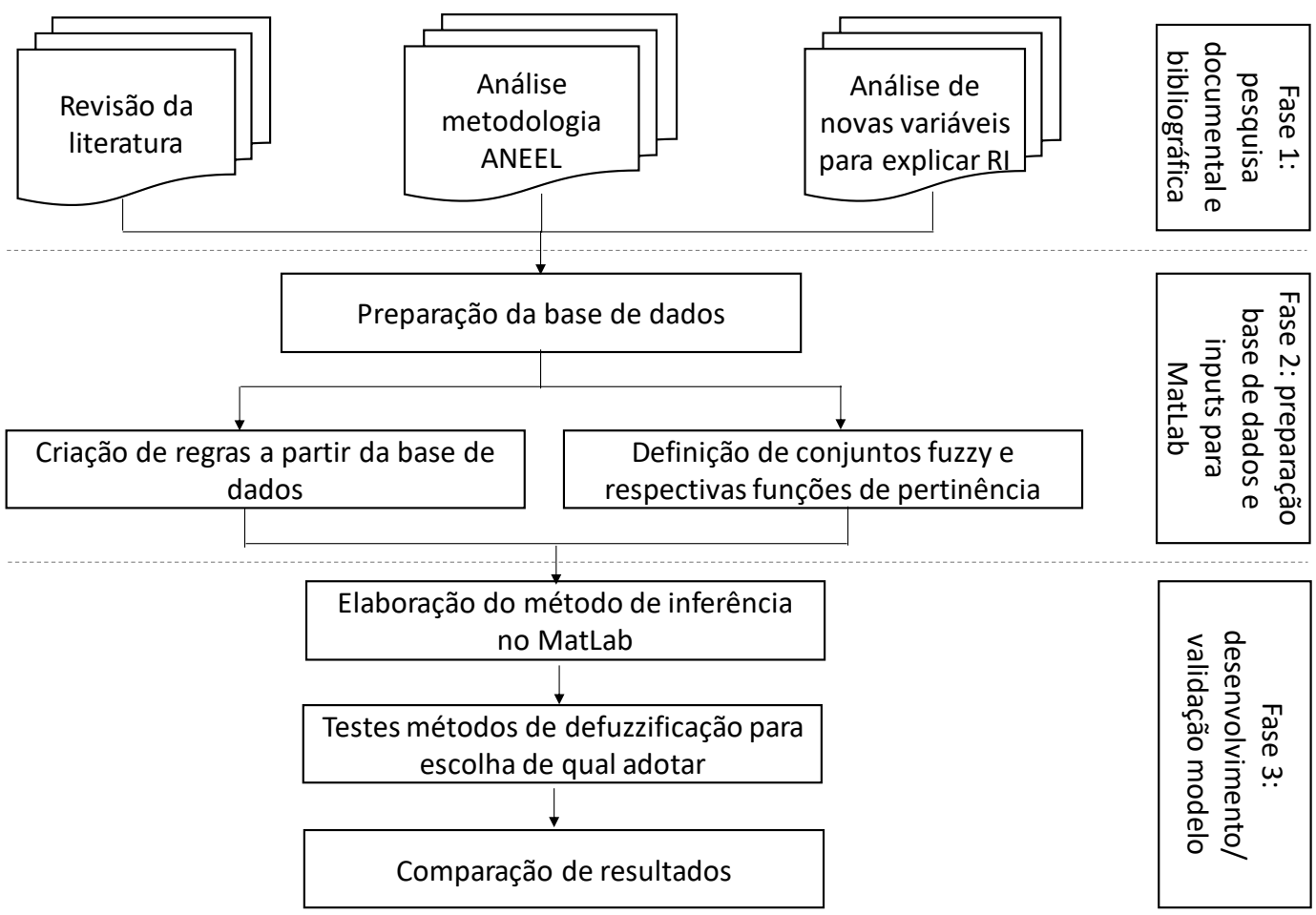

Figura 0.2 - Esquema global do modelo proposto

A seguir, de acordo com o esquema global apresentado, serão detalhadas todas as fases de desenvolvimento do modelo proposto para a definição de metas de inadimplência.

\subsection{1.}

\section{Fase 1: pesquisa documental e bibliográfica}

$\mathrm{Na}$ fase 1, após a revisão da literatura, conforme exposto no item 3.1, e de todo material disponível nas consultas e audiências públicas realizadas pela ANEEL, o primeiro passo para a construção do sistema foi definir quais seriam as variáveis de entrada.

Foram estudadas as variáveis já utilizadas pela ANEEL nos modelos de previsão de PNT e avaliadas diversas outras variáveis. O quadro 3.1, traz as principais variáveis avaliadas para a construção do modelo proposto:

Quadro 0.1 - Variáveis avaliadas para a construção do modelo proposto

\begin{tabular}{|l|l|l|}
\hline Variável & Descrição & Fonte \\
\hline Vio & Violência - Óbitos por Agressão & MS/SIM/DATASUS \\
\hline GINI & Índice de Desigualdade Social & IBGE \\
\hline
\end{tabular}




\begin{tabular}{|c|c|c|}
\hline Inad & Inadimplência do setor de crédito & BACEN \\
\hline Lixo-u & Coleta de lixo - urbano & IBGE \\
\hline Mbr.Mb1Mbr & Mercado baixa renda / Mercado B1 total & SAMP/ANEEL \\
\hline Mbr.Mbt & Mercado baixa renda / Mercado BT total & SAMP/ANEEL \\
\hline Pob2 & $\begin{array}{l}\text { Percentual de pessoas com renda per capita } \\
\text { inferior a } 1 / 2 \text { salário mínimo }\end{array}$ & $\begin{array}{l}\text { IBGE/IPEA - Banco de } \\
\text { Dados da ANEEL }\end{array}$ \\
\hline Pob & $\begin{array}{l}\text { Número de pessoas com renda abaixo } 1 / 2 \text { salário } \\
\text { mínimo }+ \text { Sem rendimentos }\end{array}$ & IBGE/IPEA \\
\hline Sub2 & $\begin{array}{l}\text { Precariedade - \% de pessoas em domicílios } \\
\text { subnormais }\end{array}$ & IBGE (Censo 2010) \\
\hline Rendtotal & $\begin{array}{l}\text { Rendimento médio do trabalho formal e } \\
\text { informal }\end{array}$ & IBGE \\
\hline Rendform & Rendimento médio do trabalho formal & IBGE \\
\hline Rendinform & Rendimento médio do trabalho informal & IBGE \\
\hline Pessoas<rend & $\begin{array}{l}\text { Número de pessoas ( } 1000 \text { pessoas) entre } 40 \% \\
\text { com menores rendimentos }\end{array}$ & IBGE \\
\hline <rend & $\begin{array}{l}\text { Rendimento das pessoas entre } 40 \% \text { com } \\
\text { menores rendimentos }\end{array}$ & IBGE \\
\hline Desocup & $\begin{array}{l}\text { Jovens de } 16 \text { a } 29 \text { anos de idade que não } \\
\text { estudam e não estão ocupados (mil pessoas) }\end{array}$ & IBGE \\
\hline Desocup2 & $\begin{array}{l}\text { Taxa de desocupação das pessoas de } 16 \text { anos ou } \\
\text { mais de idade }\end{array}$ & IBGE \\
\hline OcupForm & $\begin{array}{l}\text { Pessoas de } 16 \text { anos ou mais de idade, ocupadas } \\
\text { na semana de referência }\end{array}$ & IBGE \\
\hline OcupForm2 & $\begin{array}{l}\text { Percentual de pessoas de } 16 \text { anos ou mais de } \\
\text { idade, ocupadas na semana de referência } \\
\text { formalmente }\end{array}$ & IBGE \\
\hline Inad.pf & $\begin{array}{l}\text { Percentual de inadimplência de pessoas físicas } \\
\text { no setor de crédito }\end{array}$ & BACEN \\
\hline RGA & $\begin{array}{l}\text { Percentual de domicílios com rede geral de } \\
\text { água em pelo menos um cômodo }\end{array}$ & IBGE \\
\hline ADMD & & IBGE \\
\hline EEM & $\begin{array}{l}\text { Percentual de domicílios com mais de } 3 \\
\text { moradores em um dormitório (Alta Densidade } \\
\text { de Moradores por Dormitório) }\end{array}$ & IBGE \\
\hline Consumidores & Número de Consumidores das Distribuidoras - & ANEEL \\
\hline $\mathrm{Km}$ rede & Km de rede de distribuição & ANEEL \\
\hline Mercado & Mercado total das distribuidoras - & ANEEL \\
\hline
\end{tabular}




\subsection{2.}

\section{Fase 2: preparação base de dados e inputs para o Matlab}

Uma vez que a gestão da inadimplência pode ser mais complicada quanto maior for a área de concessão da distribuidora e, tendo em vista as variáveis descritas no Quadro 3.1, foram separadas as variáveis que determinam o porte das distribuidoras - consumidores, $\mathrm{km}$ rede e mercado.

No que se refere às demais variáveis, foi realizada uma avaliação qualitativa sobre quais seriam mais representativas para capturar a heterogeneidade das áreas de concessão em um contexto de consumidores inadimplentes, descartando variáveis de cunho semelhante e que produzem, praticamente, o mesmo efeito. Foi escolhido um conjunto de variáveis para representar o nível de vulnerabilidade a que determinada distribuidora estaria exposta.

Com o objetivo de construir um modelo robusto, mas de simples implementação, evitando um número excessivo de variáveis de entrada, que geraria complexidade ao modelo, foram adotadas duas variáveis de entrada de acordo com os agrupamentos relacionados acima.

Desta forma, chegou-se aos seguintes grupos de variáveis, que constituem as entradas do modelo:

1. Vulnerabilidade: constituída por variáveis que indicam as condições socioeconômicas da área de concessão de cada distribuidora.

2. Porte: constituída por variáveis que definem o tamanho das distribuidoras.

A variável de saída, a ser modelada, é a própria taxa de inadimplência de energia de cada distribuidora.

Nessa fase, deu-se início à preparação da base de dados, onde as variáveis que compõe cada uma das entradas foram normalizadas, a fim de se obter a média de todas para a utilização de um único valor em cada uma das 2 entradas (porte e vulnerabilidade).

A normalização foi realizada por meio da subtração da média dos valores (de cada variável), realizada para cada uma das distribuidoras, dividida pelo desvio padrão de cada variável apurado para cada distribuidora. 
Logo em seguida, foram criados 5 grupos fuzzy de forma a classificar cada variável de entrada e saída. Os grupos foram denominados de Muito Baixo, Baixo, Moderado, Alto e Muito Alto.

Os grupos foram representados por funções de pertinência triangulares e, para o último grupamento, trapezoidal. Cada função de pertinência foi definida por valores relativos aos 3 vértices de um triângulo e aos 4 vértices de um trapézio.

Os limites dos grupos fuzzy foram obtidos por meio dos seguintes passos:

1. Determinação da amplitude de cada uma das variáveis do modelo e obtenção de intervalos de classe iguais para os grupos fuzzy, representados por N1, N2, N3, N4, N5, N6.

2. Uma vez definidos os intervalos, foram determinados os vértices das funções de pertinência.

- Muito Baixo - Triangular com vértices em: N1; N1; N2.

- Baixo - Triangular com vértices em: N1; N2; N3.

- Moderado - Triangular com vértices em: N2; N3; N4.

- Alto - Triangular com vértices em: N3; N4; N5.

- Muito Alto - Trapezoidal com vértices em: N4; N5; N6; N6

Por meio da figura 3.3, observa-se graficamente a definição dos grupos fuzzy, conforme estrutura descrita anteriormente:

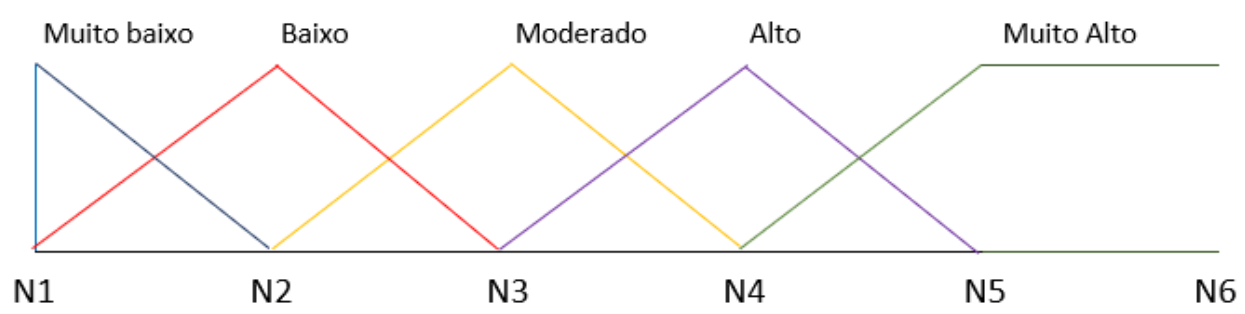

Figura 0.3 - Grupos fuzzy considerados na modelagem

Posteriormente, realizou-se a definição das regras por meio da análise da própria base de dados. Os dados foram classificados dentro de cada um dos 5 grupos definidos, utilizando-se os mesmos intervalos de classe mencionados anteriormente.

O procedimento adotado foi fixar um par de entradas (vulnerabilidade e porte) e analisar a variável de saída (inadimplência). O padrão em evidência foi indicado para formar a regra. 
Deve-se ressaltar que as regras foram estabelecidas tendo em vista os princípios da regulação por incentivo, assim, quando padrões conflituosos eram obtidos no processo, a definição da regra era feita de acordo com o padrão apresentado pela(s) empresa(s) de melhor performance. Em outras palavras, uma vez fixada as duas variáveis de entrada "vulnerabilidade" e "porte" em valores dentro de um grupo fuzzy (alto por exemplo), caso se apresente padrões de "inadimplência" (variável de saída) diferentes com igual probabilidade dentre a análise de cada uma das distribuidoras, a definição da regra se dará pelo padrão mais eficiente.

\subsection{3.}

\section{Fase 3: desenvolvimento/validação do modelo}

Nessa fase, foi elaborado o algoritmo para a inferência fuzzy no software MatLab. Por meio do método de Mamdani utilizado para a construção da Base de Regras, utiliza-se a ideia do mínimo ( $\wedge$, conector linguístico e) e do máximo ( $\vee$, conector linguístico ou) para que se possa inferir as condições de saída. No presente trabalho, tendo em vista os princípios da regulação por incentivo, utilizouse o mínimo para ativar as regras e formar as saídas. A adoção do mínimo, nesse caso, faz com que as metas adotadas sejam mais restritivas e, dessa forma, se aproximem mais dos resultados das empresas mais eficientes, estando assim, alinhadas com o conceito da yardstick competition.

Quanto ao processo de defuzzyficação, encontra-se no MatLab, os seguintes métodos:

- Centroid: calcula o output determinando o centro da área sob as funções de pertinência ativadas.

- Bisector: calcula o output pela posição exata que divide a função de pertinência em duas áreas iguais.

- MoM - Mean of maximus: calcula o output determinando a média dos valores de pertinência máximos.

- SoM - Smoler of maximus: calcula o output determinando o menor valor de pertinência entre os máximos.

- LoM - Larger of maximus: calcula o output determinando o maior valor de pertinência entre os máximos. 
Por meio da figura 3.4 pode-se visualizar graficamente a representação de cada um dos métodos de defuzzyficação.

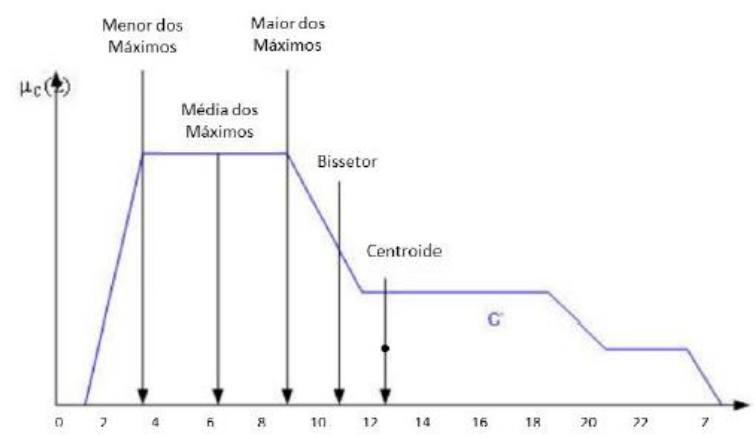

Figura 0.4 - Representação dos métodos de defuzzyficação

Fonte: MARAJ, SHATRI E RUGOVA (2008).

A escolha foi realizada testando todos os principais métodos descritos na literatura e comparando os erros quadráticos médios entre as previsões do sistema fuzzy e os valores declarados pelas distribuidoras. Dessa forma, uma rotina em MatLab foi escrita com o objetivo de calcular sistematicamente a taxa de inadimplência (com cada um dos métodos de defuzzyficação descritos anteriormente) e os erros quadráticos médios entre (i) as previsões do sistema fuzzy e (ii) os valores declarados pelas distribuidoras. A escolha se deu pelo método de defuzzyficação com menor erro quadrático.

Após a escolha do método de defuzzificação, foram comparadas as metas regulatórias de inadimplência propostas pela metodologia fuzzy com as metas propostas pela metodologia ANEEL e com a inadimplência real das distribuidoras, o que será detalhado no próximo capítulo.

Por todo o exposto, alcança-se o terceiro objetivo específico, qual seja, o desenvolvimento de um modelo alternativo ao utilizado pela ANEEL para a definição das metas regulatórias de inadimplência das distribuidoras de energia elétrica do país. 


\section{3.}

\section{Considerações sobre o capítulo}

Após conhecer os princípios da regulação por incentivo e a metodologia de apuração das metas regulatórias de inadimplência, bem como suas fragilidades, foco do capítulo 2, o presente capítulo traz a proposição de um modelo alternativo ao vigente.

A escolha do modelo proposto se deu por meio de pesquisa e estudo de trabalhos já desenvolvidos sobre o tema de inadimplência. Buscou-se identificar uma metodologia que se mostrasse aderente aos princípios e objetivos almejados para a construção de um modelo robusto e de simples implementação.

Embora a inferência fuzzy não tenha sido utilizada no contexto de apuração de metas de inadimplência, seus conceitos e formulação se mostraram coerentes com os objetivos almejados para a determinação das metas regulatórias de inadimplência, sendo totalmente aplicável em um contexto de regulação por incentivo, o que ficará mais claro no decorrer do próximo capítulo.

O capítulo 4 demonstrará a aplicabilidade do modelo construído ao caso da determinação das metas regulatórias de inadimplência das distribuidoras brasileiras de energia elétrica. 


\section{4}

\section{Aplicabilidade do modelo proposto}

Nesse capítulo serão detalhadas cada uma das fases de construção do modelo proposto no capítulo 3. A seção 4.1 se refere à Fase 1 de desenvolvimento do modelo, aplicada ao contexto das distribuidoras de energia elétrica brasileiras. Nessa fase, levantou-se o referencial teórico para a escolha e tratamento das variáveis que compõem o modelo.

Na seção 4.2 é mostrado o passo a passo para a preparação de dados e inputs para o modelo construído no Matlab, desde a criação dos agrupamentos fuzzy até a formação das regras, fundamentais para o aprendizado do modelo e geração dos dados de saída.

A seção 4.3 trata do desenvolvimento e validação do modelo por meio da análise dos resultados de saída para cada uma das classes de consumo das distribuidoras.

Por fim, a seção 4.4 traz as considerações sobre o capítulo.

\section{1. \\ Fase 1: pesquisa documental e bibliográfica}

De acordo com as fases descritas anteriormente, o primeiro passo para a implementação do modelo proposto, após realizada a pesquisa conceitual na literatura e o estudo da metodologia atual utilizada pela ANEEL, foi o levantamento de quais variáveis deveriam ser utilizadas.

Ainda nessa fase foi realizado estudo para encontrar a melhor maneira de utilizar as variáveis disponíveis, tendo em vista o objetivo principal em tela: caracterizar o cenário socioeconômico no qual cada distribuidora está inserida e, simultaneamente, o quanto suas próprias características podem influenciar sobre a forma de gestão empregada para contornar o problema da inadimplência.

Como foram levantadas diferentes variáveis, o caminho seria testar a correlação de cada uma delas com a inadimplência apurada de cada distribuidora, o que agregaria mais complexidade ao estudo, pois não só seriam testadas cada variáveis, como também suas defasagens no tempo para que fosse captado o 
efeito real de cada uma das variáveis sobre a inadimplência das distribuidoras. Por exemplo, em quantos meses uma queda no emprego formal no dia de hoje afeta a inadimplência. Para responder essa questão, seria necessário testar a correlação temporal dessas duas variáveis. O mesmo procedimento deveria ser realizado com cada uma das variáveis. Cabe ressaltar nesse ponto, que a apuração da inadimplência das distribuidoras é realizada por meio da média de faturas não pagas, utilizando-se (na metodologia atual), uma curva de aging de 49 a 60 meses de faturamentos não recebidos em relação à data de referência, o que gera maior complexidade na obtenção da correlação com as demais variáveis.

Dessa forma, para explicar o tratamento que foi dado às variáveis do modelo proposto, faz-se necessário discorrer sobre os conceitos de variáveis dependentes, independentes e espúrias, com base nas definições propostas por RAUEN (2012).

A variável dependente ou variável resposta é aquela que se quer explicar, que pode ser influenciada ou até mesmo determinada por outras variáveis. No caso do presente estudo, a inadimplência das faturas das distribuidoras é a variável dependente e também a variável de saída no modelo proposto por meio da inferência fuzzy.

Já as variáveis independentes ou variáveis explicativas são aquelas que influenciam, afetam ou determinam o comportamento de outras variáveis, especialmente de uma variável dependente. Nesse caso, todas as possíveis variáveis levantadas e relacionadas no Quadro 3.1, na seção 3.2.1 podem ser consideradas variáveis independentes.

Variáveis espúrias são aquelas que não possuem uma correlação real com a variáveis dependente, ou seja, não existe a relação causa e efeito entre as variáveis resposta e explicativas. No entanto, tais variáveis podem influenciar ou modificar o efeito de uma variável independente sobre a variável dependente.

Assim, de acordo com RAUEN (2012), um investigador deve-se sempre perguntar se a suposta relação entre duas variáveis é real ou acidental, nesse último caso se trataria de uma relação espúria.

Para o modelo proposto, foram escolhidas variáveis que conceitualmente afetam a inadimplência, porém, para se evitar correlações espúrias, essas variáveis foram agrupadas de forma a indicar um único fator correspondente ao cenário socioeconômico em que cada distribuidora está inserida. Esse grupo de variáveis foi nomeado de "Vulnerabilidade". 
O mesmo procedimento foi realizado com as variáveis que contribuem para a caracterização do porte das empresas distribuidoras de energia elétrica, grupo denominado de "Porte".

O Quadro 4.1 apresenta as variáveis que compõem os grupos de porte e vulnerabilidade para as distribuidoras.

Quadro 0.1 - Variáveis utilizadas para a construção das variáveis fuzzy.

\begin{tabular}{|c|c|c|}
\hline $\begin{array}{l}\text { Grupo de } \\
\text { variáveis }\end{array}$ & Variável & Descrição e fonte das variáveis \\
\hline \multirow{10}{*}{$\begin{array}{l}\text { Vulnerabilidade } \\
\text { (base 20166) }\end{array}$} & Pob & $\begin{array}{l}\% \text { de pessoas com renda per capita inferior a } 1 / 2 \text { salário mínimo } \\
\text { (IBGE/IPEA) }\end{array}$ \\
\hline & Vio & Óbitos por Agressão (DATASUS) \\
\hline & Sub2 & \% de pessoas em domicílios subnormais (Censo 2010 - IBGE) \\
\hline & Gini & Índice de Gini - concentração de renda (IBGE) \\
\hline & Inadpf & $\begin{array}{l}\text { \% de Inadimplência de pessoas físicas no setor de crédito } \\
\text { (BACEN) }\end{array}$ \\
\hline & Rendtotal & Rendimento médio do trabalho formal e informal (IBGE) \\
\hline & Ocupform & $\begin{array}{l}\text { \% de pessoas de } 16 \text { anos ou mais de idade, ocupadas na semana } \\
\text { de referência formalmente (IBGE) }\end{array}$ \\
\hline & RGA & $\begin{array}{l}\text { \% de domicílios com rede geral de água em pelo menos um } \\
\text { cômodo. (IBGE - Estimativa para } 2016 \text { com base nas taxas de } \\
\text { crescimento das tabelas similares da PNADs Estaduais). }\end{array}$ \\
\hline & ADMD & $\begin{array}{l}\text { \% de domícilios com mais de } 3 \text { moradores por dormitório (alta } \\
\text { densidade de morador por domicílio). (IBGE - Estimativa para } \\
2016 \text { com base nas taxas de crescimento das tabelas similares da } \\
\text { PNADs Estaduais). }\end{array}$ \\
\hline & EEM & $\begin{array}{l}\text { \% de pessoas acima de } 25 \text { anos que se evadiram do ensino } \\
\text { médio. (IBGE - Estimativa para } 2016 \text { com base nas taxas de } \\
\text { crescimento das tabelas similares da PNADs Estaduais). }\end{array}$ \\
\hline \multirow{3}{*}{$\begin{array}{l}\text { Porte } \\
\text { (base 2016) }\end{array}$} & $\begin{array}{c}\text { Mercado } \\
\text { (GWh) }\end{array}$ & Consumo faturado das distribuidoras de energia (SAMPE) \\
\hline & $\begin{array}{l}\text { Número de } \\
\text { Consumidor }\end{array}$ & $\begin{array}{l}\text { Número de consumidores total das distribuidoras de energia } \\
\text { (SAMPE) }\end{array}$ \\
\hline & $\mathrm{Km}$ de rede & $\mathrm{Km}$ de rede das linhas de transmissão das distribuidoras (SAMPE) \\
\hline
\end{tabular}

Ressalta-se que, uma vez que essas variáveis foram transformadas em um fator que representa as condições de vulnerabilidade e porte em que cada distribuidora se insere, não foram utilizados dados históricos, mas somente uma base cuja referência é 2016, mesma referência utilizada para a formação da base de inadimplência das distribuidoras.

Quanto à variável de saída, que é a própria inadimplência apurada, o modelo proposto foi testado considerando a curva de aging adotada na metodologia

${ }^{6} \mathrm{O}$ modelo foi construído com a base de dados preparada para o Projeto de Pesquisa e Desenvolvimento sobre metodologia de apuração das perdas não técnicas e inadimplência de energia elétrica, desenvolvido pela PUC/Rio por solicitação da Enel Rio. 
vigente, ou seja, faturamentos não recebidos de 49 a 60 meses das datas de referência, bem como uma curva de aging de faturamentos recebidos de 25 a 36 meses das datas de referência, conforme sugestão de alguns agentes nas consultas públicas sobre esse tema.

\section{2.}

\section{Fase 2: preparação base de dados e inputs para o Matlab}

Essa fase apresenta os agrupamentos fuzzy e a formação de regras, fundamentais para a criação da base de dados e inputs para o modelo desenvolvido em Matlab com base na metodologia de inferência fuzzy.

\subsection{1.}

\section{Definição dos agrupamentos fuzzy}

As variáveis utilizadas na definição dos fatores de vulnerabilidade e porte, foram normalizadas para que pudessem ser comparadas em uma base única, obtendo-se posteriormente, a média dessas variáveis em cada caso. Segue o passo a passo desse procedimento:

1ำ passo: média e desvio padrão

- Apuração da média de cada uma das variáveis, considerando todas as 59 distribuidoras.

- Apuração do desvio padrão de cada uma das variáveis, considerando todas as 59 distribuidoras.

$2^{\circ}$ passo: normalização das variáveis

- As variáveis originais, para cada distribuidora, formam normalizadas por meio da seguinte equação 4.1 .

Variável normalizada $=\frac{\text { variável original-média }}{\text { desvio padrão }}$

3ำ passo: obtenção das variáveis de entrada

- A variável vulnerabilidade foi obtida por meio do fator constituído pela média das variáveis normalizadas que compõe esse grupo, conforme demonstrado no Quadro 4.1;

- A variável porte foi obtida por meio do fator constituído pela média das variáveis normalizadas que compõe esse grupo, conforme demonstrado no Quadro 4.1. 
Em sequência, com base nos procedimentos descritos no Capítulo 3, seção 3.2.2, foram obtidos os grupos fuzzy para as duas variáveis de entrada da metodologia de inferência fuzzy - vulnerabilidade e porte, conforme pode ser visto na Figura 4.1.

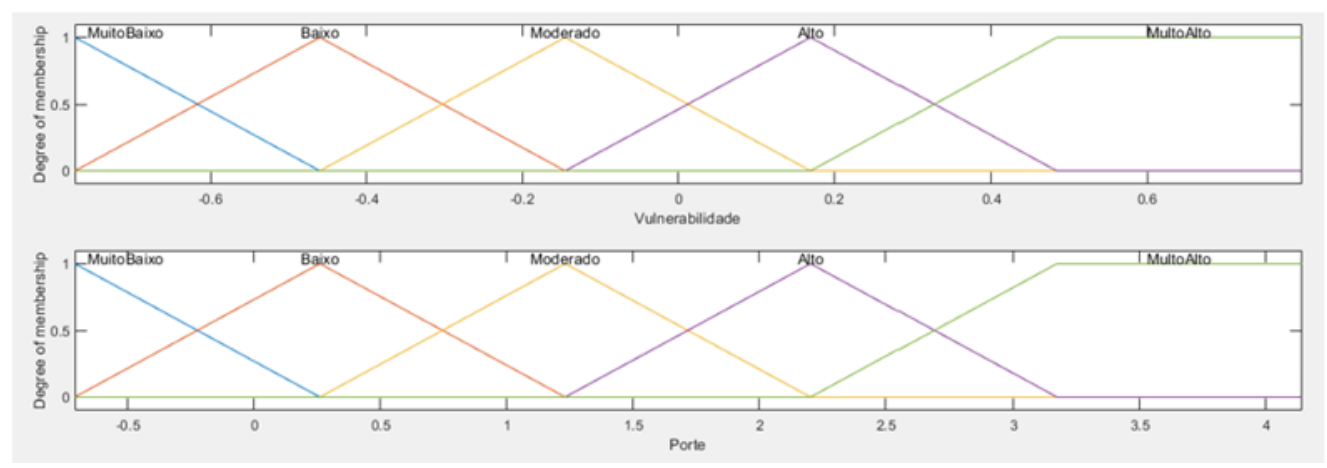

Figura 0.1 - Agrupamentos fuzzy para Vulnerabilidade e Porte

Nessa fase também foram definidos os demais agrupamentos fuzzy, seguindo o disposto no Capítulo 3, item 3.2.2, criando-se agrupamentos no mesmo modelo da figura anterior para as classes residencial, industrial, comercial, rural, poder público, iluminação pública e serviço público.

Observa-se que, os limites dos agrupamentos para cada uma das classes de consumo variam de acordo com a adoção da curva de aging de faturamentos não recebidos de 49 a 60 meses e de 25 a 36 meses a partir da data base de referência (2016).

\subsection{2. \\ Definição das regras}

Outro passo importante para a especificação do modelo, reside na criação das regras fuzzy. A metodologia empregada se baseou na análise da base de dados referente a vulnerabilidade, porte e inadimplência declarada por cada distribuidora, procurando por padrões existentes entre as duas primeiras variáveis e a última. Assim, o procedimento adotado foi o de fixar um par de entradas (vulnerabilidade e porte) e analisar a variável de saída (inadimplência). Considere o exemplo realizado para o segmento residencial, considerando a curva de aging de 25 a 36 meses: para fator de vulnerabilidade "moderado" e fator de porte "baixo" tem-se os casos relatados no Quadro 4.2. 
Quadro 0.2 - Exemplo de formação de regra para o segmento residencial, considerando curva de aging de 25 a 36 meses

\begin{tabular}{|c|c|c|}
\hline Vulnerabilidade & Porte & Inadimplência real \\
\hline moderado & Baixo & Alto \\
\hline moderado & Baixo & Moderado \\
\hline moderado & Baixo & muito baixo \\
\hline moderado & Baixo & muito baixo \\
\hline
\end{tabular}

Dessa forma, considerando o disposto no Quadro 4.2, para esse exemplo, a relação que mais aparece é a que indica inadimplência "muito baixo". Logo, esse padrão é então usado para criar-se a regra de saída (Inadimplência) quando Vulnerabilidade é moderada e Porte é baixo.

A lógica dessa regra é que existem empresas de mesmo porte, inseridas em um contexto de vulnerabilidade semelhantes, que conseguem manter o nível de inadimplência residencial muito baixo. Nesse contexto, as demais distribuidoras devem perseguir na busca por níveis melhores de inadimplência ou arcar com o que ficar acima da meta regulatória estabelecida com base nos princípios da regulação por incentivo.

Cabe observar, no entanto, que o resultado do modelo não indicará um percentual de inadimplência unicamente em função do enquadramento das variáveis aos grupos fuzzy (e consequente ativação de determinada regra). Isso se dá, visto que outros fatores influenciarão no resultado do modelo; fatores como o grau de pertencimento a esses grupos, definido pelas funções de pertinência e método de defuzzyficação, influenciando diretamente no resultado final do modelo.

Ainda no que se refere às regras, importa destacar que nem sempre um padrão evidente se apresentava, indicando uma regra fuzzy. Houve casos em que não se chegou a uma unanimidade na indicação da inadimplência para um mesmo par de entradas e outros em que apenas uma distribuidora ficou como representante de uma regra.

Desta forma, para representar a incerteza das regras formadas segundo esses cenários, foram atribuídos pesos para as regras. Assim, se estabeleceu que uma regra teria peso igual a 1 quando esta era formada por padrões bem definidos (pelo menos 2 empresas com a mesma indicação, caso do exemplo anterior) e 0,6 para as demais regras ( 1 única empresa que representa uma regra 
e padrões de repetição não muito claros, como por exemplo: 2 casos de vulnerabilidade muito alta, empresas de baixo porte, uma delas com inadimplência muito baixa e outra com inadimplência baixa, a regra é definida de forma mais restritiva, inadimplência muito baixa, e se atribui um peso menor à regra). Assim é atribuído uma menor força (menor peso) às regras que tiveram maior incerteza na sua formação. É importante mencionar que a intensidade do peso foi definida através de testes sucessivos com diferentes valores de pesos até se chegar ao valor que proporcionava melhor resposta.

O diagrama da figura 4.2 mostra o processo de elaboração de uma regra e a atribuição do peso de acordo com exemplos de casos possíveis. No caso 1 , após fixar-se a vulnerabilidade e o porte em "Muito Baixo" e observar-se a saída (inadimplência), observou-se duas ou mais empresas com inadimplência "Muito Baixo", formando uma regra de peso 1. Os demais casos são exemplos de regras de peso 0,6, no Caso 2 não houve uma predominância de determinado grupo fuzzy para a saída e o Caso 3 se refere àquelas regras que foram criadas em função do comportamento de uma única empresa.

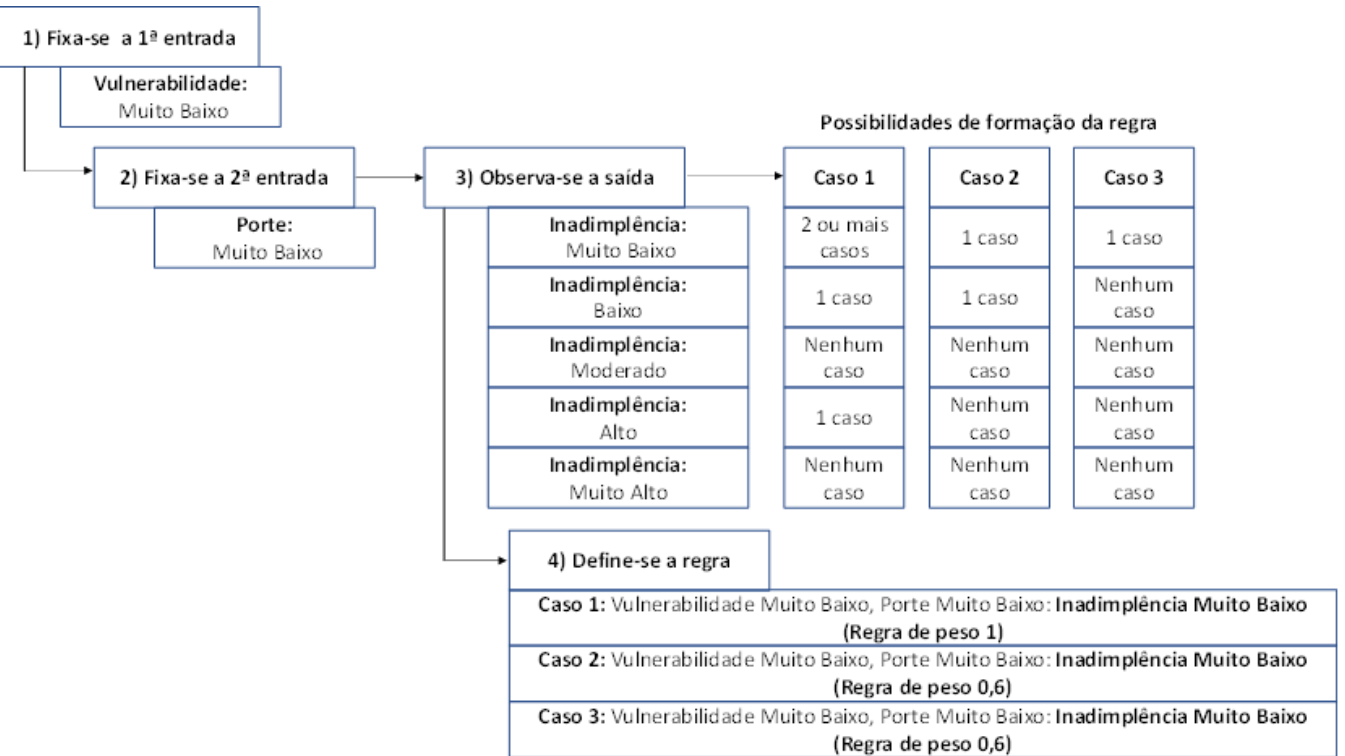

Figura 0.2 - Diagrama de formação de regras

Por meio da Figuras 4.3 e 4.4, visualiza-se o quadro que representa as regras definidas para a inadimplência residencial para cada uma das curvas de aging adotadas. A leitura dessas regras pode ser feita ao se observar o cruzamento das linhas (grupos fuzzy da primeira variável - Vulnerabilidade) com as colunas (grupos fuzzy da segunda variável - Porte), resultando na indicação para a variável de saída (inadimplência). 
Depreende-se da Figura 4.3 (curva de aging de 49 a 60 meses), que uma distribuidora com índice de vulnerabilidade muito alto (MA) e porte baixo (B), possui uma inadimplência de nível moderado, e sua regra fuzzy pode ser lida como: se Vulnerabilidade é Muito Alta e Porte Baixo, então sua inadimplência será moderada.

\section{Residencial}

\begin{tabular}{|c|c|c|c|c|c|c|c|c|}
\hline & & \multicolumn{7}{|c|}{ Porte } \\
\hline & & $\mathrm{MB}$ & B & & $M$ & & $A$ & MA \\
\hline \multirow{5}{*}{\begin{tabular}{|l}
$\frac{0}{0}$ \\
$\frac{\pi}{0}$ \\
$\frac{0}{\overline{0}}$ \\
$\frac{0}{0}$ \\
$\frac{0}{5}$ \\
$\frac{1}{3}$
\end{tabular}} & $\mathrm{MB}$ & & & 3 & & & & \\
\hline & $B$ & & & 1 & & 1 & & \\
\hline & $\mathrm{M}$ & & & 3 & 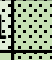 & 2 & & 1 \\
\hline & A & & & 2 & 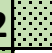 & 2 & 2 & \\
\hline & $\mathrm{MA}$ & & 1. & 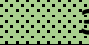 & 3 & & & \\
\hline
\end{tabular}

\begin{tabular}{|c|c|}
\hline Grupo & Inad. \\
\hline $\mathrm{MB}$ & $\mathbf{1}$ \\
\hline $\mathrm{B}$ & $\mathbf{2}$ \\
\hline $\mathrm{M}$ & $\mathbf{3}$ \\
\hline $\mathrm{A}$ & $\mathbf{4}$ \\
\hline $\mathrm{MA}$ & $\mathbf{5}$ \\
\hline
\end{tabular}

Sendo MB - muito baixo, B - baixo, $M$ - moderado, $\mathrm{A}$ - alto e MA - muito alto e células rachuradas - regras com peso 0,6 .

Figura 0.3 -Regras fuzzy - Residencial - curva de aging de 49 a 60 meses

Ao se modificar a curva de aging para 25 a 36 meses (Figura 4.4), essa regra se altera, como mostra a figura 4.3, e passa a ser: se vulnerabilidade é Muito Alta e porte é Baixo, então sua inadimplência será Muito Alta.

No entanto, a formação dessa regra não apresentou um padrão bem definido (para as duas curvas de aging), sendo, portanto, atribuído um peso de 0,6 para essa regra (célula hachurada).

\begin{tabular}{|c|c|c|c|c|c|c|c|c|}
\hline & \multicolumn{8}{|c|}{ Residencial } \\
\hline & & \multicolumn{7}{|c|}{ Porte } \\
\hline & & $M B$ & & 3 & $M$ & A & & MA \\
\hline \multirow{5}{*}{$\begin{array}{l}\frac{0}{0} \\
\frac{\pi}{0} \\
\frac{0}{\overline{0}} \\
\frac{\pi}{\pi} \\
\frac{\pi}{0} \\
\frac{5}{3}\end{array}$} & $\mathrm{MB}$ & & S & 1 & & & & \\
\hline & B & & & 1 & 1 & & & S \\
\hline & $M$ & & & 1 & 1 & & & \\
\hline & $A$ & & & & & & 2 & \\
\hline & MA & & 3 & 2 & & & & \\
\hline
\end{tabular}

\begin{tabular}{|c|c|}
\hline Grupo & Inad. \\
\hline $\mathrm{MB}$ & $\mathbf{1}$ \\
\hline $\mathrm{B}$ & $\mathbf{2}$ \\
\hline $\mathrm{M}$ & $\mathbf{3}$ \\
\hline $\mathrm{A}$ & $\mathbf{4}$ \\
\hline $\mathrm{MA}$ & $\mathbf{5}$ \\
\hline
\end{tabular}

Sendo MB - muito baixo, $B$ - baixo, $M$ - moderado, $A$ - alto e $M A$ - muito alto e células rachuradas - regras com peso 0,6.

Figura 0.4 - Regras fuzzy - Residencial - curva de aging de 25 a 36 meses

Ressalta-se que, como as regras foram obtidas por meio dos dados reais, algumas combinações como, por exemplo, vulnerabilidade muito alta (MA) e porte (MA) não foram observadas no padrão de inadimplência das distribuidoras 
analisadas, razão pela qual não foram inseridas as demais regras que seriam possíveis, teoricamente.

\section{3.}

\section{Fase 3: desenvolvimento/validação do modelo}

A apresentação dessa fase será segmentada de acordo com cada uma das classes de consumo das distribuidoras: residencial, industrial, comercial, rural, poder público, iluminação pública e serviço público. Ao longo das seções serão comparados os resultados obtidos por meio do modelo de inferência fuzzy com os dados reais e com a metodologia atual (ANEEL). As comparações serão realizadas com base nas duas curvas de aging em estudo.

Após a análise de cada uma das classes individualmente, serão discutidos, de forma geral, os resultados obtidos por meio da inferência fuzzy e realizadas as considerações finais do capítulo.

\subsection{1. \\ Classe residencial}

Segundo o Anuário Estatístico de 2020, publicado pela EPE, a classe residencial representa $45 \%$ do consumo cativo do Brasil, sendo a maior classe em termos de consumo e de consumidores, onde o percentual de representação é $86 \%$ do total de consumidores do mercado cativo brasileiro. Assim sendo, grande parte da inadimplência das faturas das distribuidoras são provenientes dessa classe de consumo.

Esse segmento, sem dúvida alguma, é fortemente impactado pelas condições socioeconômicas em que se insere, bem como pelo porte das distribuidoras, uma vez que quanto maior a extensão para fiscalizar, menor sua eficácia.

Para a classe residencial, foi adotado o método de defuzzyficação do centroid com a curva de aging de 49 a 60 meses e bissector para a curva de aging de 25 a 36 meses de faturamentos não recebidos, os quais minimizaram os erros quadráticos médios da previsão em relação aos valores reais, como pode ser visualizado por meio da figura 4.5. 


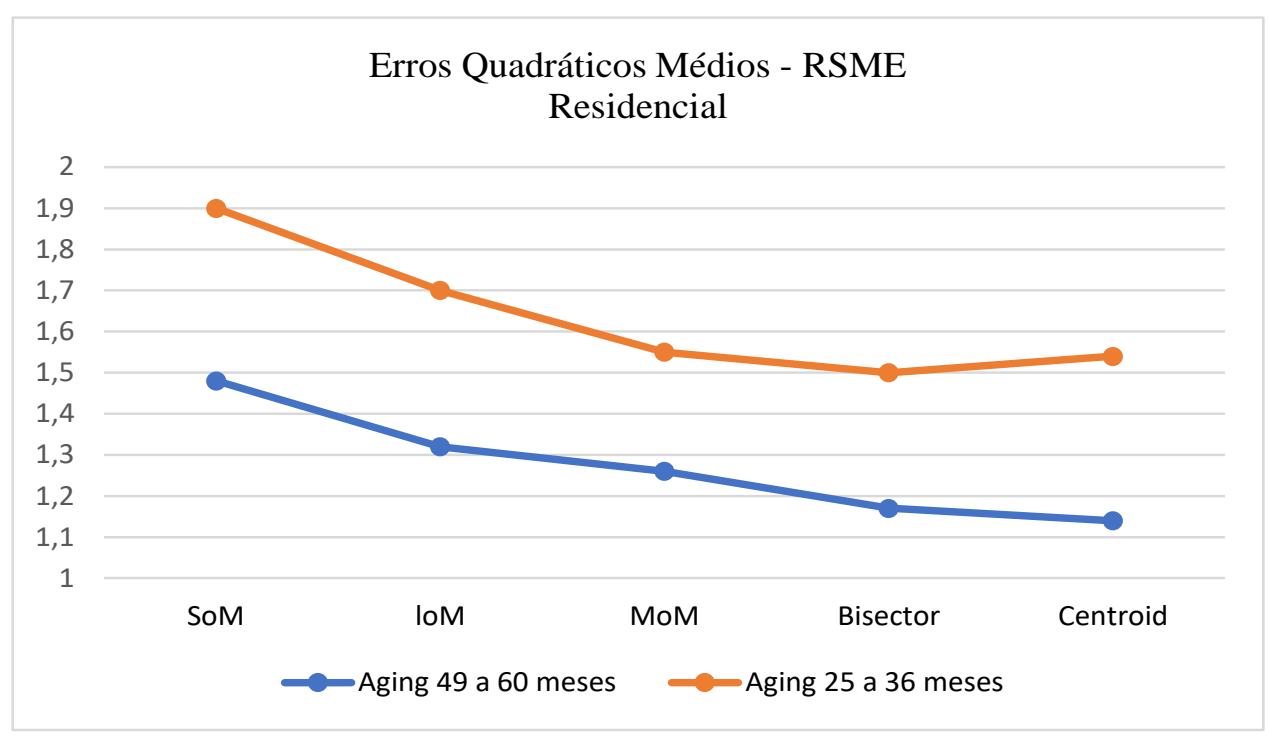

Figura 0.5 - Escolha do método de defuzzyficação para o residencial - curvas de aging de 49 a 60 meses e de 25 a 36 meses

Os resultados do modelo para a classe residencial, considerando as duas curvas de aging, podem ser visualizados na Tabela 4.1. Por meio dessa tabela é possível verificar os desvios entre os valores reais, apurados com base nas duas curvas de aging, e os valores de saída do modelo fuzzy. Cabe ressaltar que, como as metas de inadimplência são valores percentuais, os desvios foram apurados pela subtração entre real e previsto. O desvio médio para a curva de aging de 49 a 60 meses foi de apenas $0,25 \%$, enquanto para a curva de 25 a 36 meses foi de $0,58 \%$. 
Tabela 0.1 - Resultado modelo para a classe residencial - valores \%

\begin{tabular}{|c|c|c|c|c|c|c|}
\hline \multirow{2}{*}{ Residencial } & \multicolumn{2}{|c|}{ Resultado Fuzzy } & \multicolumn{2}{|c|}{ Real } & \multicolumn{2}{|c|}{ Desvio Real menos previsto } \\
\hline & 49 a 60 meses & 25 a 36 meses & 49 a 60 meses & 25 a 36 meses & 49 a 60 meses & 25 a 36 meses \\
\hline $1 \mathrm{AES} \mathrm{SUL}$ & 0,42 & 0,43 & 0,67 & 0,81 & 0,25 & 0,38 \\
\hline 2 CEAM & 2,81 & 4,19 & 5,62 & 7,23 & 2,81 & 3,04 \\
\hline 3 AMPLA & 2,24 & 1,08 & 2,03 & 2,12 & $-0,21$ & 1,03 \\
\hline 4 BANDEIRANTE & 1,43 & 1,30 & 0,77 & 1,07 & $-0,66$ & $-0,23$ \\
\hline 5 CAIUÁ & 0,44 & 0,29 & 0,08 & 0,10 & $-0,35$ & $-0,19$ \\
\hline 6 CEAL & 0,95 & 0,36 & 3,48 & 5,00 & 2,53 & 4,64 \\
\hline 7 CEB & 1,04 & 0,65 & 0,45 & 0,67 & $-0,59$ & 0,02 \\
\hline 8 CEEE & 1,03 & 0,43 & 0,02 & 0,15 & $-1,02$ & $-0,29$ \\
\hline 9 CELESC & 0,42 & 0,43 & 0,58 & 0,55 & 0,15 & 0,11 \\
\hline 10 CELG & 0,77 & 0,43 & 0,27 & 0,43 & $-0,50$ & $-0,01$ \\
\hline 11 CELPA & 1,10 & 0,51 & 2,64 & 4,85 & 1,54 & 4,34 \\
\hline 12 CELPE & 1,07 & 0,51 & 3,47 & 3,28 & 2,40 & 2,78 \\
\hline 13 CELTINS & 0,42 & 0,43 & 0,29 & 0,45 & $-0,13$ & 0,02 \\
\hline 14 CEMAR & 0,64 & 0,43 & 2,16 & 3,33 & 1,52 & 2,90 \\
\hline 15 CEMAT & 0,44 & 0,36 & 0,53 & 0,62 & 0,09 & 0,26 \\
\hline 16 CEMIG & 0,44 & 1,08 & 0,91 & 1,71 & 0,47 & 0,62 \\
\hline 17 CEPISA & 0,43 & 0,43 & 5,02 & 6,32 & 4,59 & 5,88 \\
\hline 18 CERON & 0,40 & 0,36 & 0,06 & 0,02 & $-0,34$ & $-0,34$ \\
\hline 19 CFLO & 0,40 & 0,36 & 0,07 & 0,08 & $-0,34$ & $-0,28$ \\
\hline 20 CHESP & 0,40 & 0,36 & 0,05 & 0,07 & $-0,35$ & $-0,29$ \\
\hline $21 \mathrm{CJE}$ & 0,48 & 0,36 & 0,26 & 0,15 & $-0,22$ & $-0,21$ \\
\hline 22 MOCOCA & 0,36 & 0,29 & 0,37 & 0,23 & 0,01 & $-0,06$ \\
\hline 23 SANTA CRUZ & 0,35 & 0,29 & 0,41 & 0,31 & 0,05 & 0,02 \\
\hline 24 CNEE & 0,35 & 0,29 & 0,06 & 0,09 & $-0,29$ & $-0,20$ \\
\hline 25 COCEL & 0,41 & 0,29 & 0,09 & 0,08 & $-0,32$ & $-0,20$ \\
\hline 26 COELBA & 1,10 & 1,08 & 1,76 & 1,42 & 0,66 & 0,34 \\
\hline 27 COELCE & 1,05 & 0,43 & 0,73 & 1,02 & $-0,31$ & 0,59 \\
\hline 28 COOPERALIANÇA & 0,36 & 0,29 & 0,18 & 0,26 & $-0,18$ & $-0,03$ \\
\hline 29 COPEL & 1,05 & 0,51 & 0,50 & 0,73 & $-0,55$ & 0,23 \\
\hline 30 COSERN & 0,44 & 0,43 & 0,34 & 0,35 & $-0,09$ & $-0,09$ \\
\hline 31 CPEE & 0,37 & 0,36 & 0,58 & 0,26 & 0,20 & $-0,10$ \\
\hline 32 CPFL PIRATININGA & 1,17 & 1,88 & 1,11 & 1,02 & $-0,06$ & $-0,85$ \\
\hline 33 CPFL PAULISTA & 1,10 & 0,72 & 2,16 & 1,96 & 1,06 & 1,24 \\
\hline 34 CSPE & 0,54 & 0,36 & 0,93 & 0,54 & 0,39 & 0,18 \\
\hline 35 DEMEI & 0,40 & 0,36 & 0,62 & 0,85 & 0,22 & 0,49 \\
\hline 36 DMEPC & 0,44 & 0,29 & 0,62 & 0,67 & 0,18 & 0,38 \\
\hline 37 CELB & 0,58 & 0,36 & 0,22 & 0,85 & $-0,36$ & 0,49 \\
\hline 38 EDEVP & 0,35 & 0,29 & 0,09 & 0,11 & $-0,26$ & $-0,18$ \\
\hline $39 \mathrm{EEB}$ & 0,37 & 0,36 & 0,07 & 0,09 & $-0,30$ & $-0,27$ \\
\hline 40 JOAO CESA & 0,41 & 0,36 & 0,00 & 0,13 & $-0,41$ & $-0,23$ \\
\hline 41 EFLUL & 0,35 & 0,29 & 0,00 & 0,03 & $-0,35$ & $-0,26$ \\
\hline 42 ELEKTRO & 1,04 & 0,43 & 1,03 & 0,87 & $-0,02$ & 0,43 \\
\hline 43 ELETROACRE & 0,39 & 0,36 & 4,36 & 4,81 & 3,97 & 4,45 \\
\hline 44 ELETROCAR & 0,35 & 0,29 & 0,18 & 0,25 & $-0,17$ & $-0,04$ \\
\hline 45 ELETROPAULO & 1,10 & 1,08 & 1,81 & 1,98 & 0,71 & 0,90 \\
\hline 46 ELFSM & 0,36 & 0,29 & 0,05 & 0,05 & $-0,31$ & $-0,24$ \\
\hline $47 \mathrm{EMG}$ & 0,37 & 0,36 & 0,18 & 0,22 & $-0,19$ & $-0,14$ \\
\hline 48 ENERSUL & 0,38 & 0,36 & 0,80 & 0,94 & 0,42 & 0,57 \\
\hline 49 CENF & 0,50 & 0,36 & 0,24 & 0,15 & $-0,27$ & $-0,21$ \\
\hline 50 SAELPA & 0,41 & 0,36 & 0,70 & 0,93 & 0,28 & 0,57 \\
\hline 51 ESCELSA & 0,93 & 0,43 & 1,35 & 1,92 & 0,41 & 1,48 \\
\hline 52 ENERGIPE & 0,85 & 0,36 & 0,62 & 0,59 & $-0,23$ & 0,23 \\
\hline 53 HIDROPAN & 0,37 & 0,36 & 0,00 & 0,00 & $-0,37$ & $-0,36$ \\
\hline 54 IGUAÇU & 0,38 & 0,36 & 0,05 & 0,03 & $-0,33$ & $-0,33$ \\
\hline 55 LIGHT & 2,81 & 1,08 & 2,80 & 2,34 & 0,00 & 1,25 \\
\hline 56 MUXFELDT & 0,35 & 0,29 & 0,01 & 0,03 & $-0,34$ & $-0,26$ \\
\hline 57 RGE & 0,41 & 0,36 & 0,69 & 0,56 & 0,28 & 0,20 \\
\hline 58 SULGIPE & 0,41 & 0,36 & 0,38 & 0,53 & $-0,02$ & 0,17 \\
\hline 59 NOVA PALMA & 0,35 & 0,29 & 0,24 & 0,26 & $-0,12$ & $-0,03$ \\
\hline Máximo & 2,81 & 4,19 & 5,62 & 7,23 & 4,59 & 5,88 \\
\hline Mínimo & 0,35 & 0,29 & 0,00 & 0,00 & $-1,02$ & $-0,85$ \\
\hline Média & 0,70 & 0,55 & 0,94 & 1,13 & 0,25 & 0,58 \\
\hline
\end{tabular}


Por meio da Figura 4.6, observa-se, graficamente, as metas de inadimplência (valores percentuais) propostas pelo modelo fuzzy em comparação com os valores reais apurados de acordo com cada uma das curvas de aging em estudo (Tabela 4.1), bem como em relação à metodologia atual empregada pela ANEEL. Para as duas curvas de aging (60 meses Figura 4.6a e 36 meses, Figura $4.6 b)$ as metas estabelecidas foram significativamente inferiores aos valores reais.

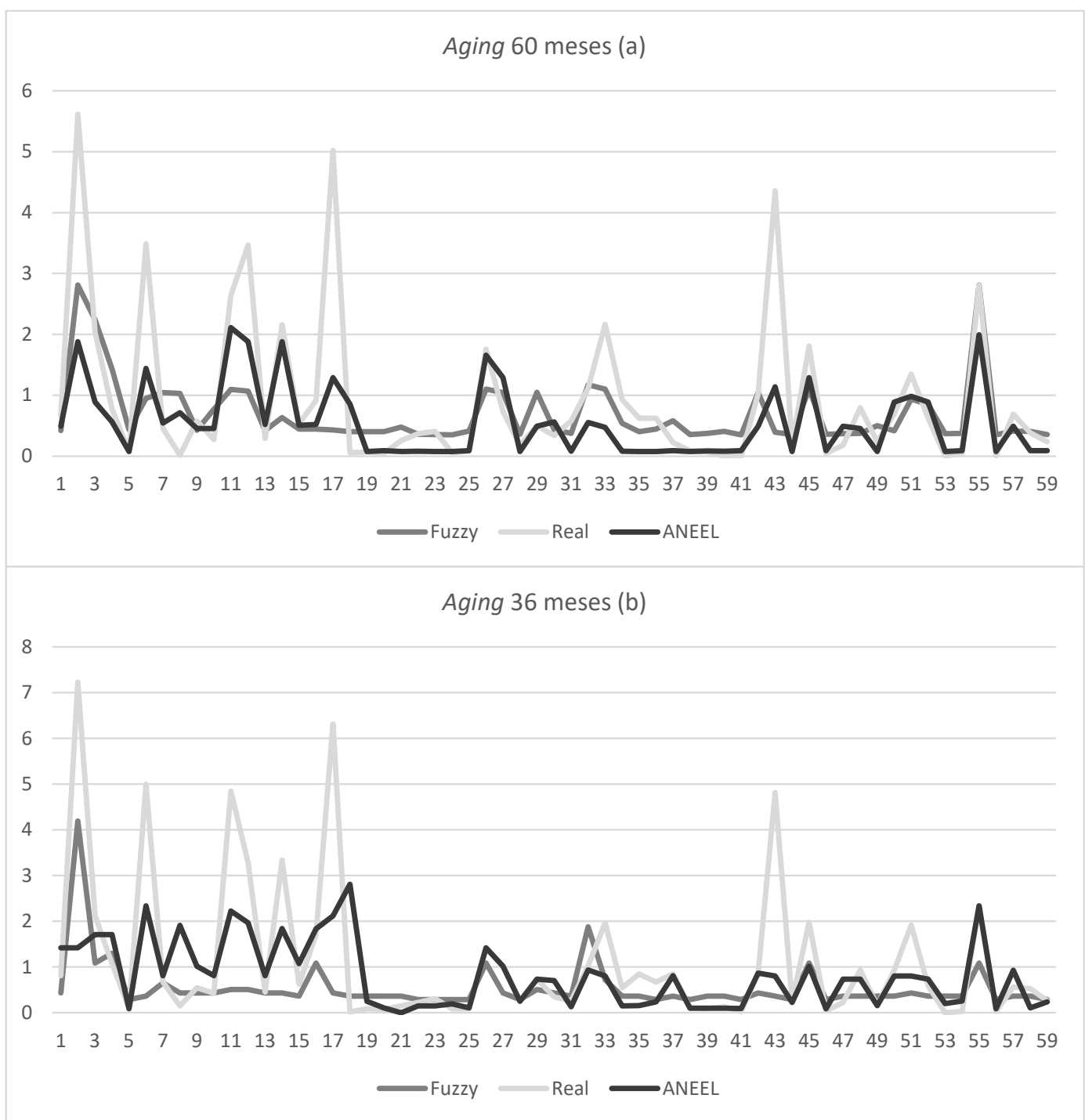

Figura 0.6 - Metas de inadimplência (\%): reais, estimativas modelo fuzzy, estimativas metodologia ANEEL. Em (a) aging de 60 meses e em (b) aging de 36 meses.

Cabe destacar que a alteração da curva de aging não provoca grandes mudanças nas metas estabelecidas, aproximadamente $67 \%$ (40 das 59 distribuidoras) apresentaram alterações mínimas (Figura 4.7). 


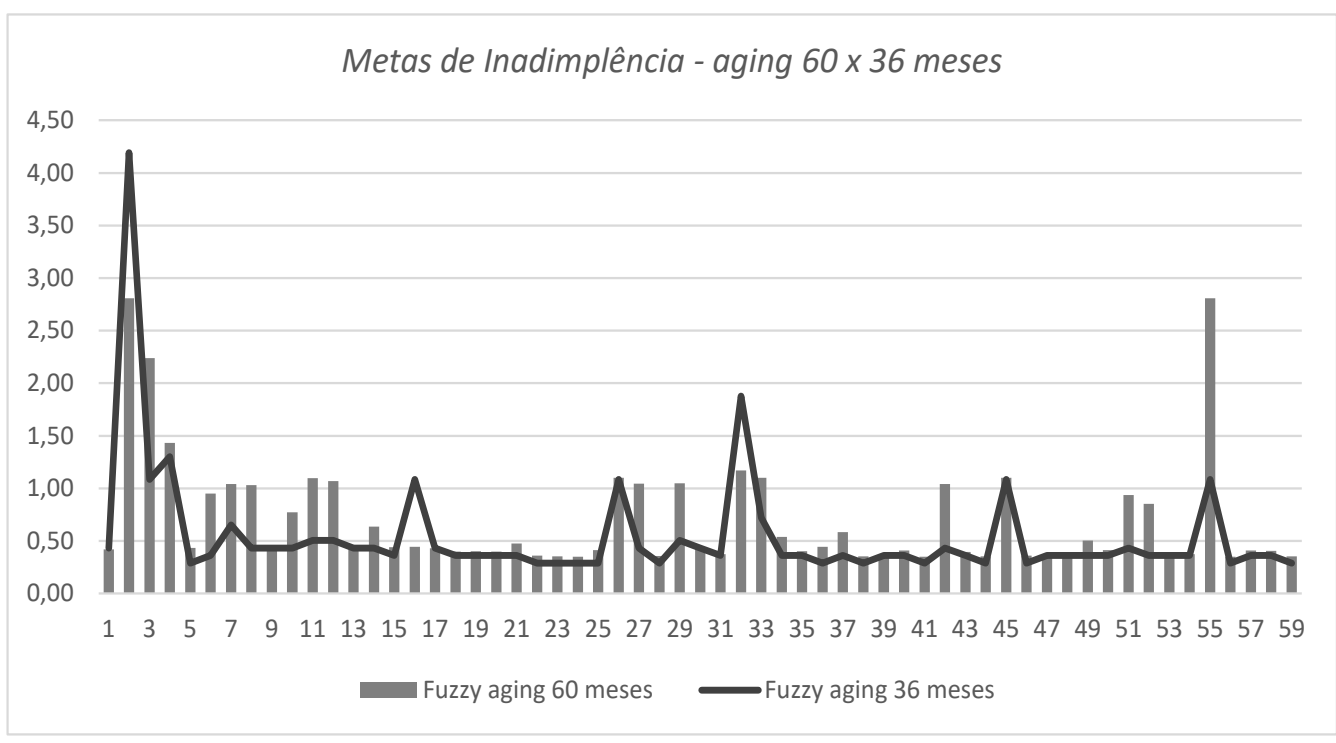

Figura 0.7 - Comparação das metas obtidas com curva de aging de 49 a 60 meses e de 25 a 36 meses

Quando se compara os valores reais das metas de inadimplência (\%), considerando as duas curvas de aging, aos valores obtidos por meio da metodologia fuzzy e metodologia ANEEL, observa-se que há uma grande concentração de desvios (valores reais menos previstos por cada metodologia) em torno de $0,5 \%$, em módulo.

Tabela 0.2 - Quantidade percentual de desvios entre $-0,5 \%$ e $+0,5 \%$

\begin{tabular}{|c|c|c|}
\hline \multirow{2}{*}{ Curva proposta } & \multicolumn{2}{|c|}{ Qtd percentual de desvios $-0,5 \%<0 \%<0,5 \%$} \\
\cline { 2 - 3 } & Valores reais - ANEEL & Valores reais - fuzzy \\
\hline Aging 49 a 60 meses & $69 \%$ & $76 \%$ \\
\hline Aging 25 a 36 meses & $72 \%$ & $71 \%$ \\
\hline
\end{tabular}

A Figura 4.8 permite melhor visualização da concentração dos desvios em torno de 0,5\%. Observa-se que, ao se considerar a curva de aging de 60 meses, o maior desvio encontrado foi de 4,59\% (CEPISA), obtido em relação à metodologia fuzzy (Figura 4.8a). Para esse mesmo caso, o desvio em relação à metodologia ANEEL foi de 3,73\%, mostrando que o modelo fuzzy foi mais conservador que a metodologia aplicada pela ANEEL. Cabe ressaltar que os desvios estão sendo apurados por meio dos valores reais menos valores previstos, o que significa, nesse caso, que a empresa em foco possui um nível de inadimplência bem acima daquele esperado para o seu contexto (desvio positivo). Essa mesma empresa também apresentou o maior desvio ao se utilizar a curva de aging de 36 meses (Figura 4.8b): 5,8\% em relação à metodologia fuzzy e 4,2\% em relação à metodologia ANEEL - Figura 4.8 (b). 


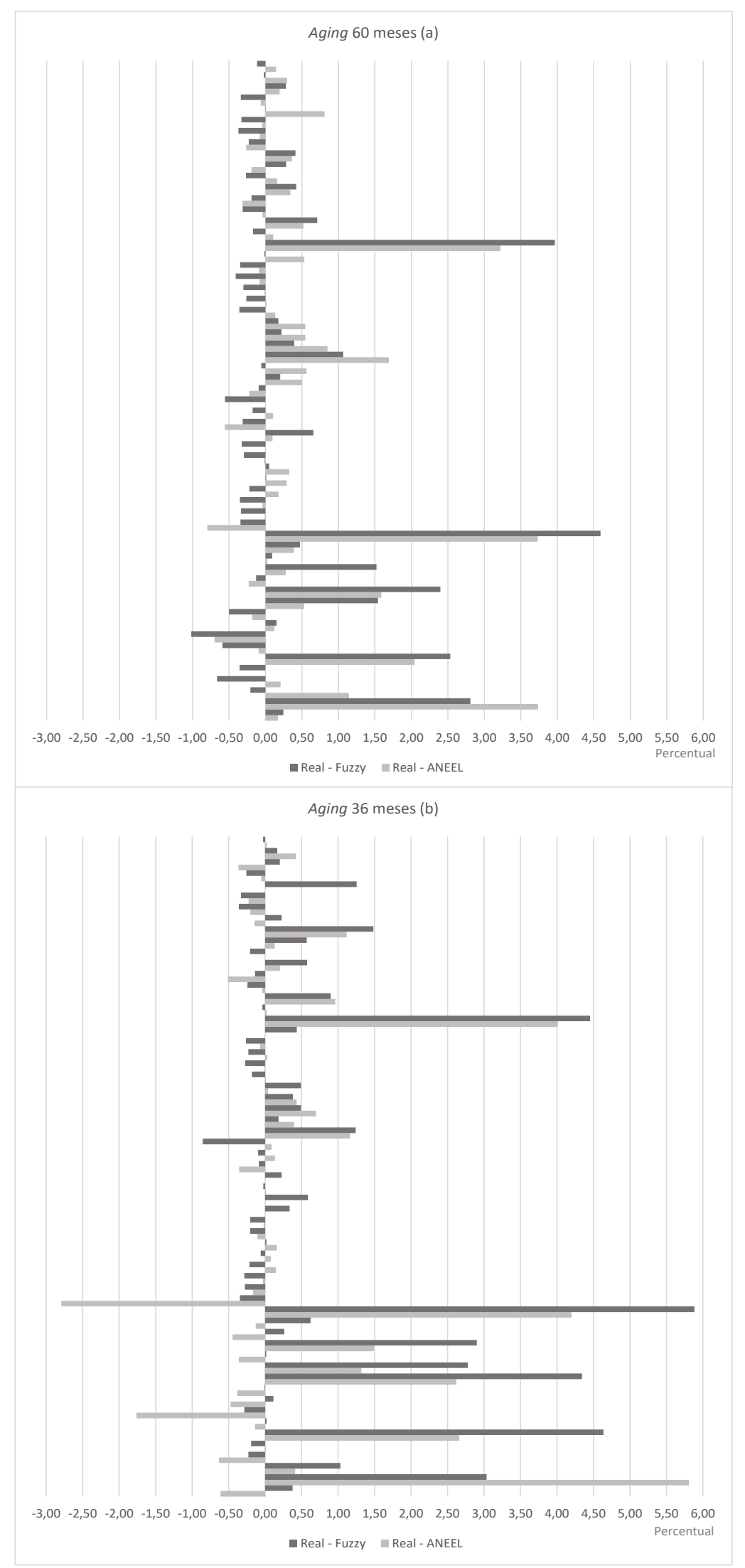

Figura 0.8 - Desvios \% Inadimplência real x fuzzy x ANEEL. Em (a) aging de 60 meses e em (b) aging de 36 meses 
Em uma análise mais qualitativa, procurou-se inferir se as previsões pela metodologia fuzzy e pela metodologia ANEEL, embora em níveis percentuais absolutos diferentes, estariam dentro dos limites atribuídos aos conjuntos fuzzy de saída (inadimplência). Consiste em uma análise macro, onde a comparação é feita por meio das próprias faixas dos limites estabelecidos para a elaboração das regras (Capítulo 3 - Item 3.2).

Com base nas Figuras 4.9 e 4.10, pode-se notar que as regras definidas conseguiram capturar bem o que a base real dos dados de inadimplência declarada pelas distribuidoras, aliada às variáveis de porte e vulnerabilidade, forneceram como insumo. Pode-se perceber que, quando a inadimplência real é muito baixa, na maioria dos casos, esse nível foi captado pela metodologia fuzzy e também ficou compatível com a metodologia ANEEL. Nos níveis mais altos de inadimplência real, no entanto, o modelo fuzzy se mostrou mais conservador que ANEEL. Tal fato ocorre em função da metodologia fuzzy definir as metas de inadimplência com base no comportamento de empresas de mesmo porte e vulnerabilidade e com níveis mais baixos de inadimplência, deixando explícito empresas que estão com um nível acima do esperado, dentro de um contexto semelhante.

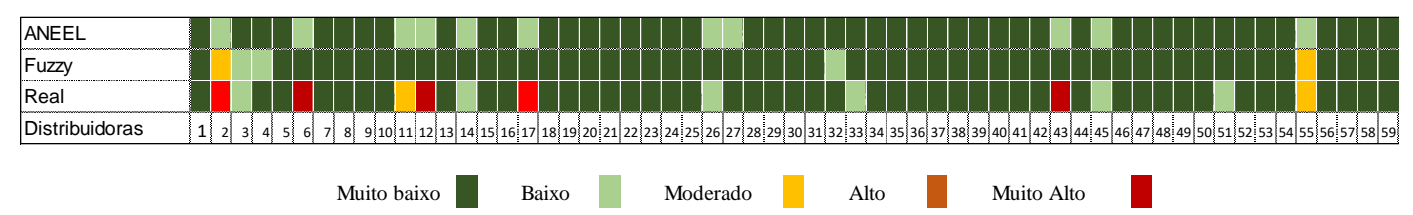

Figura 0.9 - Comparação da meta ANELL, com a meta estabelecida no modelo fuzzy e a inadimplência real declarada pelas distribuidoras de energia elétrica do Brasil - curva de aging de 49 a 60 meses

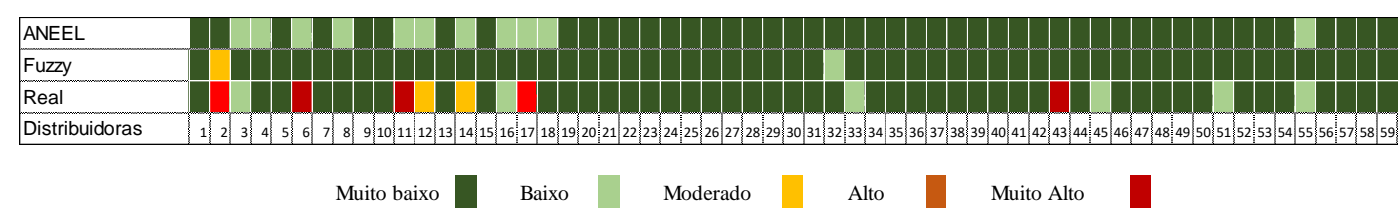

Figura 0.10 - Comparação da meta ANELL, com a meta estabelecida no modelo fuzzy e a inadimplência real declarada pelas distribuidoras de energia elétrica do Brasil - curva de aging de 25 a 36 meses

Observa-se que a diferenciação da curva de aging produz poucas variações nos patamares de inadimplência, apresentando poucos casos com alteração de classificação para outro grupo fuzzy. 


\subsection{2.}

\section{Classe industrial}

Segundo o Anuário Estatístico de 2020 (referência 2019), publicado pela EPE, a classe industrial responde por $9 \%$ do consumo cativo do Brasil, com uma representação de $0,5 \%$ em termos do número de consumidores. Os consumidores de maior porte deste segmento se encontram no mercado livre de energia.

Para a classe industrial, foi adotado o método de defuzzyficação do MoM Mean of maximus para as duas curvas de aging, os quais minimizaram os erros quadráticos médios da previsão em relação aos valores reais, como pode ser visualizado por meio da Figura 4.11.

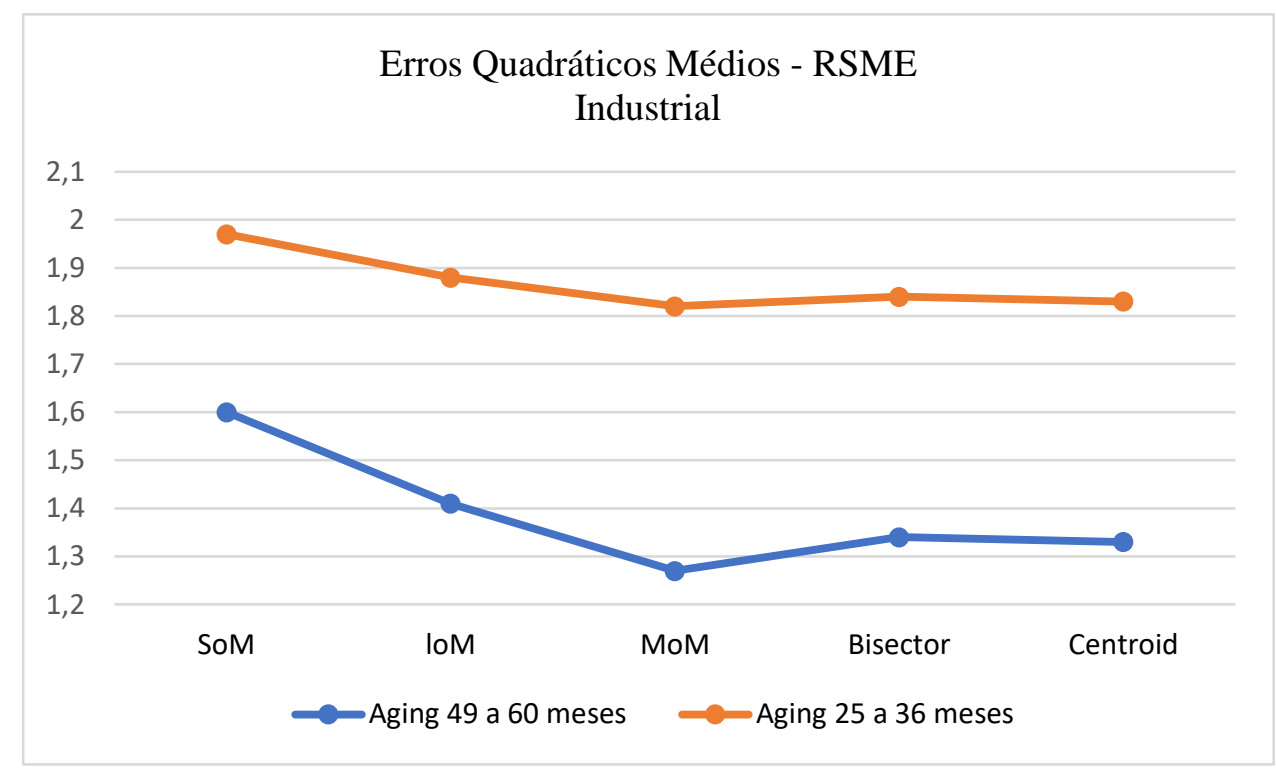

Figura 0.11 - Escolha do método de defuzzyficação para o industrial - curvas de aging de 49 a 60 meses e de 25 a 36 meses

Os resultados do modelo para a classe industrial, considerando as duas curvas de aging, podem ser visualizados na Tabela 4.3. O desvio médio para as duas curvas de aging ficaram muito próximos, sendo de 0,28\% para a curva de aging de 49 a 60 meses e de 0,23\% para a curva de 25 a 36 meses. 
Tabela 0.3 - Resultado modelo para a classe industrial - valores \%

\begin{tabular}{|c|c|c|c|c|c|c|}
\hline \multirow{2}{*}{ Industrial } & \multicolumn{2}{|c|}{ Resultado Fuzzy } & \multicolumn{2}{|c|}{ Real } & \multicolumn{2}{|c|}{ Desvio Real menos previsto } \\
\hline & 49 a 60 meses & 25 a 36 meses & 49 a 60 meses & 25 a 36 meses & 49 a 60 meses & 25 a 36 meses \\
\hline $1 \mathrm{AES} \mathrm{SUL}$ & 0,35 & 0,14 & 0,27 & 0,45 & $-0,08$ & 0,31 \\
\hline 2 CEAM & 3,46 & 0,36 & 2,19 & 1,32 & $-1,26$ & 0,97 \\
\hline 3 AMPLA & 0,31 & 0,06 & 0,53 & 0,75 & 0,22 & 0,69 \\
\hline 4 BANDEIRANTE & 0,24 & 0,43 & 0,43 & 0,35 & 0,19 & $-0,08$ \\
\hline 5 CAIUÁ & 0,07 & 0,08 & 0,38 & 0,32 & 0,31 & 0,24 \\
\hline 6 CEAL & 0,31 & 0,34 & 5,79 & 1,56 & 5,48 & 1,22 \\
\hline 7 CEB & 0,31 & 0,34 & 0,19 & 0,11 & $-0,12$ & $-0,23$ \\
\hline 8 CEEE & 0,35 & 0,34 & 0,06 & 0,02 & $-0,29$ & $-0,32$ \\
\hline 9 CELESC & 0,38 & 0,37 & 0,24 & 0,45 & $-0,14$ & 0,08 \\
\hline 10 CELG & 0,38 & 0,37 & 0,37 & 0,51 & $-0,01$ & 0,13 \\
\hline 11 CELPA & 0,24 & 0,65 & 1,45 & 2,39 & 1,21 & 1,74 \\
\hline 12 CELPE & 0,38 & 0,47 & 1,27 & 1,32 & 0,89 & 0,85 \\
\hline 13 CELTINS & 0,35 & 0,32 & 0,42 & 0,41 & 0,08 & 0,09 \\
\hline 14 CEMAR & 0,35 & 0,16 & 1,08 & 1,95 & 0,74 & 1,79 \\
\hline 15 CEMAT & 0,31 & 0,30 & 0,42 & 0,35 & 0,11 & 0,06 \\
\hline 16 CEMIG & 0,41 & 0,53 & 0,26 & 0,53 & $-0,15$ & $-0,01$ \\
\hline 17 CEPISA & 0,38 & 0,20 & 4,08 & 3,06 & 3,70 & 2,86 \\
\hline 18 CERON & 0,28 & 0,30 & 0,00 & 0,00 & $-0,28$ & $-0,30$ \\
\hline 19 CFLO & 0,28 & 0,30 & 0,00 & 0,01 & $-0,28$ & $-0,29$ \\
\hline 20 CHESP & 0,28 & 0,30 & 0,02 & 0,65 & $-0,25$ & 0,36 \\
\hline $21 \mathrm{CJE}$ & 0,28 & 0,30 & 0,06 & 0,04 & $-0,21$ & $-0,26$ \\
\hline 22 MOCOCA & 0,10 & 0,12 & 0,04 & 0,05 & $-0,06$ & $-0,07$ \\
\hline 23 SANTA CRUZ & 0,07 & 0,08 & 0,47 & 0,09 & 0,40 & 0,01 \\
\hline 24 CNEE & 0,03 & 0,04 & 0,12 & 0,01 & 0,09 & $-0,03$ \\
\hline 25 COCEL & 0,00 & 0,00 & 0,00 & 0,02 & 0,00 & 0,02 \\
\hline 26 COELBA & 0,48 & 0,51 & 0,24 & 0,34 & $-0,25$ & $-0,18$ \\
\hline 27 COELCE & 0,38 & 0,36 & 0,15 & 0,20 & $-0,23$ & $-0,16$ \\
\hline 28 COOPERALIANÇA & 0,10 & 0,10 & 0,06 & 0,53 & $-0,04$ & 0,43 \\
\hline 29 COPEL & 0,59 & 0,53 & 0,14 & 0,17 & $-0,45$ & $-0,36$ \\
\hline 30 COSERN & 0,41 & 0,22 & 0,22 & 0,39 & $-0,19$ & 0,18 \\
\hline 31 CPEE & 0,17 & 0,20 & 0,14 & 2,49 & $-0,03$ & 2,30 \\
\hline 32 CPFL PIRATININGA & 0,07 & 0,59 & 0,62 & 0,76 & 0,55 & 0,17 \\
\hline 33 CPFL PAULISTA & 0,41 & 0,26 & 0,39 & 0,35 & $-0,02$ & 0,09 \\
\hline 34 CSPE & 0,31 & 0,32 & 0,22 & 0,02 & $-0,09$ & $-0,29$ \\
\hline 35 DEMEI & 0,31 & 0,30 & 0,07 & 0,00 & $-0,24$ & $-0,30$ \\
\hline 36 DMEPC & 0,14 & 0,14 & 0,02 & 0,00 & $-0,12$ & $-0,14$ \\
\hline 37 CELB & 0,24 & 0,26 & 0,07 & 0,01 & $-0,17$ & $-0,25$ \\
\hline 38 EDEVP & 0,03 & 0,06 & 0,04 & 0,13 & 0,00 & 0,07 \\
\hline 39 EEB & 0,17 & 0,20 & 0,04 & 0,11 & $-0,13$ & $-0,09$ \\
\hline 40 JOAO CESA & 0,31 & 0,32 & 0,00 & 0,00 & $-0,31$ & $-0,32$ \\
\hline $41 \mathrm{EFLUL}$ & 0,00 & 0,00 & 0,00 & 0,00 & 0,00 & 0,00 \\
\hline 42 ELEKTRO & 0,35 & 0,37 & 0,74 & 0,41 & 0,40 & 0,04 \\
\hline 43 ELETROACRE & 0,28 & 0,28 & 4,24 & 3,94 & 3,96 & 3,67 \\
\hline 44 ELETROCAR & 0,07 & 0,06 & 0,01 & 0,00 & $-0,06$ & $-0,06$ \\
\hline 45 ELETROPAULO & 0,52 & 0,53 & 0,38 & 0,51 & $-0,14$ & $-0,02$ \\
\hline 46 ELFSM & 0,10 & 0,12 & 0,00 & 0,01 & $-0,10$ & $-0,11$ \\
\hline $47 \mathrm{EMG}$ & 0,14 & 0,16 & 0,11 & 0,25 & $-0,03$ & 0,10 \\
\hline 48 ENERSUL & 0,17 & 0,20 & 0,70 & 0,27 & 0,53 & 0,07 \\
\hline 49 CENF & 0,28 & 0,30 & 0,02 & 0,00 & $-0,26$ & $-0,29$ \\
\hline 50 SAELPA & 0,35 & 0,34 & 0,30 & 0,45 & $-0,04$ & 0,12 \\
\hline 51 ESCELSA & 0,38 & 0,22 & 0,75 & 0,23 & 0,37 & 0,01 \\
\hline 52 ENERGIPE & 0,24 & 0,24 & 0,13 & 0,11 & $-0,11$ & $-0,13$ \\
\hline 53 HIDROPAN & 0,17 & 0,18 & 0,00 & 0,00 & $-0,17$ & $-0,18$ \\
\hline 54 IGUAÇU & 0,17 & 0,20 & 0,00 & 0,00 & $-0,17$ & $-0,20$ \\
\hline 55 LIGHT & 3,46 & 0,59 & 0,46 & 0,34 & $-3,00$ & $-0,25$ \\
\hline 56 MUX ENERGIA & 0,00 & 0,02 & 0,00 & 0,00 & 0,00 & $-0,02$ \\
\hline 57 RGE & 0,31 & 0,34 & 0,43 & 0,45 & 0,12 & 0,12 \\
\hline 58 SULGIPE & 0,31 & 0,32 & 0,01 & 0,16 & $-0,30$ & $-0,15$ \\
\hline 59 NOVA PALMA & 0,03 & 0,06 & 6,92 & 0,00 & 6,88 & $-0,06$ \\
\hline Máximo & 3,46 & 0,65 & 6,92 & 3,94 & 6,88 & 3,67 \\
\hline Mínimo & 0,00 & 0,00 & 0,00 & 0,00 & $-3,00$ & $-0,36$ \\
\hline Média & 0,36 & 0,27 & 0,64 & 0,50 & 0,28 & 0,23 \\
\hline
\end{tabular}


A inadimplência real deste segmento, apurada por meio das curvas de aging de faturamentos não recebidos de 25 a 36 meses e de 49 a 60 meses da data de referência, em sua grande maioria, está situada abaixo da faixa de $1 \%$ de inadimplência. Utilizando-se a curva de aging de 60 meses, Figura 4.12a, percebese apenas 4 empresas com inadimplência mais elevada. Ao se considerar a curva de aging de 36 meses, por outro lado, apesar da predominância continuar sendo uma taxa média de 1\%, a volatilidade é maior, aparecendo taxas de inadimplência um pouco mais elevadas, como pode ser visto na Figura 4.12b.

Para as duas curvas de aging, as metas estabelecidas ficaram muito próximas dos valores reais, exceção dos casos onde a inadimplência se mostrou em níveis reais mais elevados, conforme pôde ser visto na Figuras 4.12a e 4.12b.

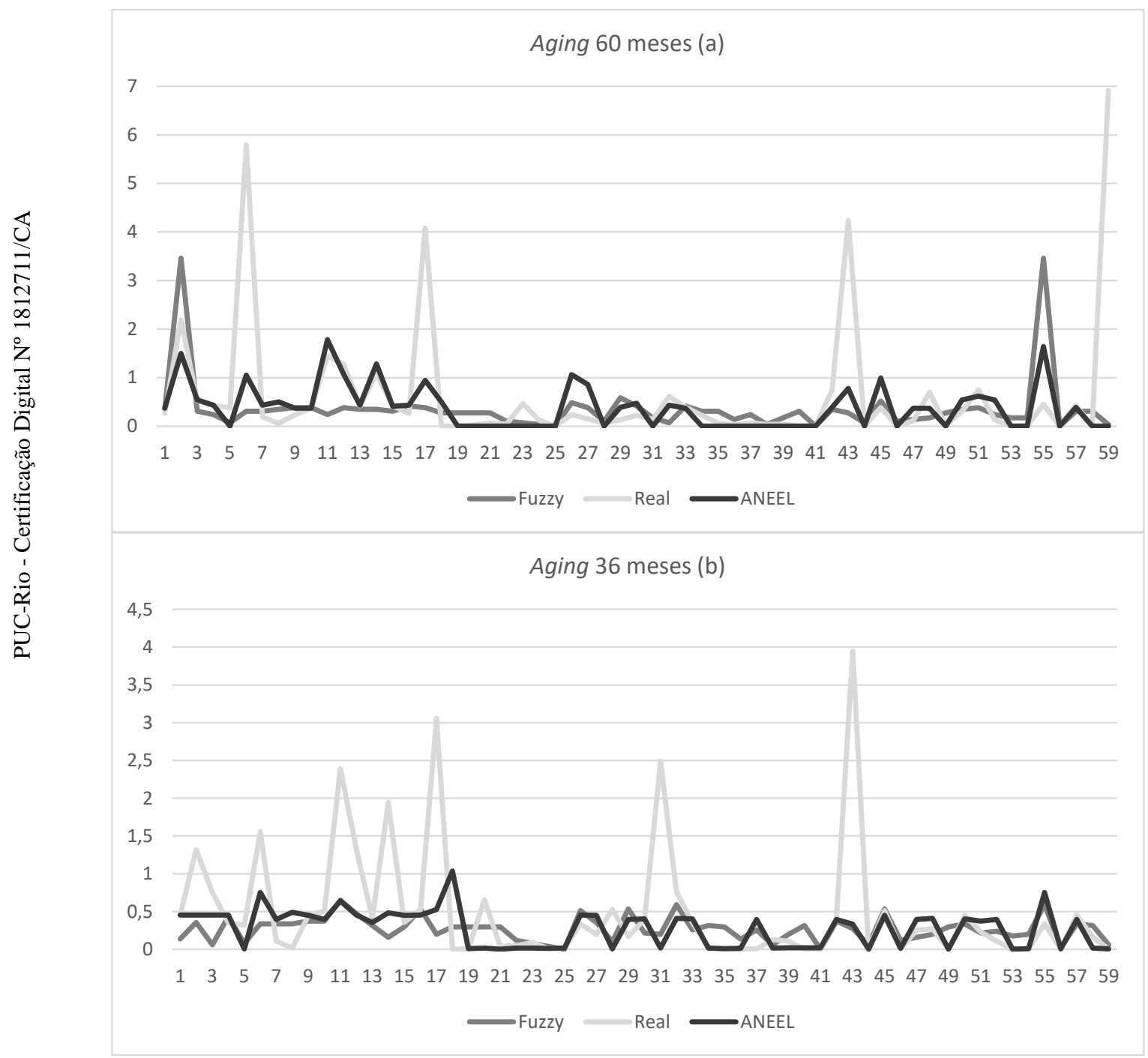

Figura 0.12 - Metas de inadimplência (\%): reais, estimativas modelo fuzzy, estimativas metodologia ANEEL. Em (a) aging de 60 meses e em (b) aging de 36 meses 
Cabe destacar que a alteração da curva de aging não provoca grandes mudanças nas metas estabelecidas, apenas 2 casos apresentaram alterações relevantes (Figura 4.13).

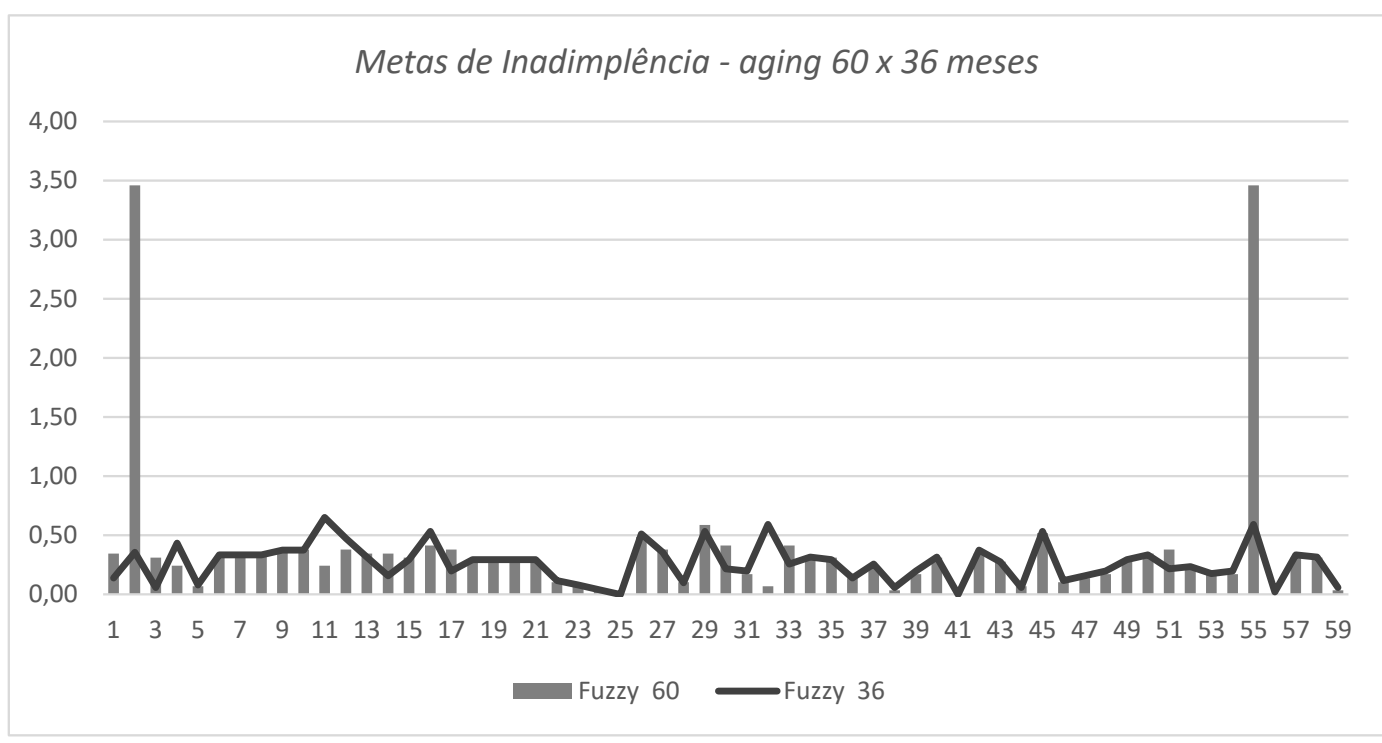

Figura 0.13 - Comparação das metas obtidas com curva de aging de 49 a 60 meses e de 25 a 36 meses

Assim como aconteceu com a classe residencial, quando se compara (Tabela 4.4) os valores reais das metas de inadimplência (\%), considerando as duas curvas de aging, aos valores obtidos por meio da metodologia fuzzy e metodologia ANEEL, observa-se que há uma grande concentração de desvios (valores reais menos previstos por cada metodologia) em torno de $0,5 \%$, em módulo.

Tabela 0.4 - quantidade percentual de desvios entre $-0,5 \%$ e $+0,5 \%$

\begin{tabular}{|c|c|c|}
\hline \multirow{2}{*}{ Curva proposta } & \multicolumn{2}{|c|}{ Qtd percentual de desvios $-0,5 \%<0 \%<0,5 \%$} \\
\cline { 2 - 3 } & Valores reais - ANEEL & Valores reais - fuzzy \\
\hline Aging 49 a 60 meses & $85 \%$ & $81 \%$ \\
\hline Aging 25 a 36 meses & $81 \%$ & $85 \%$ \\
\hline
\end{tabular}

A Figura 4.14 permite melhor visualização da concentração dos desvios em torno de $0,5 \%$. Observa-se que, ao se considerar a curva de aging de 60 meses, o maior desvio encontrado foi de $6,92 \%$ (Nova Palma), obtido em relação à metodologia ANEEL (Figura 4.14a). Para esse mesmo caso, o desvio em relação 
à metodologia fuzzy foi de $6,88 \%$. No entanto, ao se considerar a curva de aging de 36 meses para essa mesma empresa (Figura 4.14b), os desvios foram próximos de zero, o que pode indicar uma melhora na gestão da empresa. Ainda com relação à curva de aging de 36 meses, o maior desvio foi da ordem de 3,6\% para as duas metodologias, apresentado pela empresa Eletroacre (observa-se que os desvios dessa empresa foram da mesma magnitude para a curva de aging de 60 meses). 


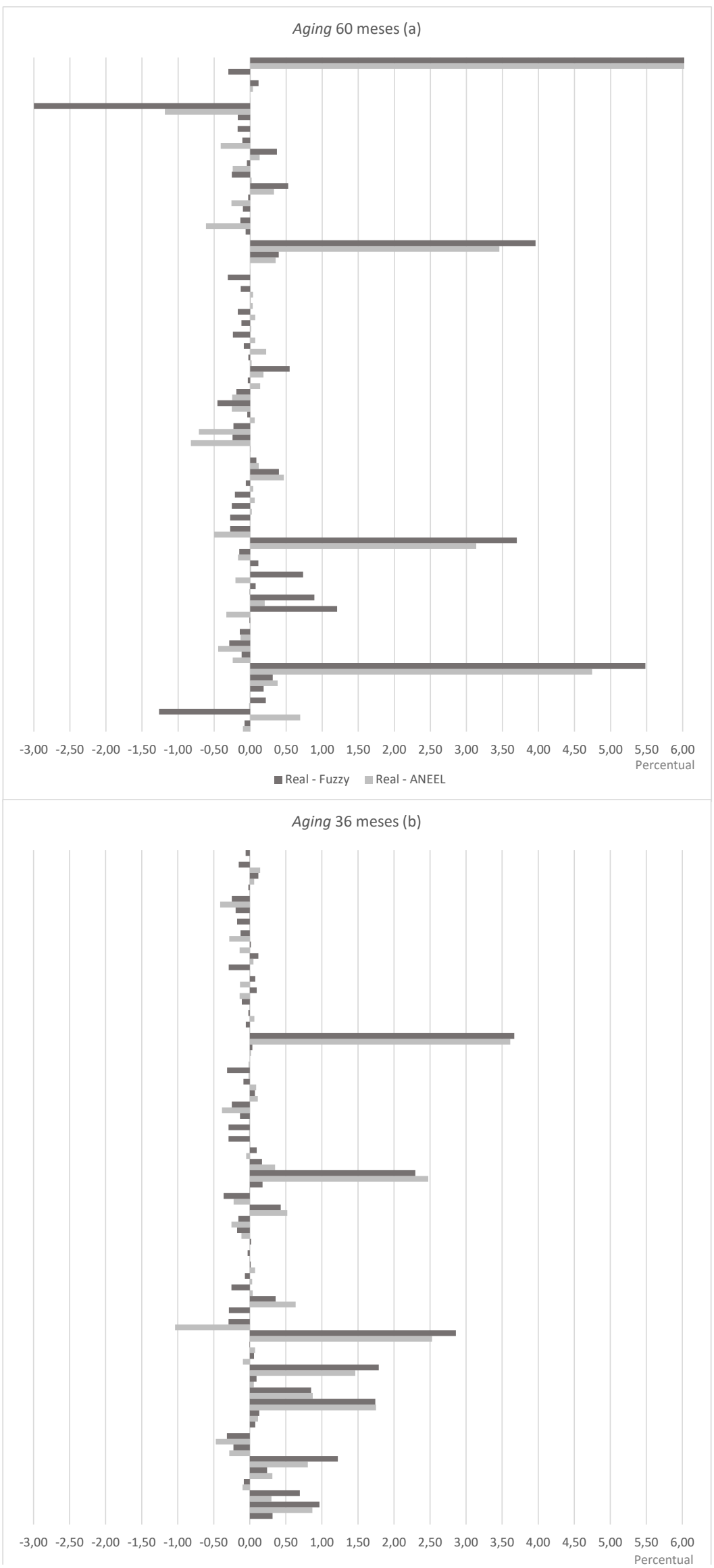

Figura 0.14 - Desvios \% Inadimplência real x fuzzy x ANEEL. Em (a) aging de 60 meses e em (b) aging de 36 meses 
Repetindo-se a análise qualitativa realizada para o segmento residencial, com base nas Figuras 4.15 e 4.16, pode-se notar que as regras definidas conseguiram capturar bem o que a base real dos dados de inadimplência declarada pelas distribuidoras, aliada às variáveis de porte e vulnerabilidade, forneceram como insumo. Pode-se perceber que as regras fuzzy penalizaram aquelas empresas com um maior nível de inadimplência, igualando seus patamares de metas aos das empresas mais eficientes. As metodologias fuzzy e ANEEL apresentaram resultados muito parecidos.

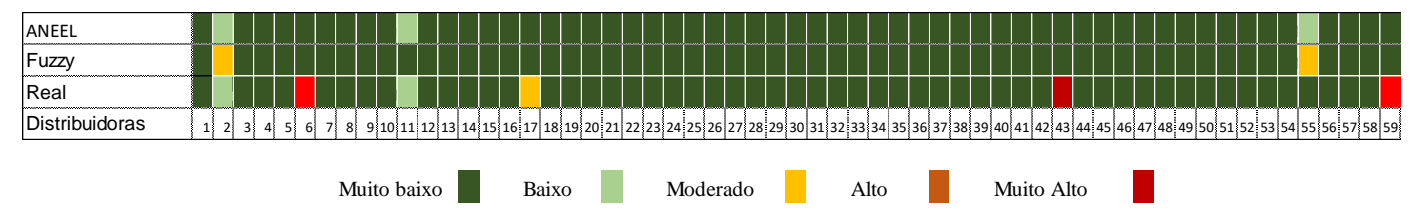

Figura 0.15 - Comparação da meta ANELL, com a meta estabelecida no modelo fuzzy e a inadimplência real declarada pelas distribuidoras de energia elétrica do Brasil - curva de aging de 49 a 60 meses

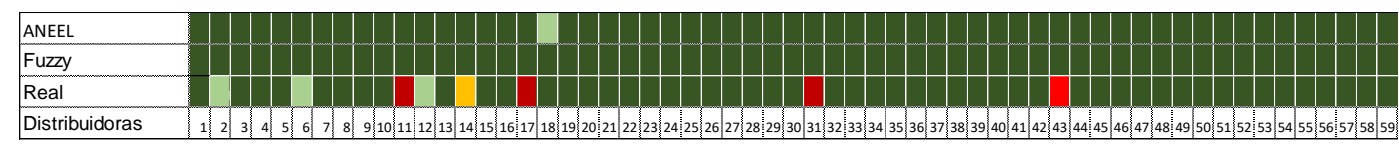

Figura 0.16 - Comparação da meta ANELL, com a meta estabelecida no modelo fuzzy e a inadimplência real declarada pelas distribuidoras de energia elétrica do Brasil - curva de aging de 25 a 36 meses

Observa-se que a diferenciação da curva de aging produz poucas variações nos patamares de inadimplência, apresentando poucos casos com alteração de classificação para outro grupo fuzzy.

\subsection{3.}

\section{Classe comercial}

Segundo o Anuário Estatístico de 2020 (referência 2019), publicado pela EPE, a classe comercial responde por $22,7 \%$ do mercado cativo do Brasil, sendo a segunda maior classe de consumo (perde apenas para a residencial). Em termos de consumidores, a representação da classe comercial é de 6,9\%.

Para a classe comercial, foi adotado o método de defuzzyficação do Centroid para a curva de aging de 49 a 60 meses e de MoM - Mean of maximus 
para a curva de aging de 25 a 36 meses, os quais minimizaram os erros quadráticos médios da previsão em relação aos valores reais (Figura 4.17).

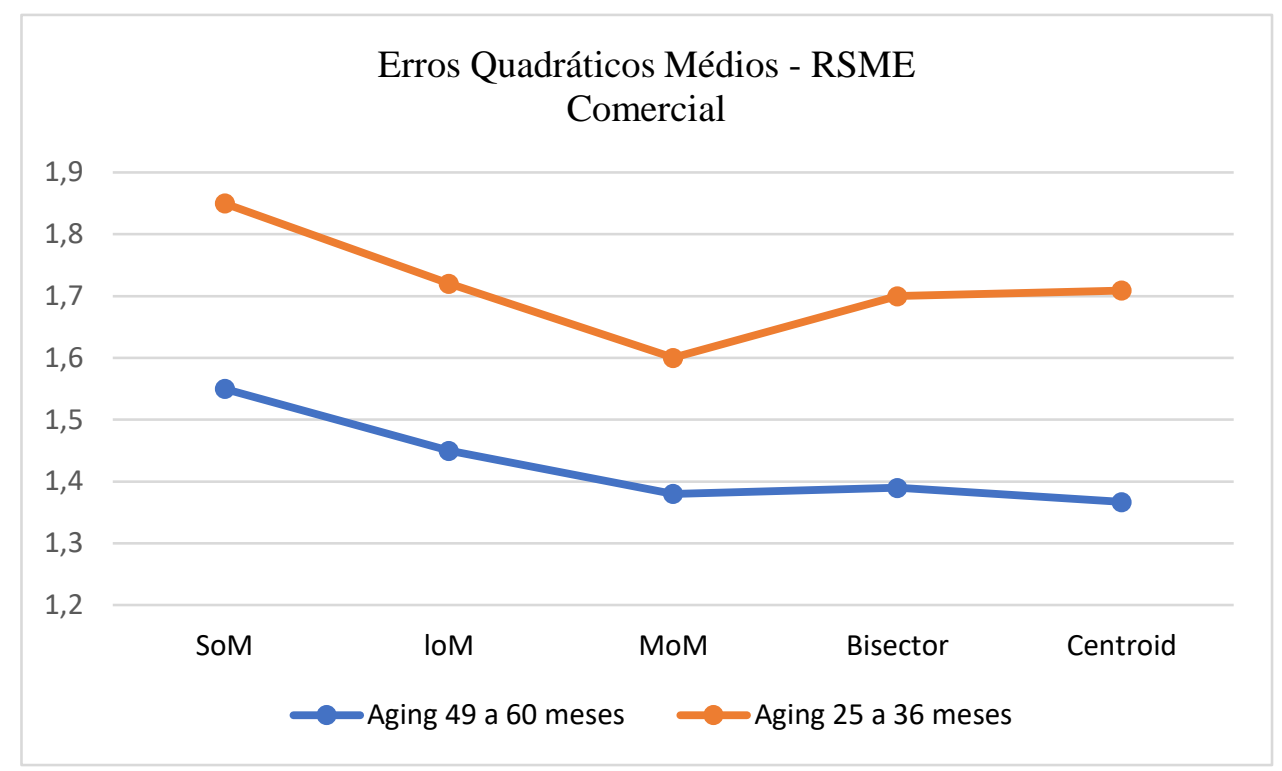

Figura 0.17 - Escolha do método de defuzzyficação para o comercial - curvas de aging de 49 a 60 meses e de 25 a 36 meses

Os resultados do modelo para a classe comercial, considerando as duas curvas de aging, podem ser visualizados na Tabela 4.5. O desvio médio para a curva de aging de 49 a 60 meses ficou em $0,18 \%$, enquanto para a curva de 25 a 36 meses ficou em 0,36\%. 
Tabela 0.5 - Resultado modelo para a classe comercial - valores \%

\begin{tabular}{|c|c|c|c|c|c|c|}
\hline \multirow{2}{*}{ Comercial } & \multicolumn{2}{|c|}{ Resultado Fuzzy } & \multicolumn{2}{|c|}{ Real } & \multicolumn{2}{|c|}{ Desvio Real menos previsto } \\
\hline & 49 a 60 meses & 25 a 36 meses & 49 a 60 meses & 25 a 36 meses & 49 a 60 meses & 25 a 36 meses \\
\hline 1 AES SUL & 0,23 & 0,15 & 1,02 & 0,66 & 0,79 & 0,51 \\
\hline 2 CEAM & 1,66 & 3,02 & 2,49 & 3,84 & 0,83 & 0,83 \\
\hline 3 AMPLA & 0,64 & 0,13 & 1,08 & 1,22 & 0,44 & 1,08 \\
\hline 4 BANDEIRANTE & 0,63 & 0,23 & 0,90 & 0,82 & 0,26 & 0,59 \\
\hline 5 CAIUÁ & 0,25 & 0,02 & 0,13 & 0,29 & $-0,12$ & 0,27 \\
\hline 6 CEAL & 0,56 & 0,13 & 3,33 & 2,63 & 2,77 & 2,50 \\
\hline 7 CEB & 0,56 & 0,13 & 0,37 & 0,54 & $-0,18$ & 0,40 \\
\hline 8 CEEE & 0,60 & 0,19 & 0,01 & 0,01 & $-0,59$ & $-0,19$ \\
\hline 9 CELESC & 0,23 & 0,15 & 0,53 & 0,38 & 0,30 & 0,22 \\
\hline 10 CELG & 0,23 & 0,15 & 0,53 & 0,43 & 0,30 & 0,28 \\
\hline 11 CELPA & 0,62 & 0,27 & 1,01 & 1,36 & 0,40 & 1,09 \\
\hline 12 CELPE & 0,54 & 0,19 & 1,49 & 0,73 & 0,95 & 0,54 \\
\hline 13 CELTINS & 0,23 & 0,15 & 0,28 & 0,33 & 0,06 & 0,18 \\
\hline 14 CEMAR & 0,23 & 0,15 & 1,06 & 1,52 & 0,83 & 1,37 \\
\hline 15 CEMAT & 0,22 & 0,13 & 0,46 & 0,62 & 0,25 & 0,48 \\
\hline 16 CEMIG & 0,24 & 0,63 & 0,53 & 0,99 & 0,28 & 0,35 \\
\hline 17 CEPISA & 0,23 & 0,17 & 2,65 & 3,38 & 2,41 & 3,20 \\
\hline 18 CERON & 0,22 & 0,12 & 0,05 & 0,07 & $-0,17$ & $-0,05$ \\
\hline 19 CFLO & 0,22 & 0,12 & 0,03 & 0,05 & $-0,18$ & $-0,06$ \\
\hline 20 CHESP & 0,22 & 0,12 & 0,09 & 0,08 & $-0,13$ & $-0,04$ \\
\hline $21 \mathrm{CJE}$ & 0,27 & 0,12 & 0,11 & 0,05 & $-0,16$ & $-0,07$ \\
\hline 22 MOCOCA & 0,20 & 0,04 & 0,07 & 0,11 & $-0,12$ & 0,07 \\
\hline 23 SANTA CRUZ & 0,19 & 0,02 & 0,40 & 0,12 & 0,21 & 0,10 \\
\hline 24 CNEE & 0,19 & 0,00 & 0,03 & 0,10 & $-0,16$ & 0,10 \\
\hline 25 COCEL & 0,23 & 0,00 & 0,01 & 0,08 & $-0,22$ & 0,08 \\
\hline 26 COELBA & 0,25 & 0,21 & 0,59 & 0,75 & 0,34 & 0,53 \\
\hline 27 COELCE & 0,60 & 0,15 & 0,37 & 0,46 & $-0,22$ & 0,30 \\
\hline 28 COOPERALIANÇA & 0,19 & 0,04 & 0,33 & 0,47 & 0,14 & 0,44 \\
\hline 29 COPEL & 0,27 & 0,23 & 0,28 & 0,36 & 0,00 & 0,13 \\
\hline 30 COSERN & 0,24 & 0,17 & 0,36 & 0,26 & 0,12 & 0,09 \\
\hline 31 CPEE & 0,20 & 0,08 & 1,16 & 0,09 & 0,95 & 0,01 \\
\hline 32 CPFL PIRATININGA & 0,63 & 0,25 & 0,44 & 0,39 & $-0,18$ & 0,14 \\
\hline 33 CPFL PAULISTA & 0,24 & 0,10 & 0,61 & 0,49 & 0,37 & 0,39 \\
\hline 34 CSPE & 0,31 & 0,13 & 0,14 & 0,05 & $-0,17$ & $-0,08$ \\
\hline 35 DEMEI & 0,22 & 0,12 & 0,20 & 0,47 & $-0,02$ & 0,35 \\
\hline 36 DMEPC & 0,25 & 0,06 & 0,21 & 0,26 & $-0,04$ & 0,20 \\
\hline 37 CELB & 0,34 & 0,12 & 0,04 & 0,08 & $-0,30$ & $-0,03$ \\
\hline 38 EDEVP & 0,19 & 0,02 & 0,12 & 0,08 & $-0,08$ & 0,06 \\
\hline $39 \mathrm{EEB}$ & 0,20 & 0,08 & 0,04 & 0,07 & $-0,16$ & $-0,01$ \\
\hline 40 JOAO CESA & 0,22 & 0,13 & 0,00 & 0,07 & $-0,22$ & $-0,06$ \\
\hline 41 EFLUL & 0,19 & 0,00 & 0,00 & 0,04 & $-0,19$ & 0,04 \\
\hline 42 ELEKTRO & 0,60 & 0,15 & 0,49 & 0,41 & $-0,10$ & 0,26 \\
\hline 43 ELETROACRE & 0,21 & 0,12 & 2,07 & 2,18 & 1,85 & 2,06 \\
\hline 44 ELETROCAR & 0,19 & 0,02 & 0,21 & 0,11 & 0,02 & 0,09 \\
\hline 45 ELETROPAULO & 0,26 & 0,23 & 0,35 & 0,23 & 0,09 & 0,00 \\
\hline 46 ELFSM & 0,20 & 0,04 & 0,10 & 0,05 & $-0,10$ & 0,01 \\
\hline $47 \mathrm{EMG}$ & 0,20 & 0,06 & 0,17 & 0,23 & $-0,03$ & 0,17 \\
\hline 48 ENERSUL & 0,20 & 0,08 & 0,79 & 0,69 & 0,59 & 0,61 \\
\hline 49 CENF & 0,29 & 0,12 & 0,26 & 0,07 & $-0,02$ & $-0,04$ \\
\hline 50 SAELPA & 0,22 & 0,13 & 0,83 & 0,53 & 0,60 & 0,40 \\
\hline 51 ESCELSA & 0,55 & 0,17 & 0,59 & 0,69 & 0,04 & 0,51 \\
\hline 52 ENERGIPE & 0,50 & 0,10 & 0,20 & 0,16 & $-0,30$ & 0,06 \\
\hline 53 HIDROPAN & 0,20 & 0,08 & 0,00 & 0,00 & $-0,20$ & $-0,08$ \\
\hline 54 IGUAÇU & 0,20 & 0,08 & 0,01 & 0,01 & $-0,19$ & $-0,07$ \\
\hline 55 LIGHT & 1,66 & 0,27 & 0,67 & 0,57 & $-1,00$ & 0,31 \\
\hline 56 MUX ENERGIA & 0,19 & 0,00 & 0,00 & 0,01 & $-0,19$ & 0,01 \\
\hline 57 RGE & 0,22 & 0,13 & 0,43 & 0,36 & 0,21 & 0,23 \\
\hline 58 SULGIPE & 0,22 & 0,13 & 0,15 & 0,33 & $-0,07$ & 0,20 \\
\hline 59 NOVA PALMA & 0,19 & 0,02 & 0,00 & 0,00 & $-0,19$ & $-0,02$ \\
\hline Máximo & 1,66 & 3,02 & 3,33 & 3,84 & 2,77 & 3,20 \\
\hline Mínimo & 0,19 & 0,00 & 0,00 & 0,00 & $-1,00$ & $-0,19$ \\
\hline édia & 0,35 & 0,18 & 0,52 & 0,53 & 0,18 & 0,36 \\
\hline
\end{tabular}




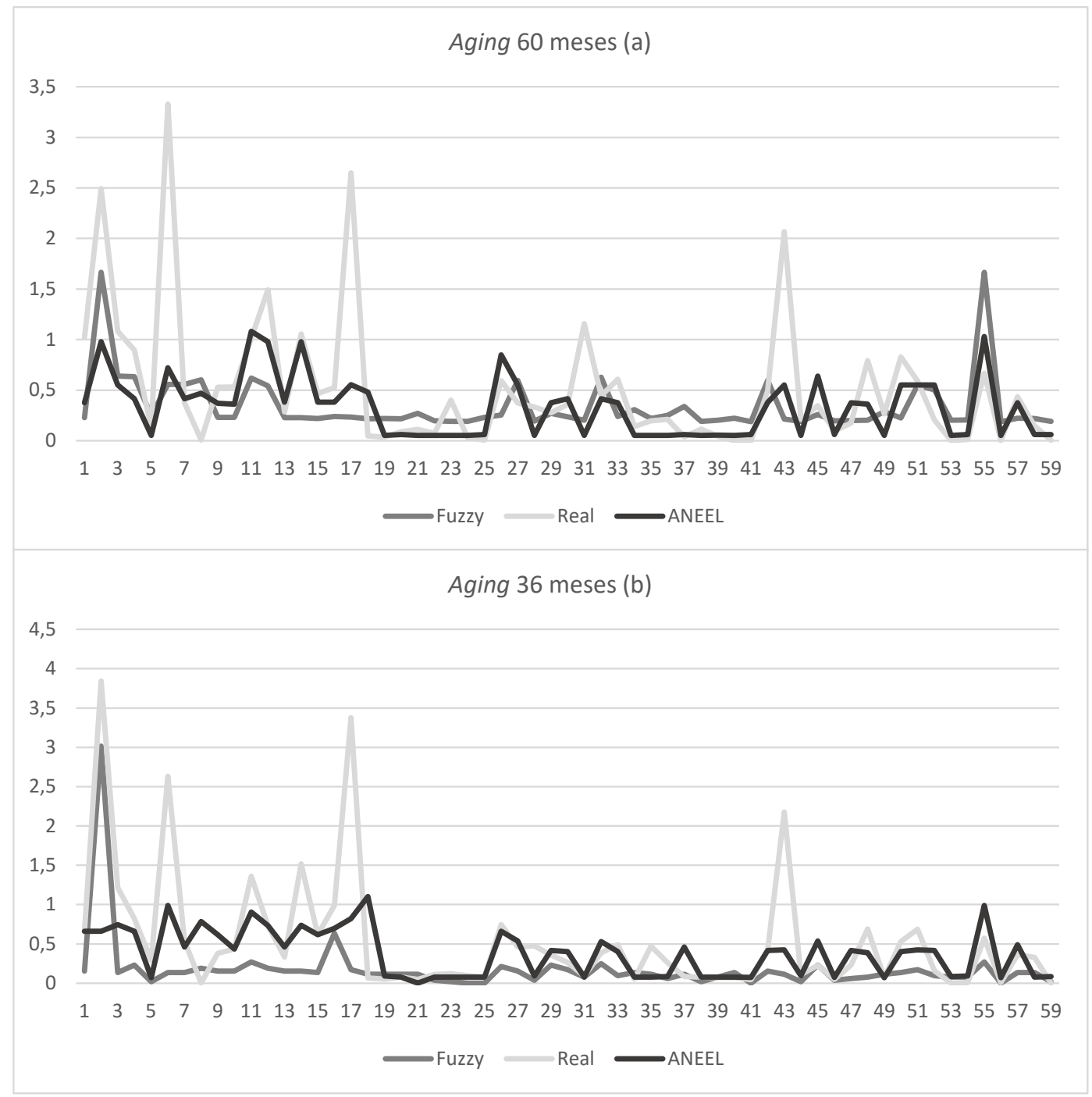

Figura 0.18 - Metas de inadimplência (\%): reais, estimativas modelo fuzzy, estimativas metodologia ANEEL. Em (a) aging de 60 meses e em (b) aging de 36 meses.

A inadimplência real deste segmento, apurada por meio das curvas de aging de faturamentos não recebidos de 25 a 36 meses e de 49 a 60 meses da data de referência, em sua grande maioria, assim como o segmento industrial, está situada em uma faixa de inadimplência abaixo de 1\%. No entanto, apresenta uma volatilidade maior, apresentando algumas empresas com taxas bem mais elevadas, tanto no caso do aging de 60 meses (figura 4.18a) quanto no caso do aging de 36 meses (figura 4.18b). Nesses casos, a metodologia fuzzy apresentou previsões bem abaixo do realizado. Nos demais casos, tanto a metodologia fuzzy, como a ANEEL, tiveram resultados bem próximos do realizado.

Deve-se ressaltar que, para o segmento comercial, as metas estabelecidas por meio da curva de aging de 36 meses ficaram, na grande maioria dos casos, 
inferiores às obtidas por meio da curva de aging de 60 meses, como pode ser visto na Figura 4.19.

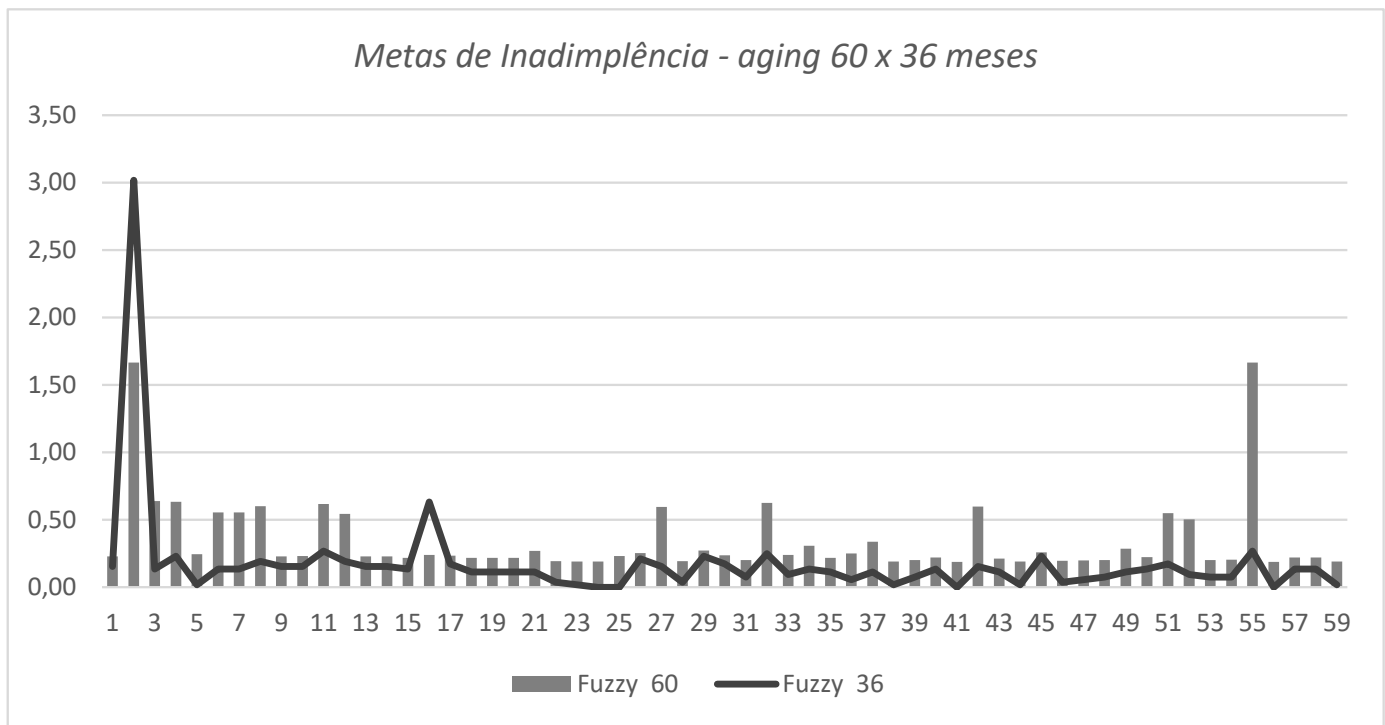

Figura 0.19 - Comparação das metas obtidas com curva de aging de 49 a 60 meses e de 25 a 36 meses

Assim como aconteceu com as classes residencial e industrial, quando se compara os valores reais das metas de inadimplência (\%), considerando as duas curvas de aging, aos valores obtidos por meio da metodologia fuzzy e metodologia ANEEL, observa-se que há uma grande concentração de desvios (valores reais menos previstos por cada metodologia) em torno de 0,5\%, em módulo (Tabela 4.6).

Tabela 0.6 - quantidade percentual de desvios entre $-0,5 \%$ e $+0,5 \%$

\begin{tabular}{|c|c|c|}
\hline \multirow{2}{*}{ Curva proposta } & \multicolumn{2}{|c|}{ Qtd percentual de desvios $-0,5 \%<0 \%<0,5 \%$} \\
\cline { 2 - 3 } & Valores reais - ANEEL & Valores reais - fuzzy \\
\hline Aging 49 a 60 meses & $86 \%$ & $80 \%$ \\
\hline Aging 25 a 36 meses & $88 \%$ & $78 \%$ \\
\hline
\end{tabular}

A Figura 4.20 permite melhor visualização da concentração dos desvios em torno de 0,5\%. Observa-se que, ao se considerar a curva de aging de 60 meses, o maior desvio encontrado foi de 2,7\% (Ceal), obtido em relação à metodologia fuzzy (Figura 4.20a). Para esse mesmo caso, o desvio em relação à metodologia ANEEL foi de 2,6\%. Com relação à curva de aging de 36 meses (Figura 4.20b), o maior desvio foi da ordem de 3,2\% (CEPISA) para a metodologia fuzzy. Com relação à metodologia ANEEL, o desvio dessa empresa foi de $2,5 \%$, embora o maior tenha sido de $3,18 \%$ para a empresa CEAM. 


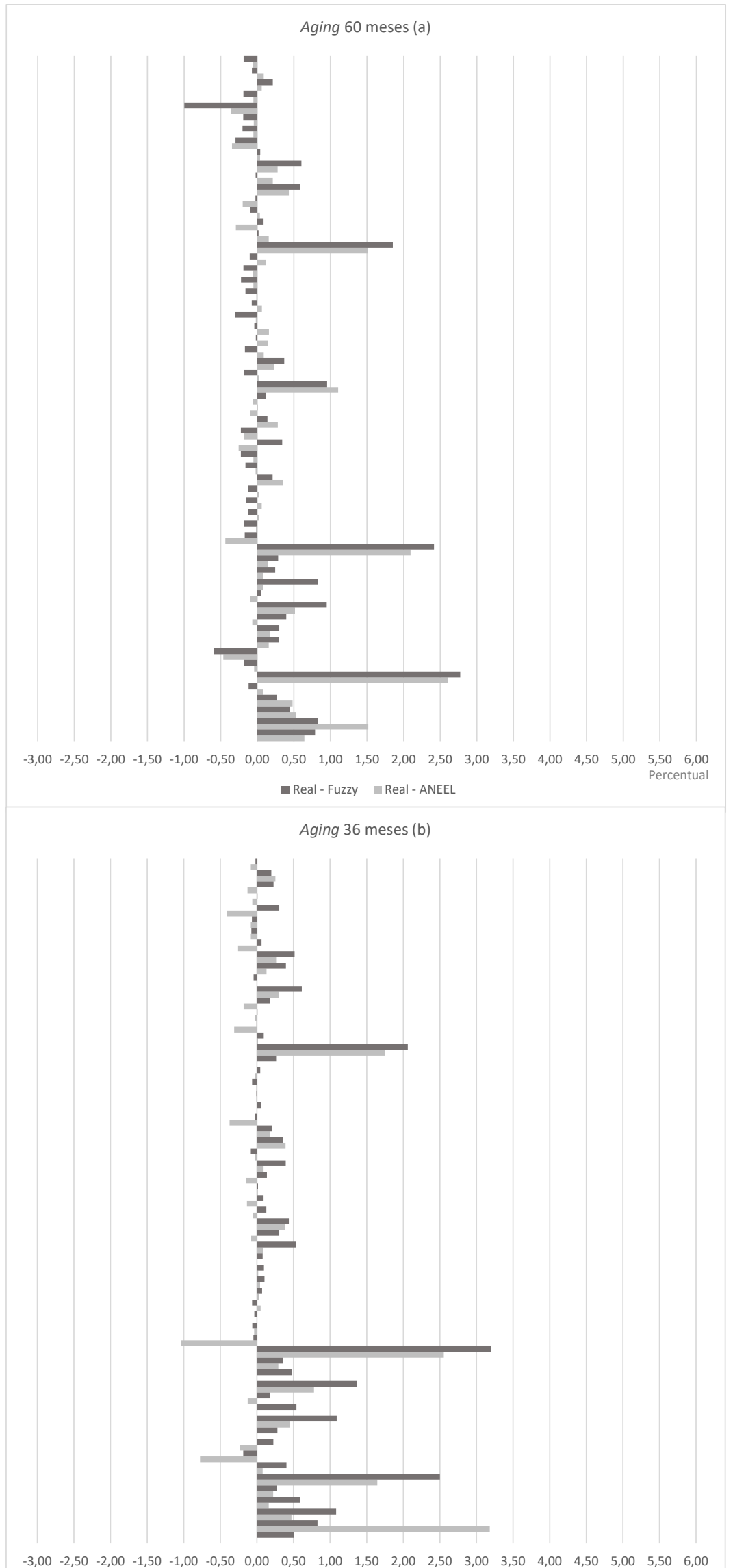

Figura 0.20 - Desvios \% Inadimplência real x fuzzy x ANEEL. Em (a) aging de 60 meses e em (b) aging de 36 meses

distribuidoras de energia elétrica do Brasil - curva de aging de 49 a 60 meses 
Repetindo-se a análise qualitativa realizada para os segmentos anteriores, com base nas Figuras 4.21 e 4.22, pode-se notar que as regras definidas conseguiram capturar bem o que a base real dos dados de inadimplência declarada pelas distribuidoras, aliada às variáveis de porte e vulnerabilidade, forneceram como insumo. Pode-se perceber que, assim como no segmento industrial, as regras fuzzy penalizaram aquelas empresas com um maior nível de inadimplência, igualando seus patamares de metas aos das empresas mais eficientes, exceção para a empresa CEAM, cuja inadimplência apurada com a curva de aging de 36 meses se mostrou muito alta e inferência fuzzy, apesar de penalizar, reconheceu uma inadimplência no patamar alto. As metodologias fuzzy e ANEEL apresentaram resultados muito parecidos.

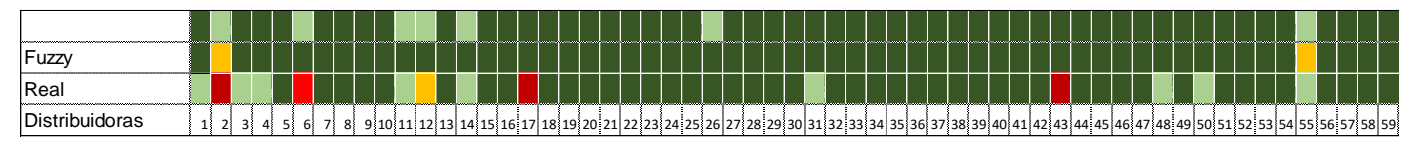

Figura 0.21 - Comparação da meta ANELL, com a meta estabelecida no modelo fuzzy e a inadimplência real declarada pelas distribuidoras de energia elétrica do Brasil - curva de aging de 49 a 60 meses

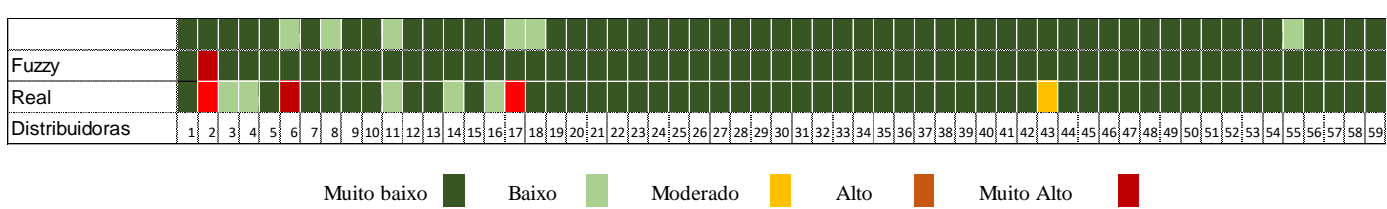

Figura 0.22 - Comparação da meta ANELL, com a meta estabelecida no modelo fuzzy e a inadimplência real declarada pelas distribuidoras de energia elétrica do Brasil - curva de aging de 25 a 36 meses

Observa-se que a diferenciação da curva de aging produz poucas variações nos patamares de inadimplência, apresentando poucos casos com alteração de classificação para outro grupo fuzzy.

\subsection{4.}

\section{Classe rural}

A classe rural responde por $8,6 \%$ do consumo do mercado cativo do Brasil (Anuário Estatístico de 2020), tendo uma representação de 5,3\% em termos do número de consumidores cativos.

Para a classe rural, foi adotado o método de defuzzyficação do bissector para a curva de aging de 49 a 60 meses e de MoM - Mean of maximus para a 
curva de aging de 25 a 36 meses, que minimizaram os desvios dos erros quadráticos médios da previsão em relação aos valores reais, como se visualiza por meio da Figura 4.23.

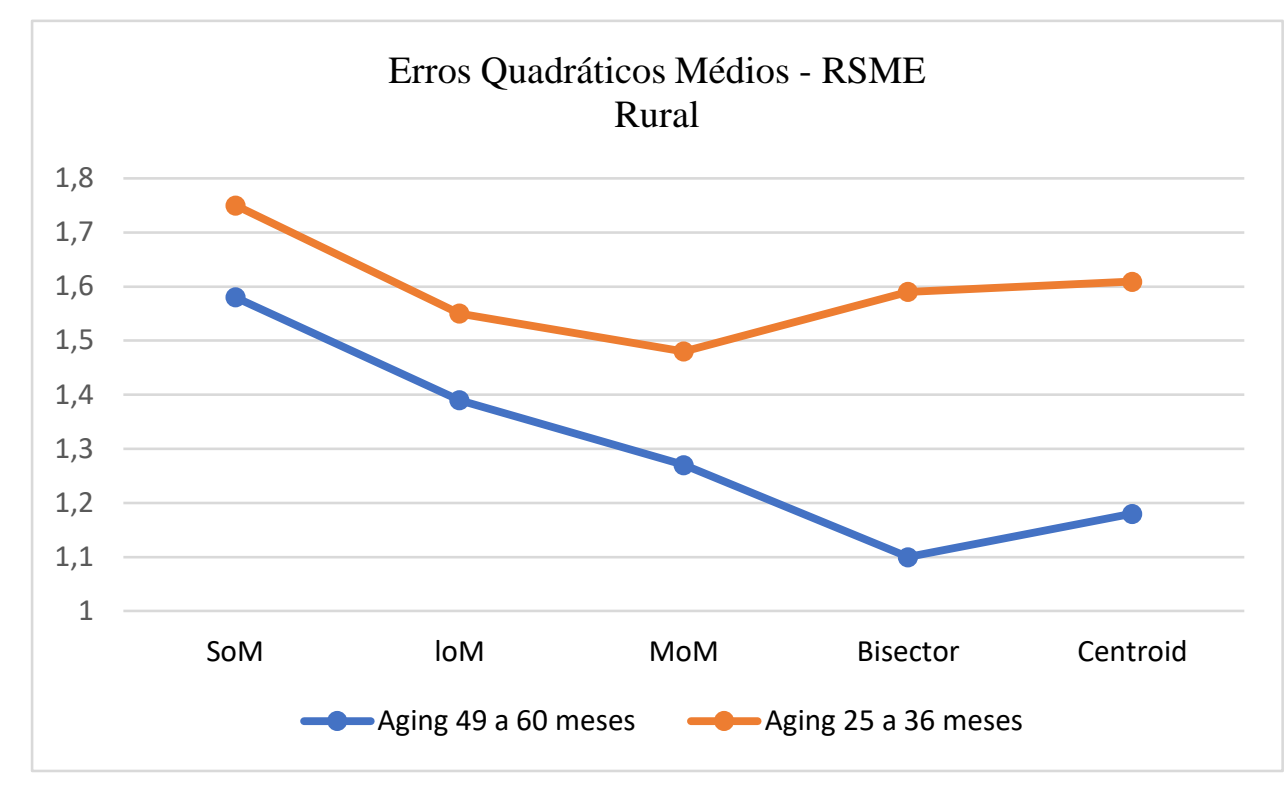

Figura 0.23 - Escolha do método de defuzzyficação para o rural - curvas de aging de 49 a 60 meses e de 25 a 36 meses

Os resultados do modelo para a classe rural, considerando as duas curvas de aging, podem ser visualizados na Tabela 4.7. O desvio médio para a curva de aging de 49 a 60 meses ficou em 0,21\%, enquanto para a curva de 25 a 36 meses ficou em $0,84 \%$, ou seja, ao se diminuir o período da curva de aging, para o caso da classe rural, aumentou-se o desvio em relação aos valores reais. 
Tabela 0.7 Resultado modelo para a classe rural - valores \%

\begin{tabular}{|c|c|c|c|c|c|c|}
\hline \multirow{2}{*}{ Rural } & \multicolumn{2}{|c|}{ Resultado Fuzzy } & \multicolumn{2}{|c|}{ Real } & \multicolumn{2}{|c|}{ Desvio Real menos previsto } \\
\hline & 49 a 60 meses & 25 a 36 meses & 49 a 60 meses & 25 a 36 meses & 49 a 60 meses & 25 a 36 meses \\
\hline 1 AES SUL & 0,49 & 0,10 & 0,37 & 0,41 & $-0,12$ & 0,31 \\
\hline 2 CEAM & 3,51 & 7,53 & 5,19 & 9,92 & 1,68 & 2,39 \\
\hline 3 AMPLA & 4,21 & 0,31 & 0,83 & 0,84 & $-3,38$ & 0,53 \\
\hline 4 BANDEIRANTE & 1,05 & 0,52 & 0,23 & 0,42 & $-0,83$ & $-0,10$ \\
\hline 5 CAIUÁ & 0,42 & 0,05 & 0,02 & 0,04 & $-0,40$ & $-0,02$ \\
\hline 6 CEAL & 0,49 & 0,31 & 4,92 & 9,08 & 4,43 & 8,77 \\
\hline 7 CEB & 0,63 & 0,31 & 0,89 & 1,22 & 0,26 & 0,91 \\
\hline 8 CEEE & 0,49 & 0,31 & 0,00 & 0,00 & $-0,49$ & $-0,31$ \\
\hline 9 CELESC & 0,49 & 0,36 & 0,17 & 0,16 & $-0,32$ & $-0,20$ \\
\hline 10 CELG & 0,56 & 0,36 & 0,26 & 0,35 & $-0,31$ & $-0,01$ \\
\hline 11 CELPA & 0,70 & 0,62 & 6,64 & 9,60 & 5,94 & 8,98 \\
\hline 12 CELPE & 1,33 & 0,47 & 5,11 & 4,48 & 3,78 & 4,01 \\
\hline 13 CELTINS & 0,49 & 0,31 & 0,12 & 0,22 & $-0,37$ & $-0,10$ \\
\hline 14 CEMAR & 0,49 & 0,16 & 2,54 & 3,82 & 2,05 & 3,67 \\
\hline 15 CEMAT & 0,56 & 0,31 & 0,20 & 0,28 & $-0,36$ & $-0,03$ \\
\hline 16 CEMIG & 0,56 & 0,52 & 0,50 & 0,85 & $-0,06$ & 0,33 \\
\hline 17 CEPISA & 0,56 & 0,21 & 5,72 & 5,84 & 5,16 & 5,63 \\
\hline 18 CERON & 0,49 & 0,26 & 0,00 & 0,00 & $-0,49$ & $-0,26$ \\
\hline 19 CFLO & 0,49 & 0,26 & 0,03 & 0,11 & $-0,46$ & $-0,15$ \\
\hline 20 CHESP & 0,49 & 0,26 & 0,04 & 0,03 & $-0,45$ & $-0,23$ \\
\hline $21 \mathrm{CJE}$ & 0,49 & 0,26 & 0,04 & 0,00 & $-0,45$ & $-0,26$ \\
\hline 22 MOCOCA & 0,42 & 0,10 & 0,12 & 0,30 & $-0,30$ & 0,19 \\
\hline 23 SANTA CRUZ & 0,42 & 0,05 & 0,37 & 0,23 & $-0,05$ & 0,18 \\
\hline 24 CNEE & 0,42 & 0,00 & 0,00 & 0,02 & $-0,42$ & 0,02 \\
\hline 25 COCEL & 0,42 & 0,00 & 0,00 & 0,00 & $-0,42$ & 0,00 \\
\hline 26 COELBA & 0,84 & 0,47 & 1,47 & 1,30 & 0,62 & 0,83 \\
\hline 27 COELCE & 1,12 & 0,36 & 1,42 & 1,79 & 0,30 & 1,43 \\
\hline 28 COOPERALIANÇA & 0,42 & 0,10 & 0,00 & 0,04 & $-0,42$ & $-0,06$ \\
\hline 29 COPEL & 0,63 & 0,52 & 0,11 & 0,15 & $-0,52$ & $-0,37$ \\
\hline 30 COSERN & 0,56 & 0,21 & 1,32 & 0,66 & 0,75 & 0,46 \\
\hline 31 CPEE & 0,42 & 0,16 & 0,22 & 0,14 & $-0,20$ & $-0,02$ \\
\hline 32 CPFL PIRATININGA & 0,49 & 0,57 & 0,53 & 0,51 & 0,04 & $-0,06$ \\
\hline 33 CPFL PAULISTA & 0,98 & 0,21 & 0,19 & 0,33 & $-0,80$ & 0,13 \\
\hline 34 CSPE & 0,49 & 0,31 & 0,39 & 0,24 & $-0,10$ & $-0,07$ \\
\hline 35 DEMEI & 0,49 & 0,31 & 0,00 & 0,00 & $-0,49$ & $-0,31$ \\
\hline 36 DMEPC & 0,42 & 0,10 & 0,64 & 0,11 & 0,22 & 0,01 \\
\hline 37 CELB & 0,49 & 0,26 & 0,36 & 0,55 & $-0,13$ & 0,29 \\
\hline 38 EDEVP & 0,42 & 0,05 & 0,01 & 0,03 & $-0,41$ & $-0,03$ \\
\hline $39 \mathrm{EEB}$ & 0,42 & 0,16 & 0,02 & 0,07 & $-0,40$ & $-0,08$ \\
\hline 40 JOAO CESA & 0,49 & 0,31 & 0,00 & 0,00 & $-0,49$ & $-0,31$ \\
\hline 41 EFLUL & 0,35 & 0,00 & 0,00 & 0,00 & $-0,35$ & 0,00 \\
\hline 42 ELEKTRO & 1,05 & 0,36 & 0,36 & 0,47 & $-0,70$ & 0,11 \\
\hline 43 ELETROACRE & 0,49 & 0,26 & 7,02 & 10,39 & 6,53 & 10,13 \\
\hline 44 ELETROCAR & 0,42 & 0,05 & 0,04 & 0,02 & $-0,38$ & $-0,03$ \\
\hline 45 ELETROPAULO & 0,63 & 0,52 & 0,01 & 0,00 & $-0,63$ & $-0,52$ \\
\hline 46 ELFSM & 0,42 & 0,10 & 0,03 & 0,02 & $-0,39$ & $-0,08$ \\
\hline $47 \mathrm{EMG}$ & 0,42 & 0,16 & 0,18 & 0,20 & $-0,25$ & 0,04 \\
\hline 48 ENERSUL & 0,56 & 0,16 & 1,89 & 2,21 & 1,33 & 2,06 \\
\hline 49 CENF & 0,49 & 0,26 & 0,01 & 0,03 & $-0,49$ & $-0,23$ \\
\hline 50 SAELPA & 0,56 & 0,31 & 1,54 & 1,31 & 0,97 & 1,00 \\
\hline 51 ESCELSA & 0,56 & 0,21 & 1,27 & 1,88 & 0,71 & 1,67 \\
\hline 52 ENERGIPE & 0,42 & 0,21 & 0,09 & 0,33 & $-0,33$ & 0,12 \\
\hline 53 HIDROPAN & 0,42 & 0,16 & 0,00 & 0,00 & $-0,42$ & $-0,16$ \\
\hline 54 IGUAÇU & 0,42 & 0,16 & 0,23 & 0,10 & $-0,19$ & $-0,06$ \\
\hline 55 LIGHT & 3,51 & 0,62 & 0,26 & 0,22 & $-3,25$ & $-0,41$ \\
\hline 56 MUX ENERGIA & 0,42 & 0,00 & 0,00 & 0,00 & $-0,42$ & 0,00 \\
\hline 57 RGE & 0,56 & 0,31 & 0,17 & 0,19 & $-0,40$ & $-0,12$ \\
\hline 58 SULGIPE & 0,49 & 0,31 & 0,19 & 0,32 & $-0,30$ & 0,01 \\
\hline 59 NOVA PALMA & 0,42 & 0,05 & 0,12 & 0,14 & $-0,30$ & 0,09 \\
\hline Máximo & 4,21 & 7,53 & 7,02 & 10,39 & 6,53 & 10,13 \\
\hline Mínimo & 0,35 & 0,00 & 0,00 & 0,00 & $-3,38$ & $-0,52$ \\
\hline Média & 0,71 & 0,38 & 0,92 & 1,22 & 0,21 & 0,84 \\
\hline
\end{tabular}


Aproximadamente $25 \%$ das empresas nesse segmento apresentam taxa de inadimplência menor do que $0,03 \%$ para apuração por meio das duas curvas de aging. No entanto, para os demais casos, percebe-se uma grande volatilidade, com algumas empresas apresentando taxas bem mais elevadas, como pode ser visto na Figura 4.24a (aging de 36 meses) e Figura 4.24b (aging de 60 meses).

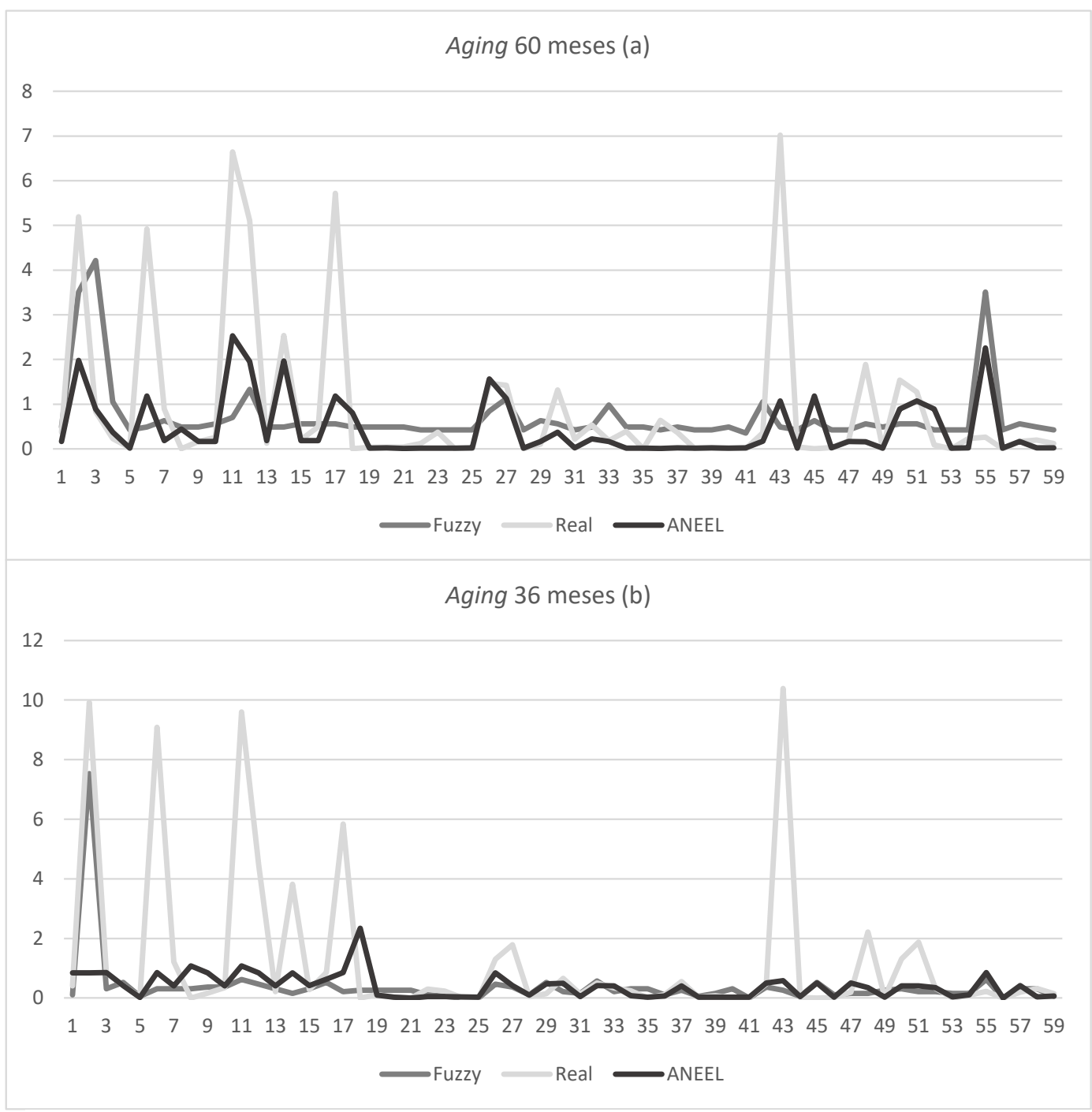

Figura 0.24 - Metas de inadimplência (\%): reais, estimativas modelo fuzzy, estimativas metodologia ANEEL. Em (a) aging de 60 meses e em (b) aging de 36 meses

Exceto para o caso da CEAM, as metas estabelecidas para o segmento rural por meio da curva de aging de 36 meses ficaram sempre abaixo daquelas obtidas por meio da curva de aging de 60 meses (Figura 4.25). 


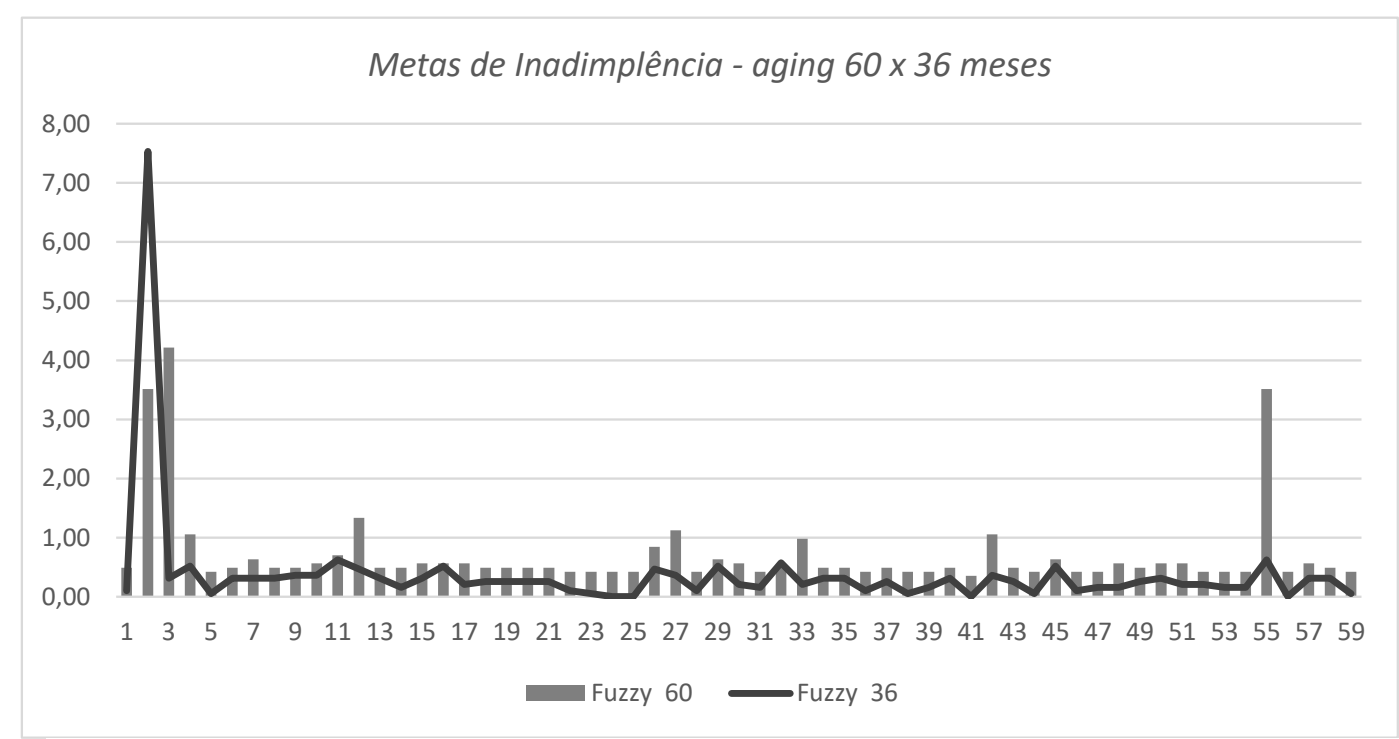

Figura 0.25 - Comparação das metas obtidas com curva de aging de 49 a 60 meses e de 25 a 36 meses

Cabe ressaltar que, como a classe rural apresenta uma inadimplência real mais baixa que as classes analisadas anteriormente, um desvio de 0,5 pontos percentuais de inadimplência (desvio absoluto - real menos previsto), pode significar uma magnitude de erro de $100 \%$ em termos relativos (real dividido pelo previsto).

A Figura 4.26 permite melhor visualização da amplitude dos desvios absolutos. Observa-se que, ao se considerar a curva de aging de 60 meses, o maior desvio encontrado foi de 6,5\% (Eletroacre), obtido em relação à metodologia fuzzy (Figura 4.26a). Para esse mesmo caso, o desvio em relação à metodologia ANEEL foi de 5,9\%. Com relação à curva de aging de 36 meses (Figura 4.26b), essa empresa continuou apresentando o maior desvio, 10,1\% para a metodologia fuzzy e 9,8\% em relação à metodologia ANEEL. 


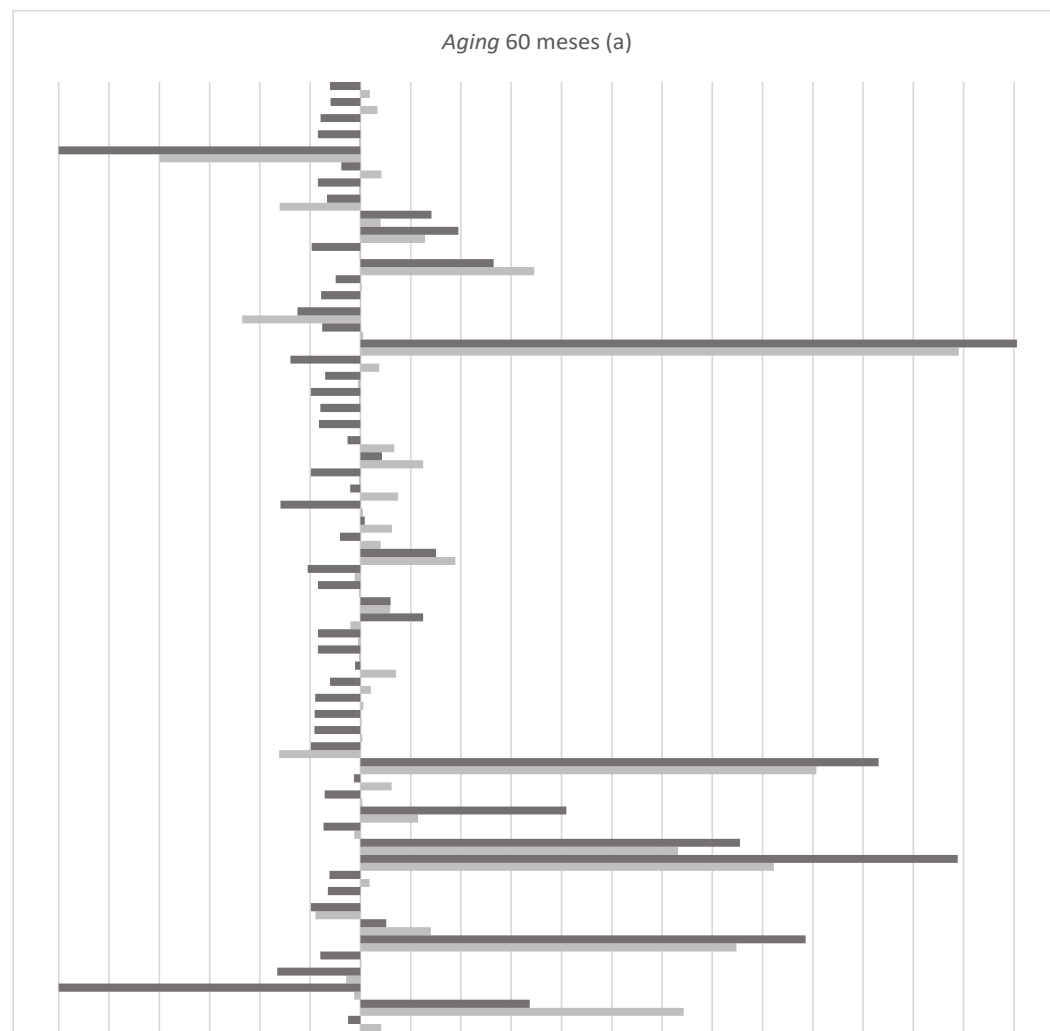

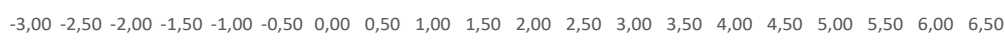
- Real - Fuzzy $\because$ Real - ANEEL

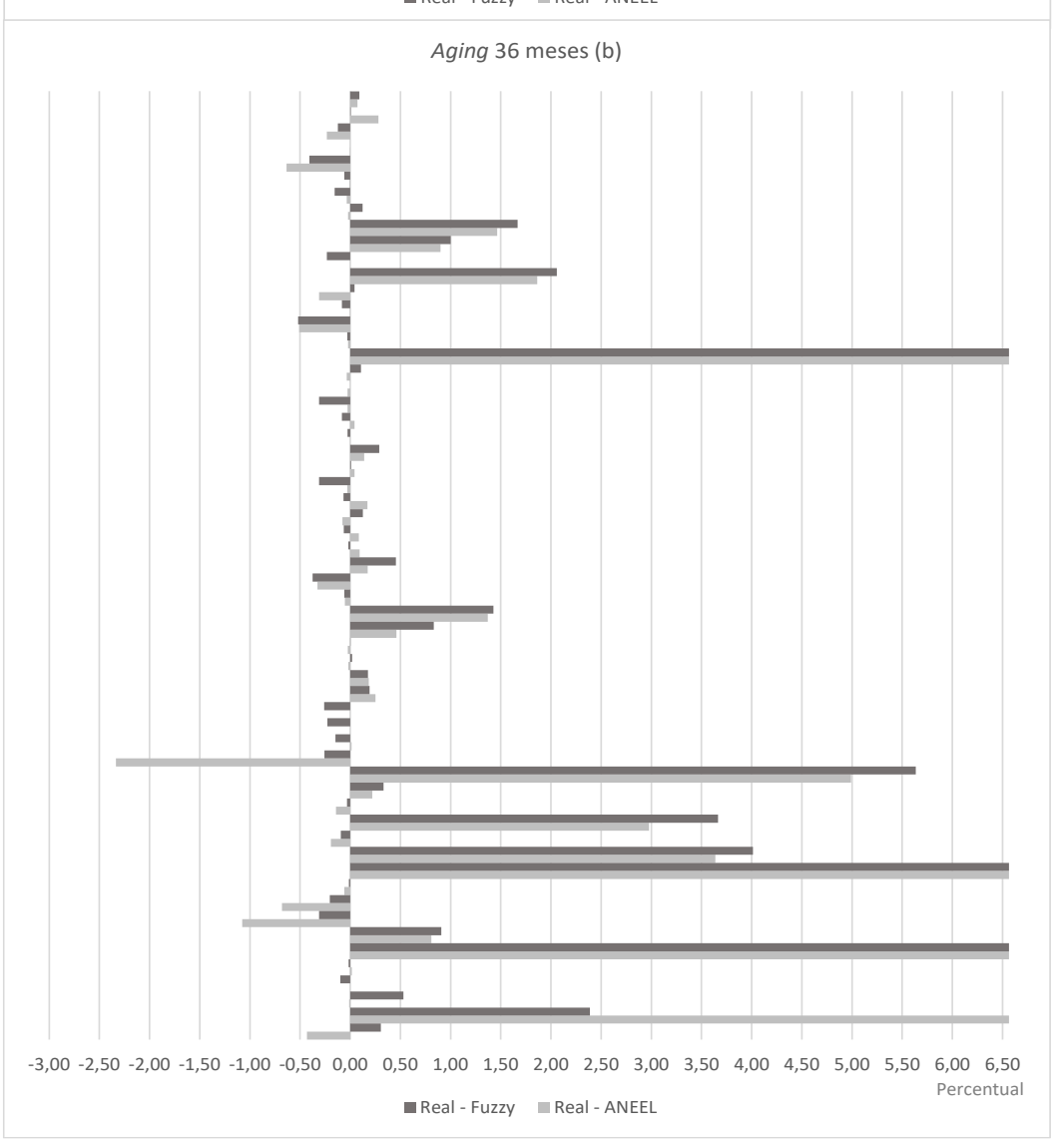

Figura 0.26 - Desvios \% Inadimplência real x fuzzy x ANEEL. Em (a) aging de 60 meses e em (b) aging de 36 meses 
De acordo com a análise qualitativa realizada, percebe que, especialmente no que se refere às empresas com taxas de inadimplência mais baixas, embora os desvios absolutos e especialmente os desvios relativos sejam altos em função da classe apresentar taxas reais muito próximas de zero, a grande maiores das empresas apresentaram previsões dentro das mesmas faixas da inadimplência real, permanecendo, entretanto, a coerência da metodologia proposta ao reduzir a previsão para empresas com taxas reais acima de outras com o mesmo porte $\mathrm{e}$ nível de vulnerabilidade. Cabe observar, no entanto, que no caso da curva de aging de 49 a 60 meses, a metodologia fuzzy apresentou 3 casos onde a faixa indicada foi superior à faixa real de inadimplência (AesSul, CEAM e Light) - Figura 4.27. Esse fato não ocorreu ao se considerar a curva de aging de 25 a 36 meses (Figura 4.28).

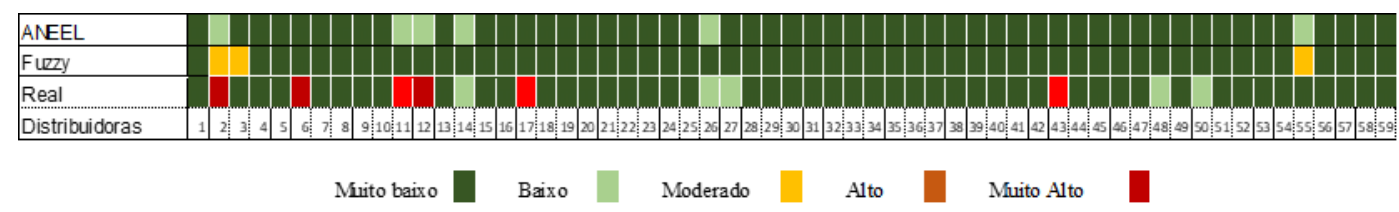

Figura 0.27 - Comparação da meta ANELL, com a meta estabelecida no modelo fuzzy e a inadimplência real declarada pelas distribuidoras de energia elétrica do Brasil - curva de aging de 49 a 60 meses

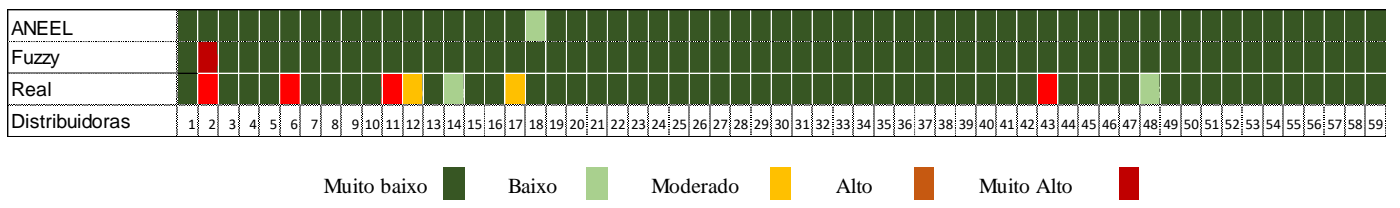

Figura 0.28 - Comparação da meta ANELL, com a meta estabelecida no modelo fuzzy e a inadimplência real declarada pelas distribuidoras de energia elétrica do Brasil - curva de aging de 25 a 36 meses

\subsection{5.}

\section{Classe poder público}

A classe poder público responde por $4,9 \%$ do consumo do mercado cativo do Brasil (Anuário Estatístico de 2020), tendo uma representação de 0,7\% em termos do número de consumidores cativos.

Para a classe poder público, foi adotado o método de defuzzyficação do MoM - Mean of maximus para as duas curvas de aging, como pode ser visualizado na figura 4.29 como o método que apresentou o menor erro quadrático médio da previsão em relação aos valores reais. 


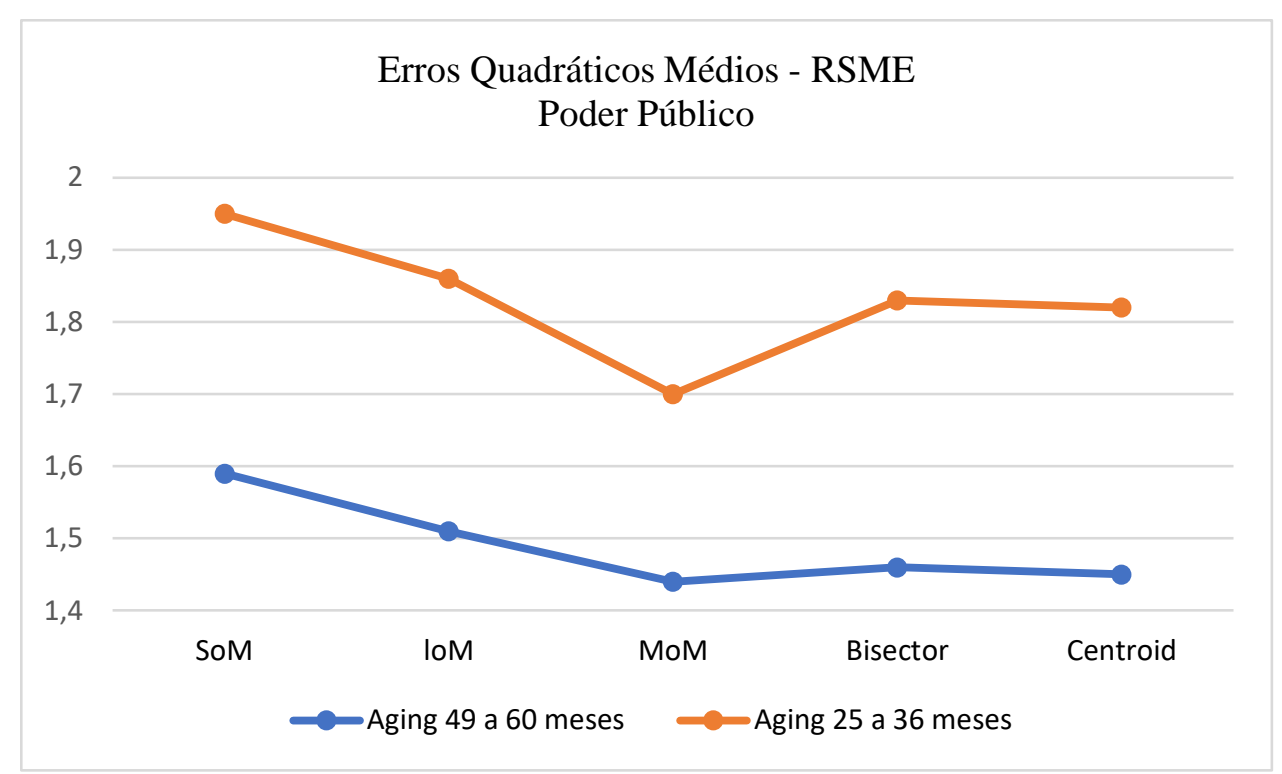

Figura 0.29 - Escolha do método de defuzzyficação para o poder público curvas de aging de 49 a 60 meses e de 25 a 36 meses

Os resultados do modelo para a classe poder público, considerando as duas curvas de aging, podem ser visualizados na Tabela 4.8. O desvio médio para a curva de aging de 49 a 60 meses ficou em 0,06\%, enquanto para a curva de 25 a 36 meses ficou em $0,34 \%$, ou seja, ao se diminuir o período da curva de aging, para o caso da classe poder público, aumentou-se o desvio em relação aos valores reais. 
Tabela 0.8 - Resultado modelo para a classe poder público - valores \%

\begin{tabular}{|c|c|c|c|c|c|c|}
\hline \multirow{2}{*}{ Poder Público } & \multicolumn{2}{|c|}{ Resultado Fuzzy } & \multicolumn{2}{|c|}{ Real } & \multicolumn{2}{|c|}{ Desvio Real menos previsto } \\
\hline & 49 a 60 meses & 25 a 36 meses & 49 a 60 meses & 25 a 36 meses & 49 a 60 meses & 525 a 36 meses \\
\hline 1 AES SUL & 0,16 & 0,04 & 0,00 & 0,18 & $-0,16$ & 0,14 \\
\hline 2 CEAM & 1,44 & 0,61 & 1,24 & 1,54 & $-0,20$ & 0,92 \\
\hline 3 AMPLA & 0,03 & 0,11 & 0,29 & 7,65 & 0,26 & 7,53 \\
\hline 4 BANDEIRANTE & 0,10 & 0,23 & 0,09 & 0,07 & $-0,01$ & $-0,16$ \\
\hline 5 CAIUÁ & 0,03 & 0,00 & 0,00 & 0,00 & $-0,03$ & 0,00 \\
\hline 6 CEAL & 0,14 & 0,19 & 2,89 & 3,60 & 2,74 & 3,41 \\
\hline 7 CEB & 0,14 & 0,19 & 0,17 & 0,24 & 0,02 & 0,05 \\
\hline 8 CEEE & 0,14 & 0,11 & 0,00 & 0,00 & $-0,14$ & $-0,11$ \\
\hline 9 CELESC & 0,16 & 0,15 & 0,04 & 0,03 & $-0,12$ & $-0,13$ \\
\hline 10 CELG & 0,16 & 0,15 & 2,16 & 1,95 & 2,00 & 1,80 \\
\hline 11 CELPA & 0,10 & 0,27 & 0,14 & 0,07 & 0,04 & $-0,20$ \\
\hline 12 CELPE & 0,17 & 0,19 & 0,22 & 0,18 & 0,05 & $-0,01$ \\
\hline 13 CELTINS & 0,16 & 0,11 & 0,00 & 0,00 & $-0,16$ & $-0,11$ \\
\hline 14 CEMAR & 0,16 & 0,04 & 0,55 & 1,15 & 0,40 & 1,12 \\
\hline 15 CEMAT & 0,59 & 0,11 & 0,89 & 1,21 & 0,30 & 1,10 \\
\hline 16 CEMIG & 0,19 & 0,15 & 0,14 & 0,44 & $-0,05$ & 0,28 \\
\hline 17 CEPISA & 0,17 & 0,08 & 0,16 & 2,18 & $-0,02$ & 2,10 \\
\hline 18 CERON & 0,12 & 0,11 & 0,07 & 0,14 & $-0,04$ & 0,02 \\
\hline 19 CFLO & 0,13 & 0,11 & 0,00 & 0,00 & $-0,13$ & $-0,11$ \\
\hline 20 CHESP & 0,13 & 0,11 & 0,21 & 0,18 & 0,08 & 0,07 \\
\hline $21 \mathrm{CJE}$ & 0,12 & 0,11 & 0,00 & 0,00 & $-0,12$ & $-0,11$ \\
\hline 22 MOCOCA & 0,04 & 0,04 & 0,05 & 0,00 & 0,01 & $-0,04$ \\
\hline 23 SANTA CRUZ & 0,03 & 0,00 & 0,03 & 0,05 & 0,00 & 0,05 \\
\hline 24 CNEE & 0,01 & 0,00 & 0,00 & 0,00 & $-0,01$ & 0,00 \\
\hline 25 COCEL & 0,00 & 0,00 & 0,00 & 0,00 & 0,00 & 0,00 \\
\hline 26 COELBA & 0,22 & 0,19 & 0,12 & 0,06 & $-0,10$ & $-0,13$ \\
\hline 27 COELCE & 0,17 & 0,15 & 0,00 & 0,20 & $-0,17$ & 0,05 \\
\hline 28 COOPERALIANÇA & 0,04 & 0,04 & 0,27 & 0,03 & 0,23 & $-0,01$ \\
\hline 29 COPEL & 0,26 & 0,23 & 0,00 & 0,69 & $-0,26$ & 0,46 \\
\hline 30 COSERN & 0,17 & 0,08 & 0,10 & 0,03 & $-0,07$ & $-0,04$ \\
\hline 31 CPEE & 0,07 & 0,08 & 0,00 & 0,46 & $-0,07$ & 0,38 \\
\hline 32 CPFL PIRATININGA & 0,03 & 0,27 & 0,08 & 0,07 & 0,05 & $-0,20$ \\
\hline 33 CPFL PAULISTA & 0,17 & 0,08 & 0,09 & 0,09 & $-0,09$ & 0,02 \\
\hline 34 CSPE & 0,13 & 0,15 & 0,49 & 0,00 & 0,36 & $-0,15$ \\
\hline 35 DEMEI & 0,13 & 0,11 & 0,00 & 0,00 & $-0,13$ & $-0,11$ \\
\hline 36 DMEPC & 0,06 & 0,04 & 0,00 & 0,00 & $-0,06$ & $-0,04$ \\
\hline 37 CELB & 0,12 & 0,15 & 0,00 & 0,00 & $-0,12$ & $-0,15$ \\
\hline 38 EDEVP & 0,01 & 0,00 & 0,00 & 0,00 & $-0,01$ & 0,00 \\
\hline $39 \mathrm{EEB}$ & 0,07 & 0,08 & 0,00 & 0,00 & $-0,07$ & $-0,08$ \\
\hline 40 JOAO CESA & 0,13 & 0,11 & 0,00 & 0,00 & $-0,13$ & $-0,11$ \\
\hline 41 EFLUL & 0,00 & 0,00 & 0,00 & 0,00 & 0,00 & 0,00 \\
\hline 42 ELEKTRO & 0,16 & 0,15 & 0,01 & 0,01 & $-0,15$ & $-0,14$ \\
\hline 43 ELETROACRE & 0,12 & 0,11 & 2,39 & 2,30 & 2,27 & 2,18 \\
\hline 44 ELETROCAR & 0,03 & 0,00 & 0,00 & 0,00 & $-0,03$ & 0,00 \\
\hline 45 ELETROPAULO & 0,23 & 0,23 & 0,08 & 0,13 & $-0,15$ & $-0,10$ \\
\hline 46 ELFSM & 0,04 & 0,04 & 0,00 & 0,00 & $-0,04$ & $-0,04$ \\
\hline 47 EMG & 0,07 & 0,04 & 0,00 & 0,04 & $-0,07$ & 0,00 \\
\hline 48 ENERSUL & 0,59 & 0,08 & 0,00 & 0,03 & $-0,59$ & $-0,05$ \\
\hline 49 CENF & 0,13 & 0,15 & 0,00 & 0,00 & $-0,13$ & $-0,15$ \\
\hline 50 SAELPA & 0,20 & 0,11 & 0,03 & 0,07 & $-0,17$ & $-0,05$ \\
\hline 51 ESCELSA & 0,17 & 0,08 & 0,02 & 0,06 & $-0,16$ & $-0,02$ \\
\hline 52 ENERGIPE & 0,10 & 0,15 & 0,00 & 0,00 & $-0,10$ & $-0,15$ \\
\hline 53 HIDROPAN & 0,07 & 0,08 & 0,00 & 0,00 & $-0,07$ & $-0,08$ \\
\hline 54 IGUAÇU & 0,09 & 0,08 & 0,00 & 0,00 & $-0,09$ & $-0,08$ \\
\hline 55 LIGHT & 1,44 & 0,27 & 0,13 & 0,70 & $-1,31$ & 0,43 \\
\hline 56 MUX ENERGIA & 0,00 & 0,00 & 0,00 & 0,00 & 0,00 & 0,00 \\
\hline 57 RGE & 0,61 & 0,11 & 0,05 & 0,10 & $-0,56$ & $-0,01$ \\
\hline 58 SULGIPE & 0,13 & 0,11 & 0,70 & 0,99 & 0,57 & 0,88 \\
\hline 59 NOVA PALMA & 0,01 & 0,13 & 0,00 & 0,00 & $-0,01$ & $-0,13$ \\
\hline Máximo & 1,44 & 0,61 & 2,89 & 7,65 & 2,74 & 7,53 \\
\hline Mínimo & 0,00 & 0,00 & 0,00 & 0,00 & $-1,31$ & $-0,20$ \\
\hline Média & 0,18 & 0,12 & 0,24 & 0,46 & 0,06 & 0,34 \\
\hline
\end{tabular}


Aproximadamente $50 \%$ das empresas nesse segmento apresentam taxa de inadimplência menor do que $0,03 \%$ para apuração por meio das duas curvas de aging. Percebe-se apenas 7 empresas (CEAM, CEAL, CELG, CEMAT, CSPE, ELETROACRE, SULGIPE) com taxas bem mais elevadas, como pode ser visto na Figura 4.30a (aging de 60 meses) e Figura 4.30b (aging de 36 meses).

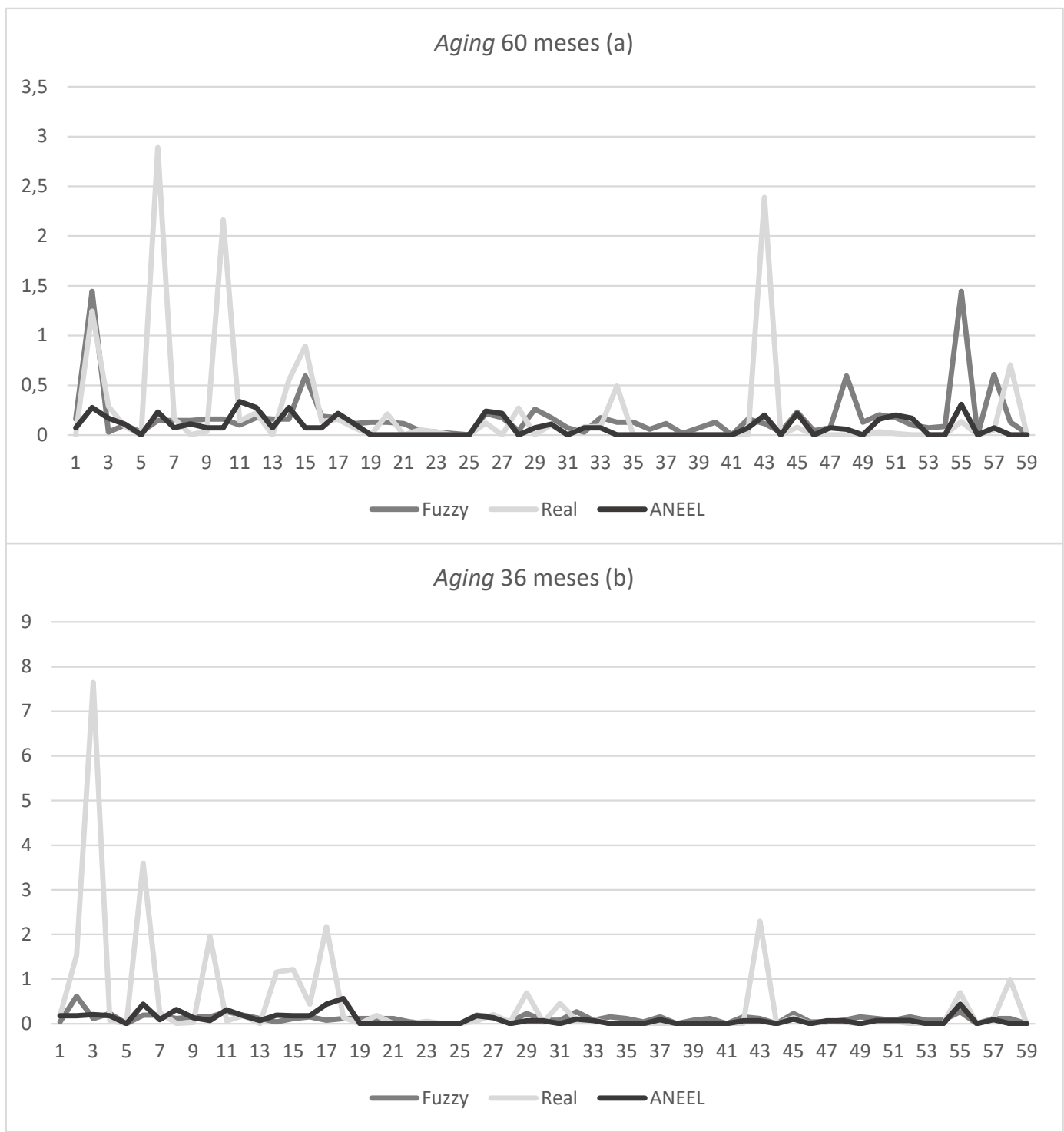

Figura 0.30 - Metas de inadimplência (\%): reais, estimativas modelo fuzzy, estimativas metodologia ANEEL. Em (a) aging de 60 meses e em (b) aging de 36 meses

Exceto para 5 empresas, as metas estabelecidas para o segmento poder público por meio da curva de aging de 36 meses e 60 meses, ficaram muito próximas, como pode ser visto na Figura 4.31. 


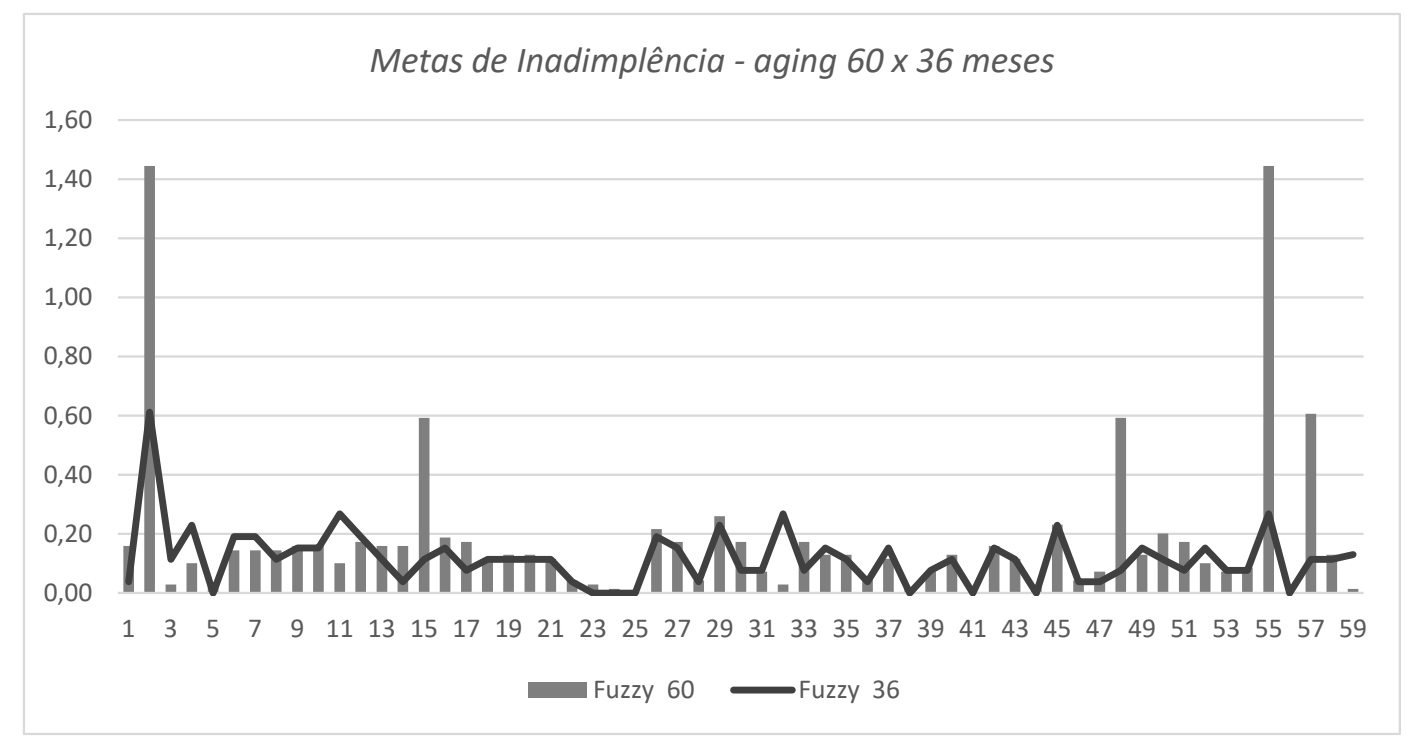

Figura 0.31 - Comparação das metas obtidas com curva de aging de 49 a 60 meses e de 25 a 36

Cabe observar que a classe poder público apresenta uma inadimplência real ainda mais baixa que a classe rural, sendo assim, conforme ressaltado anteriormente, um desvio de 0,5 pontos percentuais de inadimplência (desvio absoluto - real menos previsto), pode significar uma magnitude de erro de $100 \%$ em termos relativos (real dividido pelo previsto).

A Figura 4.32 permite melhor visualização da amplitude dos desvios absolutos. Observa-se que, ao se considerar a curva de aging de 60 meses, o maior desvio encontrado foi de 2,7\% (Ceal), obtido em relação à metodologia fuzzy e ANEEL (Figura 4.32a). Com relação à curva de aging de 36 meses (Figura 4.32b), o maior desvio foi apresentado pela Ampla (Enel Rio), 7,5\% para a metodologia fuzzy e ANEEL. Sem adentrar nas questões políticas, observa-se, nesse caso, o contexto do Estado do Rio de Janeiro. 


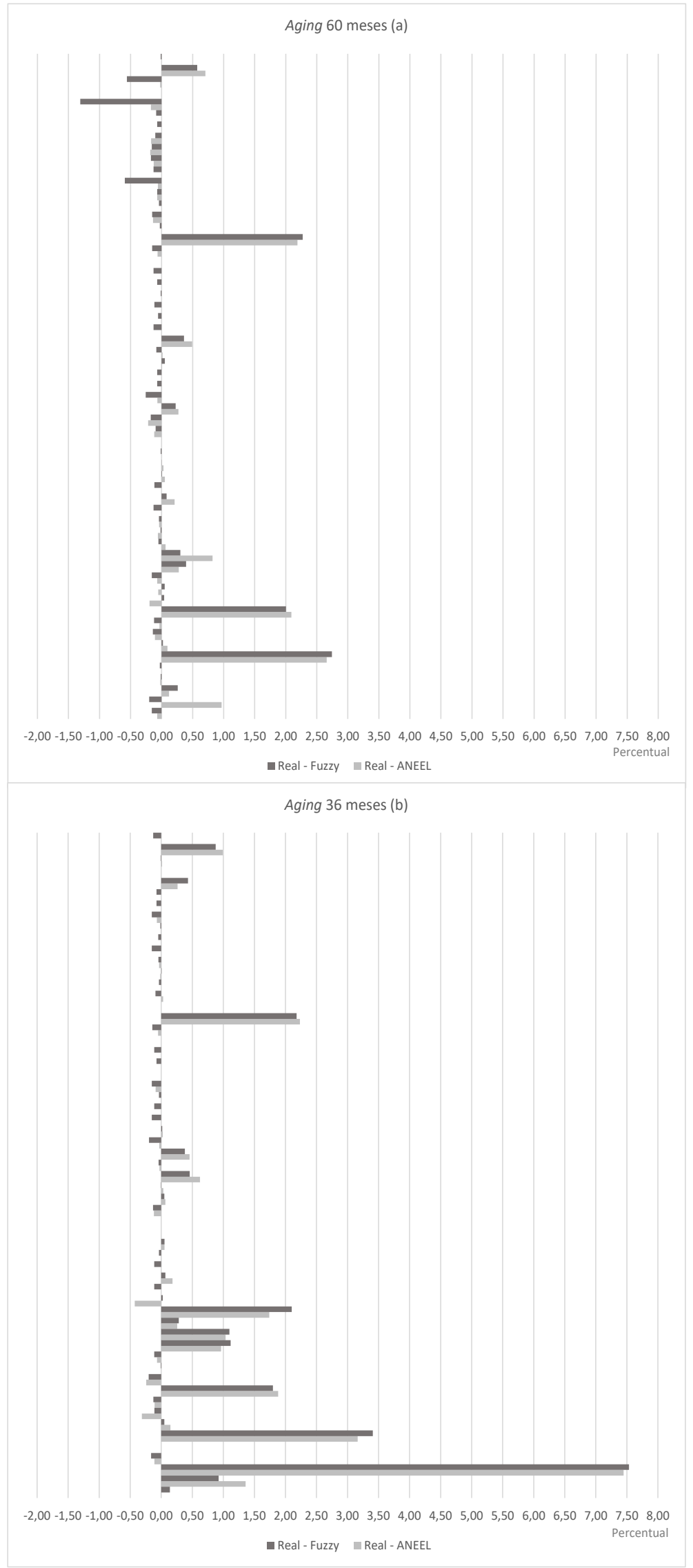

Figura 0.32 - Desvios \% Inadimplência real x fuzzy x ANEEL. Em (a) aging de 60 meses e em (b) aging de 36 meses 
De acordo com a análise qualitativa realizada - Figuras 4.33 e 4.34, percebe que, especialmente no que se refere às empresas com taxas de inadimplência mais baixas, como já comentado para a classe rural, embora os desvios absolutos e especialmente os desvios relativos sejam altos em função da classe apresentar taxas reais muito próximas de zero, a grande maioria das empresas apresentaram previsões dentro das mesmas faixas da inadimplência real, permanecendo, entretanto, a coerência da metodologia proposta ao reduzir a previsão para empresas com taxas reais acima de outras com o mesmo porte e nível de vulnerabilidade.

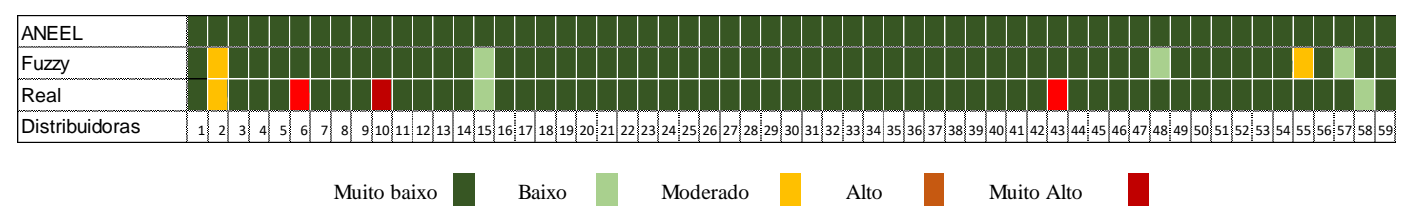

Figura 0.33 - Comparação da meta ANELL, com a meta estabelecida no modelo fuzzy e a inadimplência real declarada pelas distribuidoras de energia elétrica do Brasil - curva de aging de 49 a 60 meses

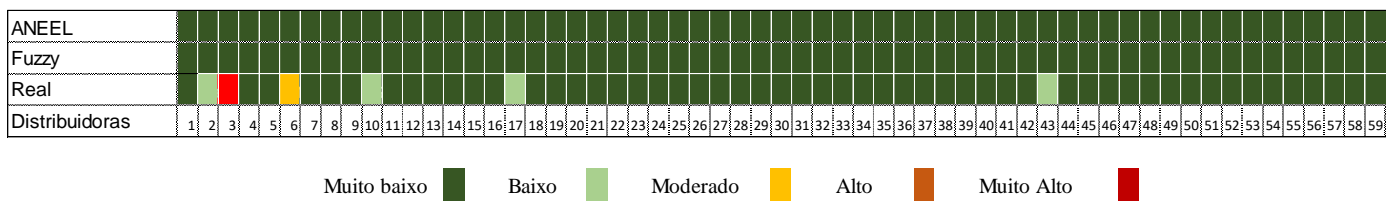

Figura 0.34 - Comparação da meta ANELL, com a meta estabelecida no modelo fuzzy e a inadimplência real declarada pelas distribuidoras de energia elétrica do Brasil - curva de aging de 25 a 36 meses

\subsection{6.}

\section{Classe iluminação pública}

A classe iluminação pública responde por $5,0 \%$ do consumo do mercado cativo do Brasil (Anuário Estatístico de 2020), tendo uma representação de apenas $0,1 \%$ em termos do número de consumidores cativos.

Para a classe iluminação pública, foi adotado o método de defuzzyficação do MoM - Mean of maximus para as duas curvas de aging, como pode ser visualizado na Figura 4.35 como o método que apresentou o menor erro quadrático médio da previsão em relação aos valores reais. 


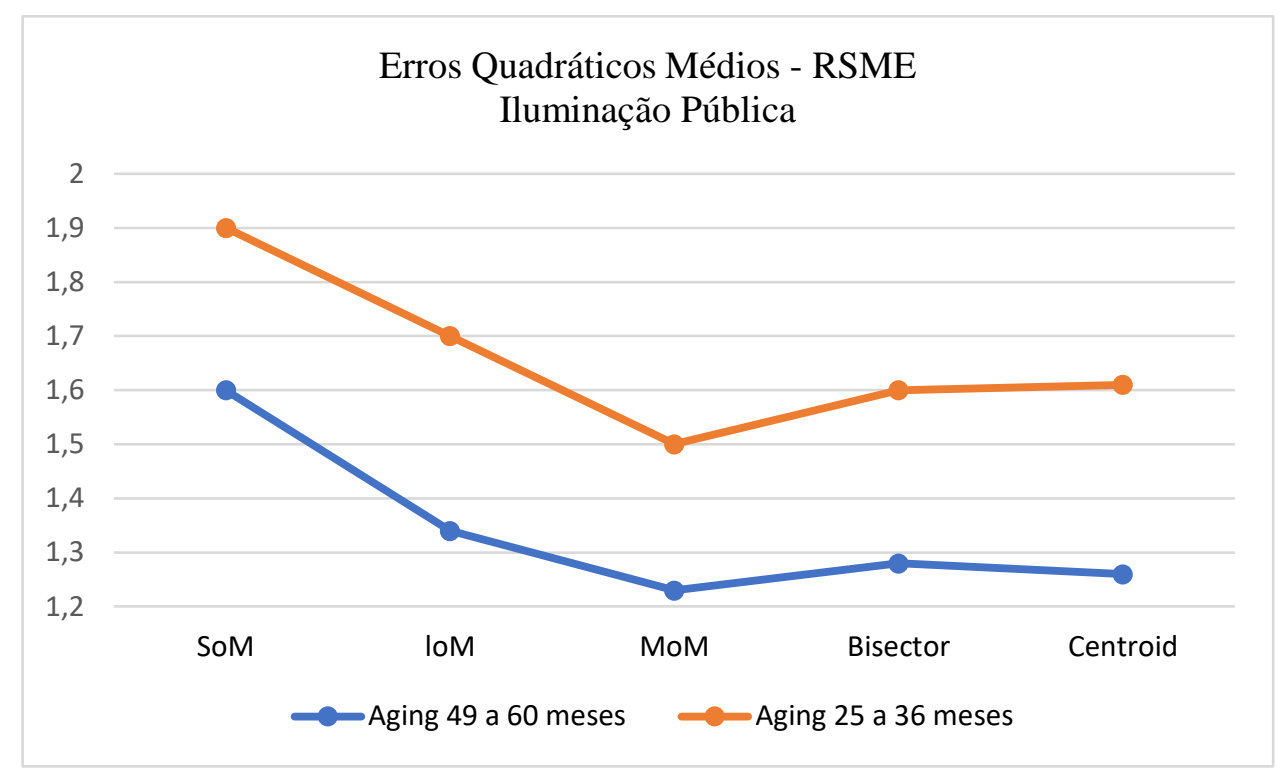

Figura 0.35 - Escolha do método de defuzzificação para a iluminação pública curvas de aging de 49 a 60 meses e de 25 a 36 meses

Os resultados do modelo para a classe iluminação pública, considerando as duas curvas de aging, podem ser visualizados na Tabela 4.9. O desvio médio para as duas curvas de aging foi muito próximo de zero, embora essa classe tenha apresentado desvios máximos significativos. 
Tabela 0.9 - Resultado modelo para a classe iluminação pública - valores \%

\begin{tabular}{|c|c|c|c|c|c|c|}
\hline \multirow{2}{*}{ Iluminação Pública } & \multicolumn{2}{|c|}{ Resultado Fuzzy } & \multicolumn{2}{|c|}{ Real } & \multicolumn{2}{|c|}{ Desvio Real menos previsto } \\
\hline & 49 a 60 meses & 25 a 36 meses & 49 a 60 meses & 25 a 36 meses & 49 a 60 meses & s 25 a 36 meses \\
\hline 1 AES SUL & 0,57 & 0,22 & 0,00 & 0,00 & $-0,57$ & $-0,22$ \\
\hline 2 CEAM & 5,72 & 0,76 & 0,98 & 0,30 & $-4,74$ & $-0,47$ \\
\hline 3 AMPLA & 0,11 & 0,49 & 3,28 & 2,91 & 3,16 & 2,42 \\
\hline 4 BANDEIRANTE & 0,40 & 0,87 & 0,00 & 0,00 & $-0,40$ & $-0,87$ \\
\hline 5 CAIUÁ & 0,11 & 0,11 & 0,00 & 0,00 & $-0,11$ & $-0,11$ \\
\hline 6 CEAL & 0,51 & 0,54 & 2,08 & 2,09 & 1,56 & 1,55 \\
\hline 7 CEB & 0,51 & 0,54 & 0,00 & 0,00 & $-0,51$ & $-0,54$ \\
\hline 8 CEEE & 0,57 & 0,54 & 0,00 & 0,23 & $-0,57$ & $-0,32$ \\
\hline 9 CELESC & 0,63 & 0,60 & 0,52 & 0,48 & $-0,11$ & $-0,12$ \\
\hline 10 CELG & 0,63 & 0,60 & 2,60 & 1,94 & 1,97 & 1,34 \\
\hline 11 CELPA & 0,40 & 1,03 & 0,00 & 0,00 & $-0,40$ & $-1,03$ \\
\hline 12 CELPE & 0,63 & 0,76 & 0,52 & 0,10 & $-0,11$ & $-0,66$ \\
\hline 13 CELTINS & 0,57 & 0,49 & 0,00 & 0,00 & $-0,57$ & $-0,49$ \\
\hline 14 CEMAR & 0,57 & 0,22 & 0,25 & 0,14 & $-0,32$ & $-0,08$ \\
\hline 15 CEMAT & 0,74 & 0,49 & 0,00 & 0,00 & $-0,74$ & $-0,49$ \\
\hline 16 CEMIG & 0,69 & 0,87 & 0,06 & 0,06 & $-0,62$ & $-0,82$ \\
\hline 17 CEPISA & 0,63 & 0,33 & 0,16 & 1,65 & $-0,47$ & 1,32 \\
\hline 18 CERON & 0,46 & 0,49 & 0,00 & 0,43 & $-0,46$ & $-0,06$ \\
\hline 19 CFLO & 0,46 & 0,49 & 0,00 & 0,00 & $-0,46$ & $-0,49$ \\
\hline 20 CHESP & 0,46 & 0,49 & 0,00 & 0,00 & $-0,46$ & $-0,49$ \\
\hline $21 \mathrm{CJE}$ & 0,46 & 0,44 & 0,00 & 0,00 & $-0,46$ & $-0,44$ \\
\hline 22 MOCOCA & 0,17 & 0,16 & 0,00 & 0,00 & $-0,17$ & $-0,16$ \\
\hline 23 SANTA CRUZ & 0,11 & 0,11 & 0,00 & 0,00 & $-0,11$ & $-0,11$ \\
\hline 24 CNEE & 0,06 & 0,05 & 0,00 & 0,00 & $-0,06$ & $-0,05$ \\
\hline 25 COCEL & 0,00 & 0,00 & 0,00 & 0,00 & 0,00 & 0,00 \\
\hline 26 COELBA & 0,80 & 0,82 & 0,21 & 0,32 & $-0,59$ & $-0,50$ \\
\hline 27 COELCE & 0,63 & 0,60 & 0,00 & 0,01 & $-0,63$ & $-0,59$ \\
\hline 28 COOPERALIANÇA & 0,17 & 0,16 & 3,19 & 0,00 & 3,02 & $-0,16$ \\
\hline 29 COPEL & 0,97 & 0,87 & 0,00 & 0,00 & $-0,97$ & $-0,87$ \\
\hline 30 COSERN & 0,69 & 0,38 & 0,00 & 0,00 & $-0,69$ & $-0,38$ \\
\hline 31 CPEE & 0,29 & 0,27 & 0,00 & 1,17 & $-0,29$ & 0,89 \\
\hline 32 CPFL PIRATININGA & 0,11 & 0,98 & 0,55 & 0,46 & 0,44 & $-0,52$ \\
\hline 33 CPFL PAULISTA & 0,69 & 0,38 & 0,48 & 0,45 & $-0,21$ & 0,07 \\
\hline 34 CSPE & 0,51 & 0,49 & 2,96 & 0,00 & 2,45 & $-0,49$ \\
\hline 35 DEMEI & 0,51 & 0,49 & 0,00 & 0,00 & $-0,51$ & $-0,49$ \\
\hline 36 DMEPC & 0,23 & 0,22 & 0,00 & 0,00 & $-0,23$ & $-0,22$ \\
\hline 37 CELB & 0,40 & 0,44 & 0,00 & 0,00 & $-0,40$ & $-0,44$ \\
\hline 38 EDEVP & 0,06 & 0,11 & 0,00 & 0,00 & $-0,06$ & $-0,11$ \\
\hline $39 \mathrm{EEB}$ & 0,29 & 0,27 & 0,00 & 0,00 & $-0,29$ & $-0,27$ \\
\hline 40 JOAO CESA & 0,51 & 0,49 & 0,00 & 0,00 & $-0,51$ & $-0,49$ \\
\hline 41 EFLUL & 0,00 & 0,00 & 0,00 & 0,00 & 0,00 & 0,00 \\
\hline 42 ELEKTRO & 0,57 & 0,60 & 0,00 & 0,00 & $-0,57$ & $-0,60$ \\
\hline 43 ELETROACRE & 0,46 & 0,44 & 11,44 & 10,89 & 10,98 & 10,46 \\
\hline 44 ELETROCAR & 0,11 & 0,11 & 0,00 & 0,00 & $-0,11$ & $-0,11$ \\
\hline 45 ELETROPAULO & 0,86 & 0,87 & 0,00 & 0,00 & $-0,86$ & $-0,87$ \\
\hline 46 ELFSM & 0,17 & 0,16 & 0,00 & 0,00 & $-0,17$ & $-0,16$ \\
\hline $47 \mathrm{EMG}$ & 0,23 & 0,27 & 0,00 & 0,00 & $-0,23$ & $-0,27$ \\
\hline 48 ENERSUL & 0,63 & 0,33 & 0,00 & 0,00 & $-0,63$ & $-0,33$ \\
\hline 49 CENF & 0,46 & 0,49 & 0,00 & 0,00 & $-0,46$ & $-0,49$ \\
\hline 50 SAELPA & 0,80 & 0,54 & 0,00 & 0,00 & $-0,80$ & $-0,54$ \\
\hline 51 ESCELSA & 0,63 & 0,33 & 0,00 & 0,00 & $-0,63$ & $-0,33$ \\
\hline 52 ENERGIPE & 0,40 & 0,38 & 0,00 & 0,00 & $-0,40$ & $-0,38$ \\
\hline 53 HIDROPAN & 0,29 & 0,27 & 0,00 & 0,00 & $-0,29$ & $-0,27$ \\
\hline 54 IGUAÇU & 0,29 & 0,33 & 0,00 & 0,00 & $-0,29$ & $-0,33$ \\
\hline 55 LIGHT & 5,72 & 1,03 & 0,00 & 0,00 & $-5,72$ & $-1,03$ \\
\hline 56 MUX ENERGIA & 0,00 & 0,00 & 0,00 & 0,00 & 0,00 & 0,00 \\
\hline 57 RGE & 0,74 & 0,54 & 0,04 & 0,11 & $-0,70$ & $-0,43$ \\
\hline 58 SULGIPE & 0,51 & 0,49 & 7,16 & 1,99 & 6,64 & 1,50 \\
\hline 59 NOVA PALMA & 0,06 & 0,05 & 0,00 & 0,00 & $-0,06$ & $-0,05$ \\
\hline Máximo & 5,72 & 1,03 & 11,44 & 10,89 & 10,98 & 10,46 \\
\hline Mínimo & 0,00 & 0,00 & 0,00 & 0,00 & $-5,72$ & $-1,03$ \\
\hline Média & 0,61 & 0,44 & 0,62 & 0,44 & 0,01 & 0,00 \\
\hline
\end{tabular}


Aproximadamente $70 \%$ das empresas nesse segmento apresentam taxa de inadimplência menor do que $0,03 \%$ para apuração por meio das duas curvas de aging. Percebe-se apenas 7 empresas (AMPLA, CEAL, CELG, COPERALIANÇA, CSPE, ELETROACRE, SULGIPE) com taxas bem mais elevadas, como pode ser visto na Figura 4.36a (aging de 60) meses e Figura 4.36b (aging de 36 meses).

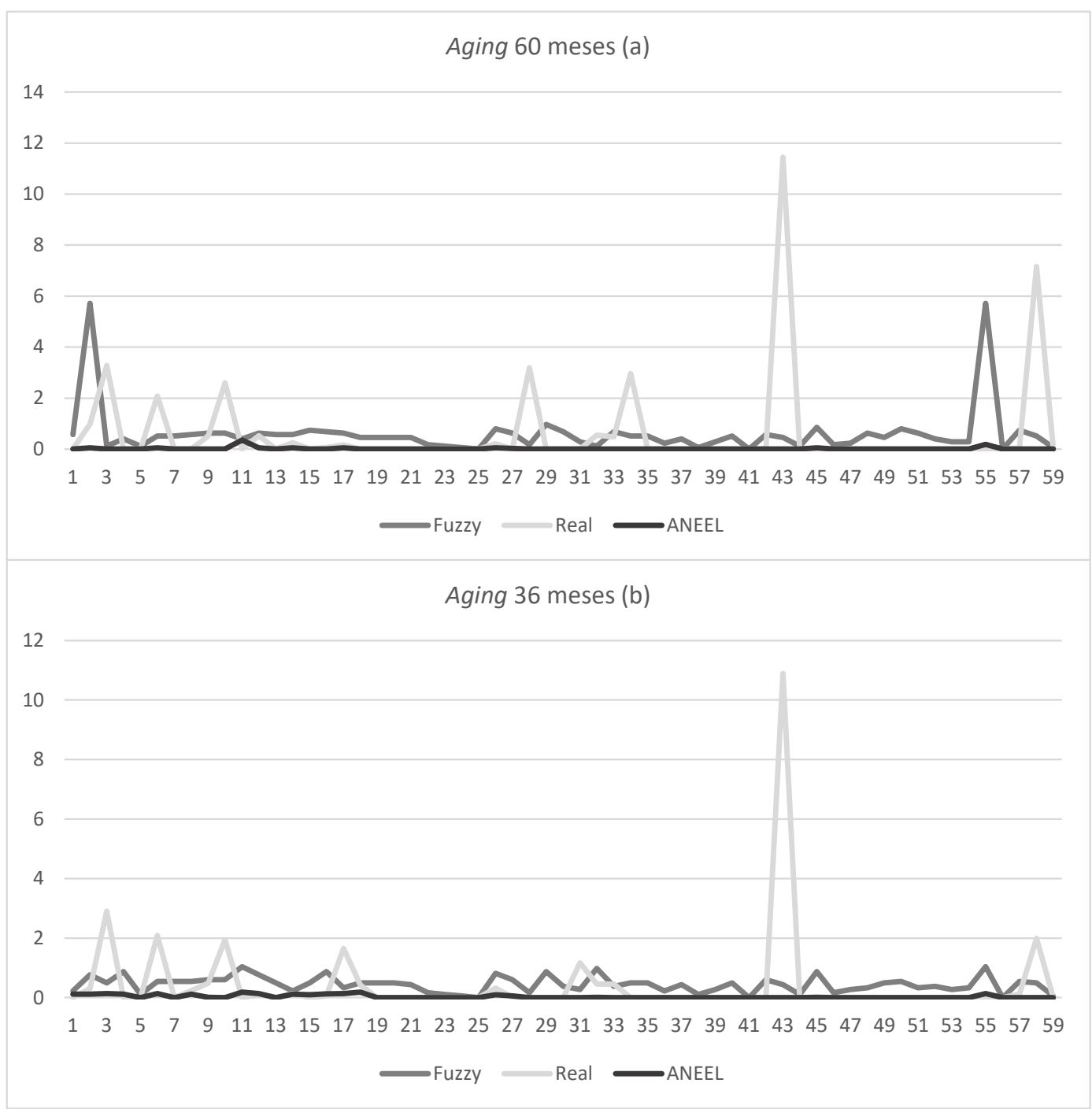

Figura 0.36 - Metas de inadimplência (\%): reais, estimativas modelo fuzzy, estimativas metodologia ANEEL. Em (a) aging de 60 meses e em (b) aging de 36 meses

As metas estabelecidas para o segmento de iluminação pública por meio da curva de aging de 36 meses ficaram sempre abaixo das metas estabelecidas por meio da curva de 60 meses, como pode ser visto na Figura 4.37. 


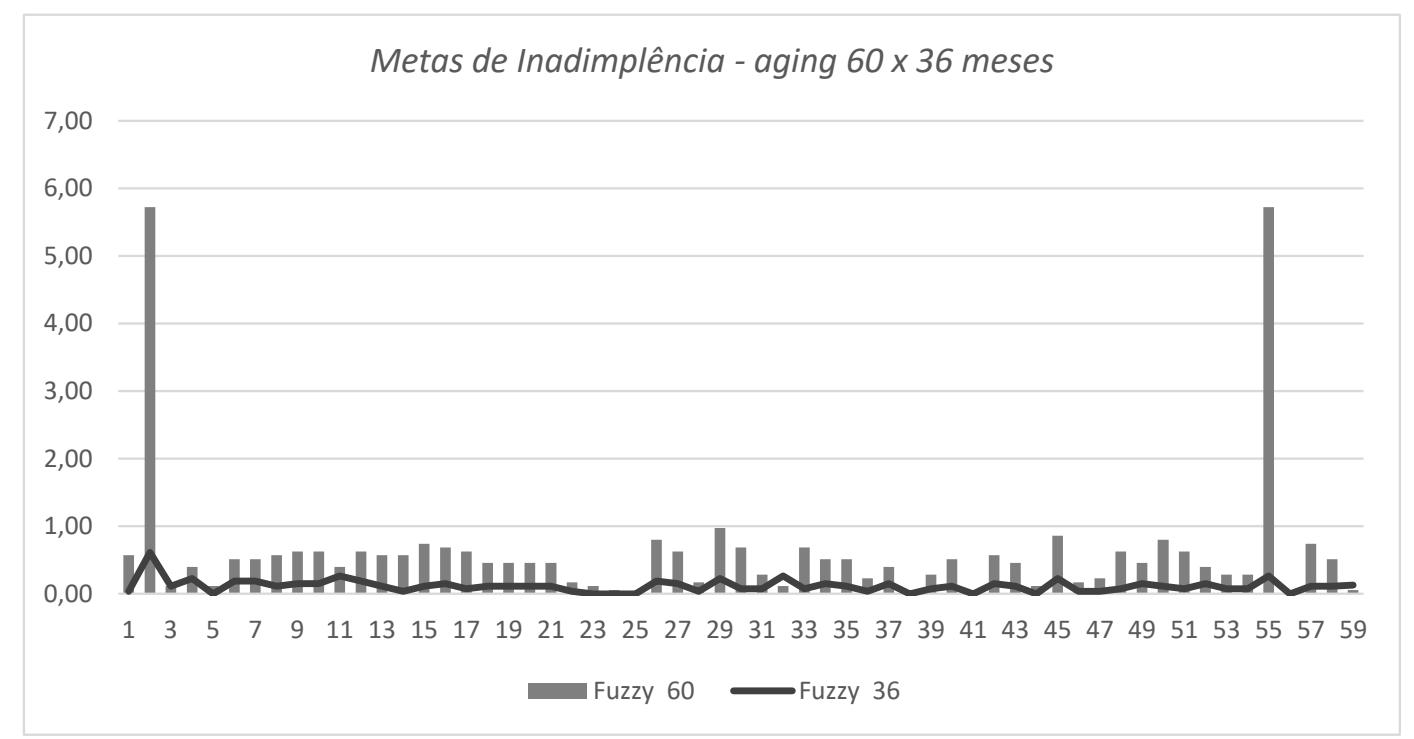

Figura 0.37 - Comparação das metas obtidas com curva de aging de 49 a 60 meses e de 25 a 36 meses

Novamente, cabe observar que, em classes onde inadimplência real é muito próxima de zero, desvios de até $0,5 \%$ (desvio absoluto - real menos previsto), pode significar uma magnitude de erro de mais de $100 \%$ em termos relativos (real dividido pelo previsto).

A Figura 4.38 permite melhor visualização da amplitude dos desvios absolutos. Observa-se que, ao se considerar a tanto a curva de aging de 60 meses (Figura 4.38a), quanto à curva de 36 meses (Figura 4.38b), o maior desvio encontrado foi da ordem de $11 \%$ (Eletroacre), obtido em relação à metodologia fuzzy e ANEEL. Os maiores desvios absolutos foram referentes às 7 empresas, já comentadas anteriormente, que apresentaram taxas reais muito acima das taxas médias desse segmento. 


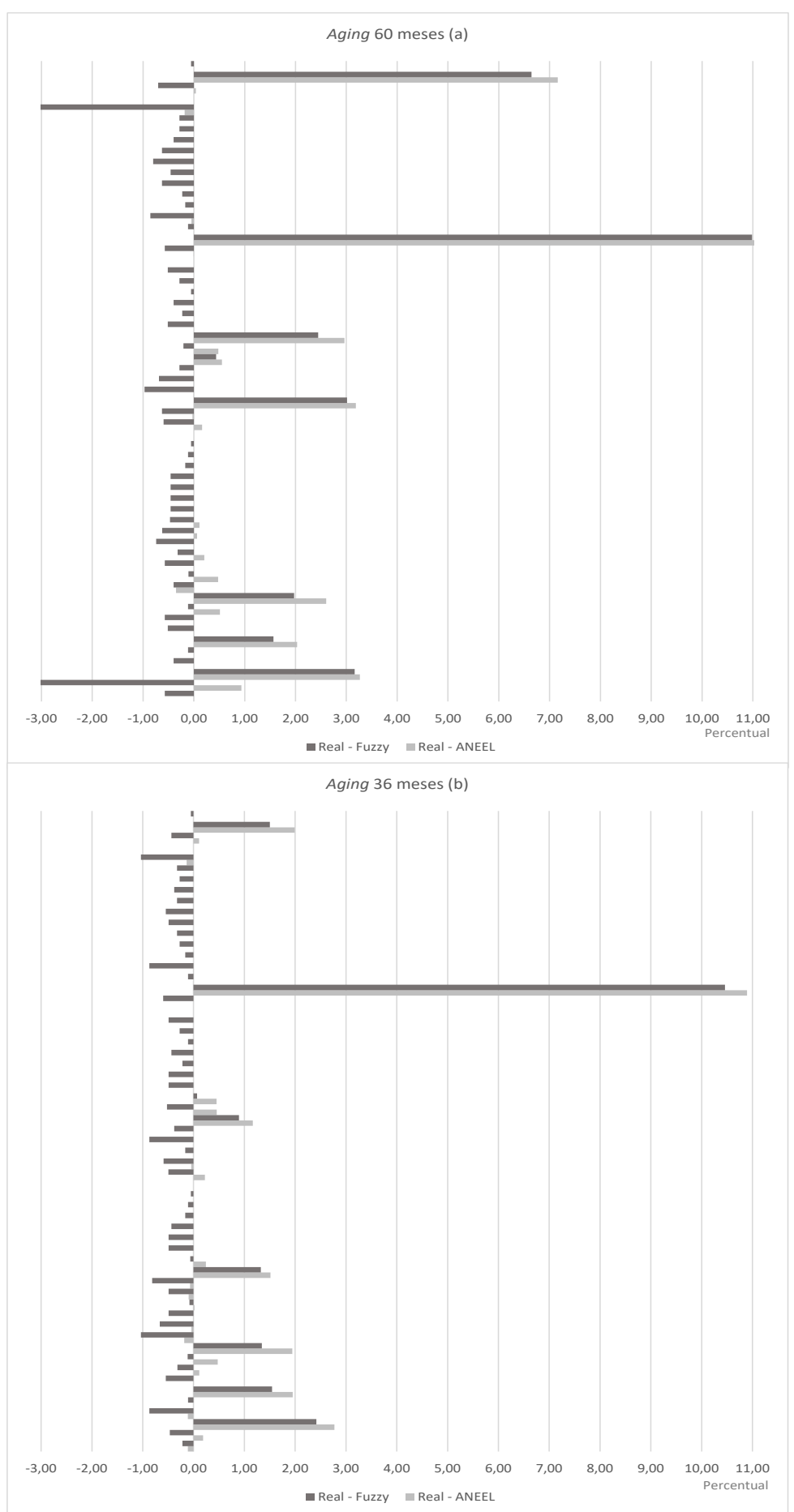

Figura 0.38 - Desvios \% Inadimplência real x fuzzy x ANEEL. Em (a) aging de 60 meses e em (b) aging de 36 meses 
De acordo com a análise qualitativa realizada Figuras 4.39 e 4.40, percebese que, especialmente no que se refere às empresas com taxas de inadimplência mais baixas, como já comentado para a classe rural e poder público, embora os desvios absolutos e especialmente os desvios relativos sejam altos em função da classe apresentar taxas reais muito próximas de zero, a grande maioria das empresas apresentaram previsões dentro das mesmas faixas da inadimplência real. Merece destaque o caso da Light, onde a metodologia fuzzy, considerando a curva de aging de 60 meses, indicou um nível moderado para o valor previsto, enquanto o real foi muito baixo. Tal resultado indica que, dado o porte e nível de vulnerabilidade onde essa empresa se insere, a taxa de inadimplência poderia ser superior à verificada, que está em $0,0 \%$.

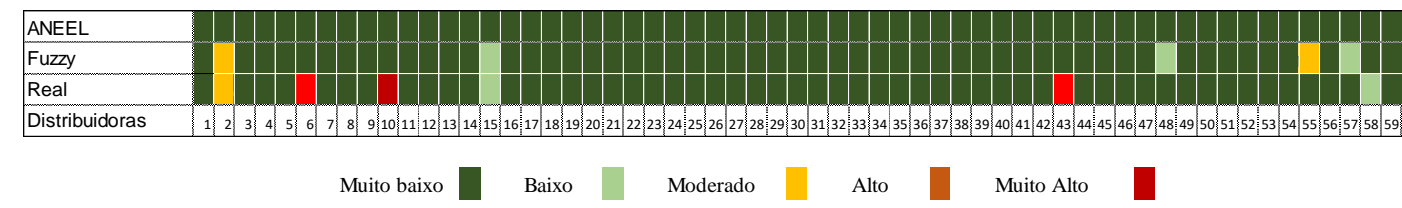

Figura 0.39 - Comparação da meta ANELL, com a meta estabelecida no modelo fuzzy e a inadimplência real declarada pelas distribuidoras de energia elétrica do Brasil - curva de aging de 49 a 60 meses

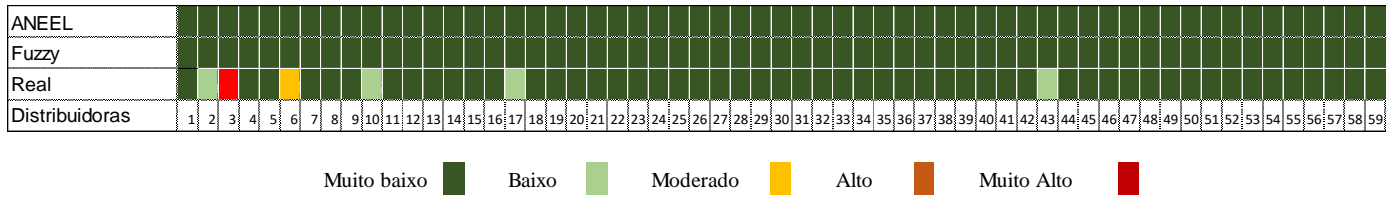

Figura 0.40 - Comparação da meta ANELL, com a meta estabelecida no modelo fuzzy e a inadimplência real declarada pelas distribuidoras de energia elétrica do Brasil - curva de aging de 25 a 36 meses

\subsection{7.}

\section{Classe serviço público}

A classe serviço público responde por $4,0 \%$ do consumo do mercado cativo do Brasil (Anuário Estatístico de 2020), tendo uma representação de apenas 0,1\% em termos do número de consumidores cativos. 
Para a classe serviço público, foi adotado o método de defuzzyficação do MoM - Mean of maximus para a curva de aging de 49 a 60 meses e de bissector para a curva de aging de 25 a 36 meses que minimizaram os erros quadráticos médios entre os valores previstos e realizados, como se visualiza por meio da Figura 4.41.

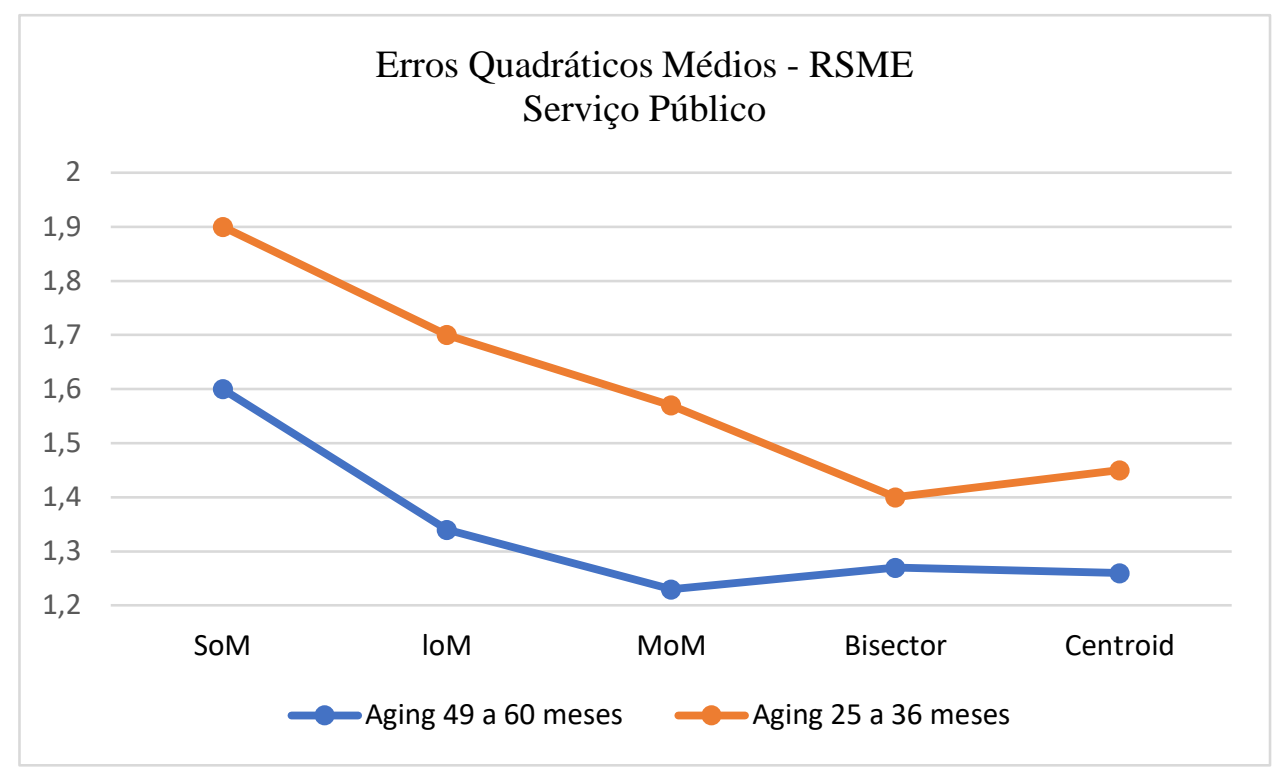

Figura 0.41 - Escolha do método de defuzzyficação para o serviço público curvas de aging de 49 a 60 meses e de 25 a 36 meses

Os resultados do modelo para a classe serviço público, considerando as duas curvas de aging, podem ser visualizados na Tabela 4.10. Embora esse segmento tenha apresentados desvios máximos bem elevados, o desvio médio para a curva de aging de 49 a 60 meses ficou em $-0,17 \%$, enquanto para a curva de 25 a 36 meses em $-0,28 \%$. 
Tabela 0.10 - Resultado modelo para a classe serviço público - valores \%

\begin{tabular}{|c|c|c|c|c|c|c|}
\hline \multirow{2}{*}{ Serviço Público } & \multicolumn{2}{|c|}{ Resultado Fuzzy } & \multicolumn{2}{|c|}{ Real } & \multicolumn{2}{|c|}{ Desvio Real menos previsto } \\
\hline & 49 a 60 meses & 25 a 36 meses & 49 a 60 meses & 25 a 36 meses & 49 a 60 meses & 25 a 36 meses \\
\hline 1 AES SUL & 0,56 & 0,62 & 0,00 & 2,86 & $-0,56$ & 2,24 \\
\hline 2 CEAM & 5,66 & 5,46 & 5,60 & 7,23 & $-0,05$ & 1,77 \\
\hline 3 AMPLA & 0,11 & 0,62 & 0,01 & 0,00 & $-0,10$ & $-0,61$ \\
\hline 4 BANDEIRANTE & 0,39 & 1,03 & 0,00 & 0,00 & $-0,39$ & $-1,03$ \\
\hline 5 CAIUÁ & 0,11 & 0,62 & 0,00 & 0,00 & $-0,11$ & $-0,62$ \\
\hline 6 CEAL & 0,50 & 0,82 & 0,78 & 3,05 & 0,28 & 2,23 \\
\hline 7 CEB & 0,50 & 1,03 & 0,00 & 0,00 & $-0,50$ & $-1,03$ \\
\hline 8 CEEE & 0,50 & 0,82 & 0,00 & 0,00 & $-0,50$ & $-0,82$ \\
\hline 9 CELESC & 0,56 & 0,82 & 0,02 & 0,09 & $-0,54$ & $-0,74$ \\
\hline 10 CELG & 0,56 & 0,82 & 1,05 & 0,93 & 0,49 & 0,11 \\
\hline 11 CELPA & 0,33 & 1,03 & 0,00 & 0,00 & $-0,33$ & $-1,03$ \\
\hline 12 CELPE & 0,62 & 0,93 & 0,71 & 0,85 & 0,09 & $-0,08$ \\
\hline 13 CELTINS & 0,56 & 0,82 & 0,00 & 0,00 & $-0,56$ & $-0,82$ \\
\hline 14 CEMAR & 0,56 & 0,62 & 1,07 & 1,43 & 0,51 & 0,81 \\
\hline 15 CEMAT & 0,73 & 0,72 & 11,32 & 10,31 & 10,59 & 9,59 \\
\hline 16 CEMIG & 0,67 & 0,93 & 0,07 & 0,14 & $-0,61$ & $-0,79$ \\
\hline 17 CEPISA & 0,62 & 0,72 & 0,03 & 1,45 & $-0,59$ & 0,73 \\
\hline 18 CERON & 0,45 & 0,72 & 0,00 & 0,00 & $-0,45$ & $-0,72$ \\
\hline 19 CFLO & 0,45 & 0,72 & 0,00 & 0,00 & $-0,45$ & $-0,72$ \\
\hline 20 CHESP & 0,45 & 0,72 & 0,00 & 0,00 & $-0,45$ & $-0,72$ \\
\hline $21 \mathrm{CJE}$ & 0,45 & 0,72 & 0,00 & 0,00 & $-0,45$ & $-0,72$ \\
\hline 22 MOCOCA & 0,16 & 0,62 & 0,00 & 0,00 & $-0,16$ & $-0,62$ \\
\hline 23 SANTA CRUZ & 0,11 & 0,62 & 0,00 & 0,00 & $-0,11$ & $-0,62$ \\
\hline 24 CNEE & 0,05 & 0,62 & 0,00 & 0,00 & $-0,05$ & $-0,62$ \\
\hline 25 COCEL & 0,00 & 0,62 & 0,00 & 0,00 & 0,00 & $-0,62$ \\
\hline 26 COELBA & 0,79 & 0,93 & 0,09 & 1,00 & $-0,70$ & 0,07 \\
\hline 27 COELCE & 0,62 & 0,82 & 0,00 & 0,16 & $-0,62$ & $-0,66$ \\
\hline 28 COOPERALIANÇA & 0,16 & 0,62 & 0,00 & 0,00 & $-0,16$ & $-0,62$ \\
\hline 29 COPEL & 0,90 & 0,93 & 0,04 & 0,12 & $-0,86$ & $-0,80$ \\
\hline 30 COSERN & 0,62 & 0,72 & 0,00 & 0,00 & $-0,62$ & $-0,72$ \\
\hline 31 CPEE & 0,28 & 0,72 & 0,00 & 0,96 & $-0,28$ & 0,24 \\
\hline 32 CPFL PIRATININGA & 0,11 & 1,85 & 0,30 & 0,23 & 0,19 & $-1,62$ \\
\hline 33 CPFL PAULISTA & 0,67 & 0,72 & 0,34 & 0,37 & $-0,33$ & $-0,35$ \\
\hline 34 CSPE & 0,50 & 0,82 & 2,22 & 0,00 & 1,71 & $-0,82$ \\
\hline 35 DEMEI & 0,45 & 0,72 & 0,00 & 0,00 & $-0,45$ & $-0,72$ \\
\hline 36 DMEPC & 0,22 & 0,62 & 0,00 & 0,00 & $-0,22$ & $-0,62$ \\
\hline 37 CELB & 0,39 & 0,72 & 0,00 & 0,00 & $-0,39$ & $-0,72$ \\
\hline 38 EDEVP & 0,05 & 0,62 & 0,00 & 0,00 & $-0,05$ & $-0,62$ \\
\hline $39 \mathrm{EEB}$ & 0,28 & 0,72 & 0,00 & 0,00 & $-0,28$ & $-0,72$ \\
\hline 40 JOAO CESA & 0,50 & 0,82 & 0,00 & 0,00 & $-0,50$ & $-0,82$ \\
\hline 41 EFLUL & 0,00 & 0,62 & 0,00 & 0,00 & 0,00 & $-0,62$ \\
\hline 42 ELEKTRO & 0,56 & 0,82 & 0,00 & 0,00 & $-0,56$ & $-0,82$ \\
\hline 43 ELETROACRE & 0,39 & 0,72 & 0,15 & 1,94 & $-0,24$ & 1,22 \\
\hline 44 ELETROCAR & 0,11 & 0,62 & 0,00 & 0,00 & $-0,11$ & $-0,62$ \\
\hline 45 ELETROPAULO & 0,84 & 0,93 & 0,00 & 0,00 & $-0,85$ & $-0,93$ \\
\hline 46 ELFSM & 0,16 & 0,62 & 0,00 & 0,00 & $-0,16$ & $-0,62$ \\
\hline $47 \mathrm{EMG}$ & 0,22 & 0,62 & 0,00 & 0,00 & $-0,22$ & $-0,62$ \\
\hline 48 ENERSUL & 0,62 & 0,72 & 0,00 & 0,00 & $-0,62$ & $-0,72$ \\
\hline $49 \mathrm{CENF}$ & 0,45 & 0,72 & 0,00 & 0,00 & $-0,45$ & $-0,72$ \\
\hline 50 SAELPA & 0,73 & 0,82 & 0,18 & 0,03 & $-0,55$ & $-0,79$ \\
\hline 51 ESCELSA & 0,62 & 0,72 & 0,00 & 0,01 & $-0,62$ & $-0,71$ \\
\hline 52 ENERGIPE & 0,33 & 0,72 & 0,00 & 0,00 & $-0,33$ & $-0,72$ \\
\hline 53 HIDROPAN & 0,28 & 0,62 & 0,00 & 0,00 & $-0,28$ & $-0,62$ \\
\hline 54 IGUAÇU & 0,28 & 0,72 & 0,00 & 0,00 & $-0,28$ & $-0,72$ \\
\hline 55 LIGHT & 5,66 & 1,03 & 0,92 & 0,02 & $-4,73$ & $-1,01$ \\
\hline 56 MUX ENERGIA & 0,00 & 0,62 & 0,00 & 0,00 & 0,00 & $-0,62$ \\
\hline 57 RGE & 0,73 & 0,82 & 0,00 & 0,10 & $-0,73$ & $-0,72$ \\
\hline 58 SULGIPE & 0,50 & 0,82 & 0,03 & 0,02 & $-0,47$ & $-0,80$ \\
\hline 59 NOVA PALMA & 0,05 & 0,62 & 0,00 & 0,00 & $-0,05$ & $-0,62$ \\
\hline Máximo & 5,66 & 5,46 & 11,32 & 10,31 & 10,59 & 9,59 \\
\hline Mínimo & 0,00 & 0,62 & 0,00 & 0,00 & $-4,73$ & $-1,62$ \\
\hline Média & 0,59 & 0,85 & 0,42 & 0,56 & $-0,17$ & $-0,28$ \\
\hline
\end{tabular}


Assim como na classe de iluminação pública, aproximadamente $70 \%$ das empresas nesse segmento apresentam taxa de inadimplência menor do que 0,03\% para apuração por meio das duas curvas de aging. Percebe-se apenas 3 empresas (CEAM, CEMAT e CSPE) com taxas bem mais elevadas, como pode ser visto na Figura 4.42a (aging de 60) meses e Figura 4.42b (aging de 36 meses).

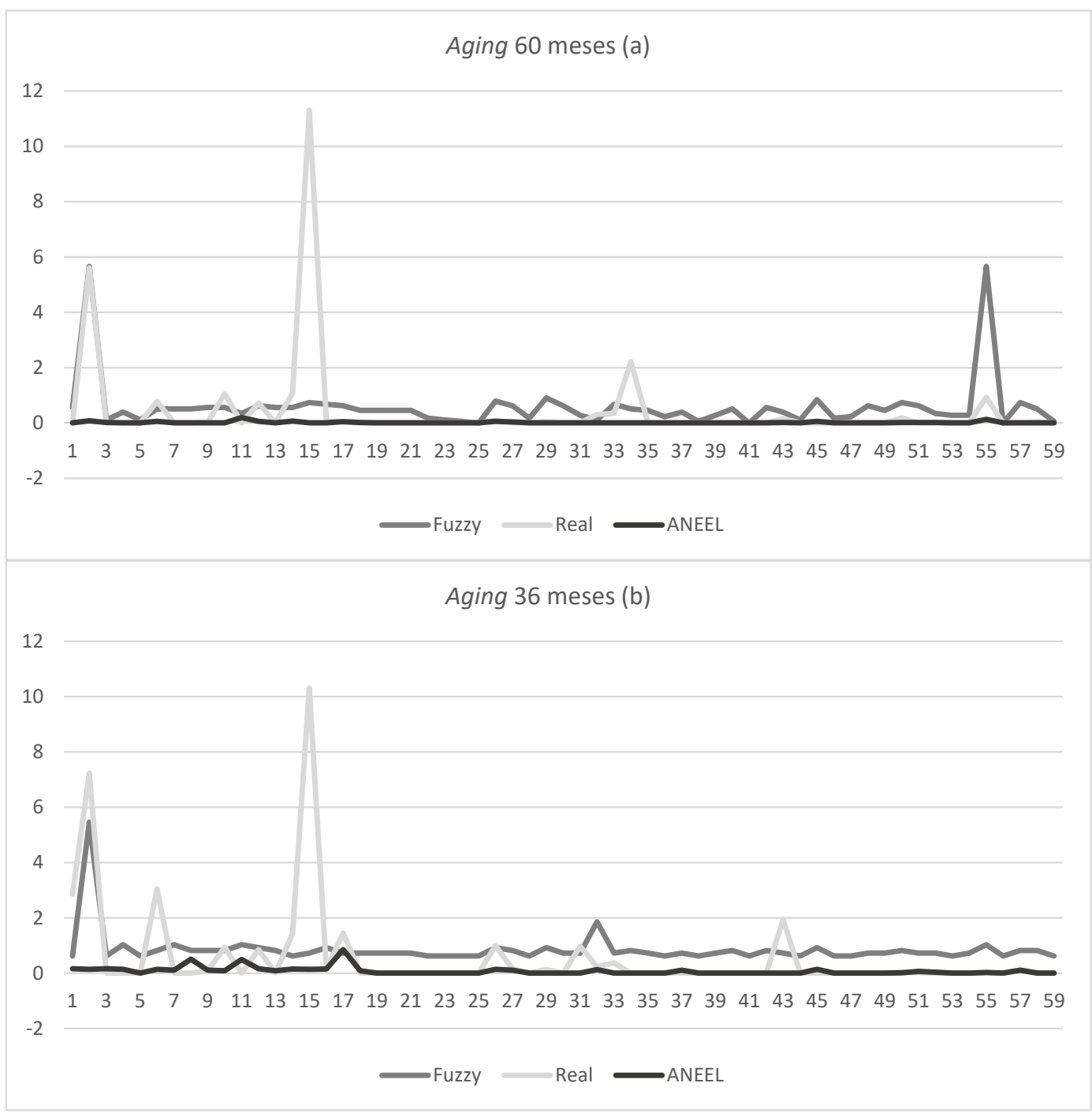

Figura 0.42 - Metas de inadimplência (\%): reais, estimativas modelo fuzzy, estimativas metodologia ANEEL. Em (a) aging de 60 meses e em (b) aging de 36 meses

As metas estabelecidas para o segmento serviço público por meio da curva de aging de 36 meses ficaram sempre abaixo das metas estabelecidas por meio da curva de 60 meses, como pode ser visto na Figura 4.43. 


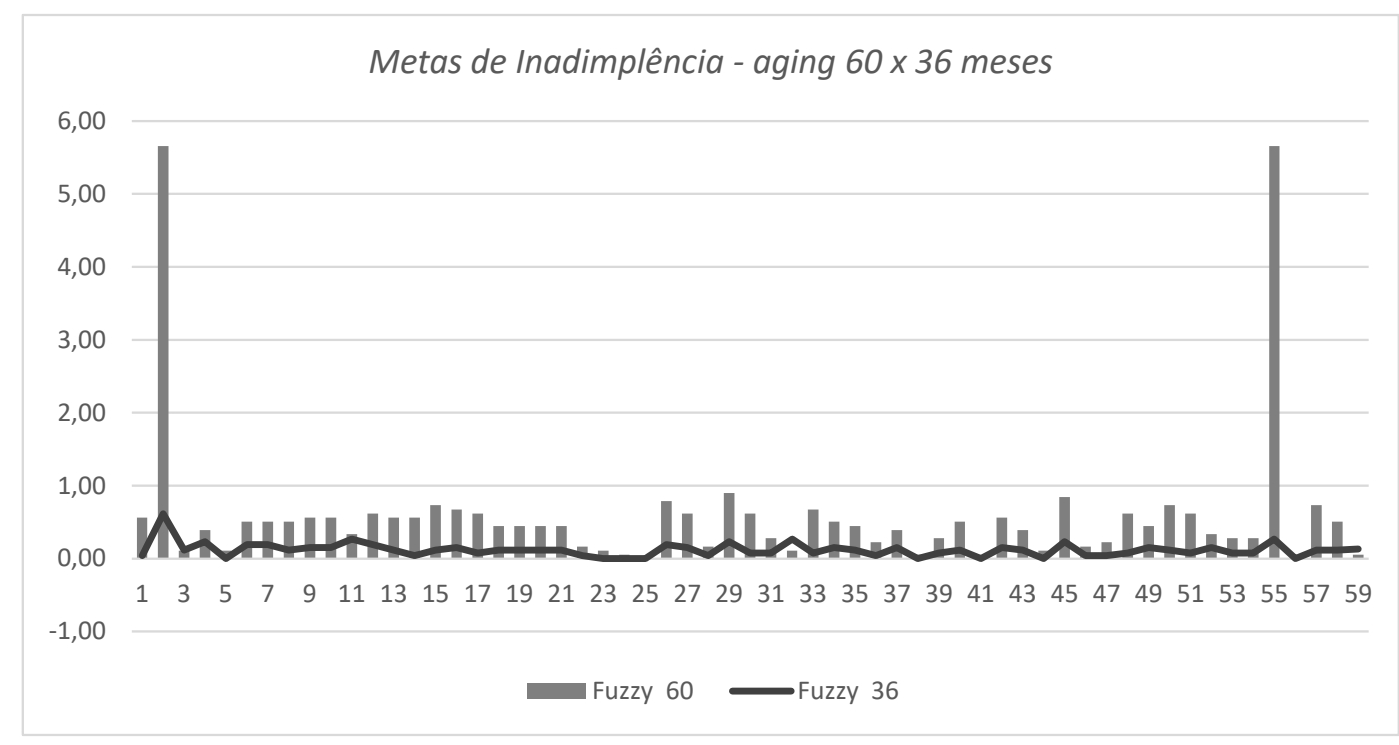

Figura 0.43 - Comparação das metas obtidas com curva de aging de 49 a 60 meses e de 25 a 36 meses

Novamente, cabe observar que, em classes onde inadimplência real é muito próxima de zero, desvios de até $0,5 \%$ (desvio absoluto - real menos previsto), pode significar uma magnitude de erro de mais de $100 \%$ em termos relativos (real dividido pelo previsto).

A Figura 4.44 permite melhor visualização da amplitude dos desvios absolutos. Observa-se que, ao se considerar a tanto a curva de aging de 60 meses, quanto à curva de 36 meses, o maior desvio encontrado foi da ordem de 10,5\% (CEMAT), obtido em relação à metodologia fuzzy e ANEEL (Figura 4.44a com aging de 60 meses e Figura 4.44b com aging de 36 meses). Os maiores desvios absolutos foram referentes às 3 empresas, já comentadas anteriormente, que apresentaram taxas reais muito acima das taxas médias desse segmento. 


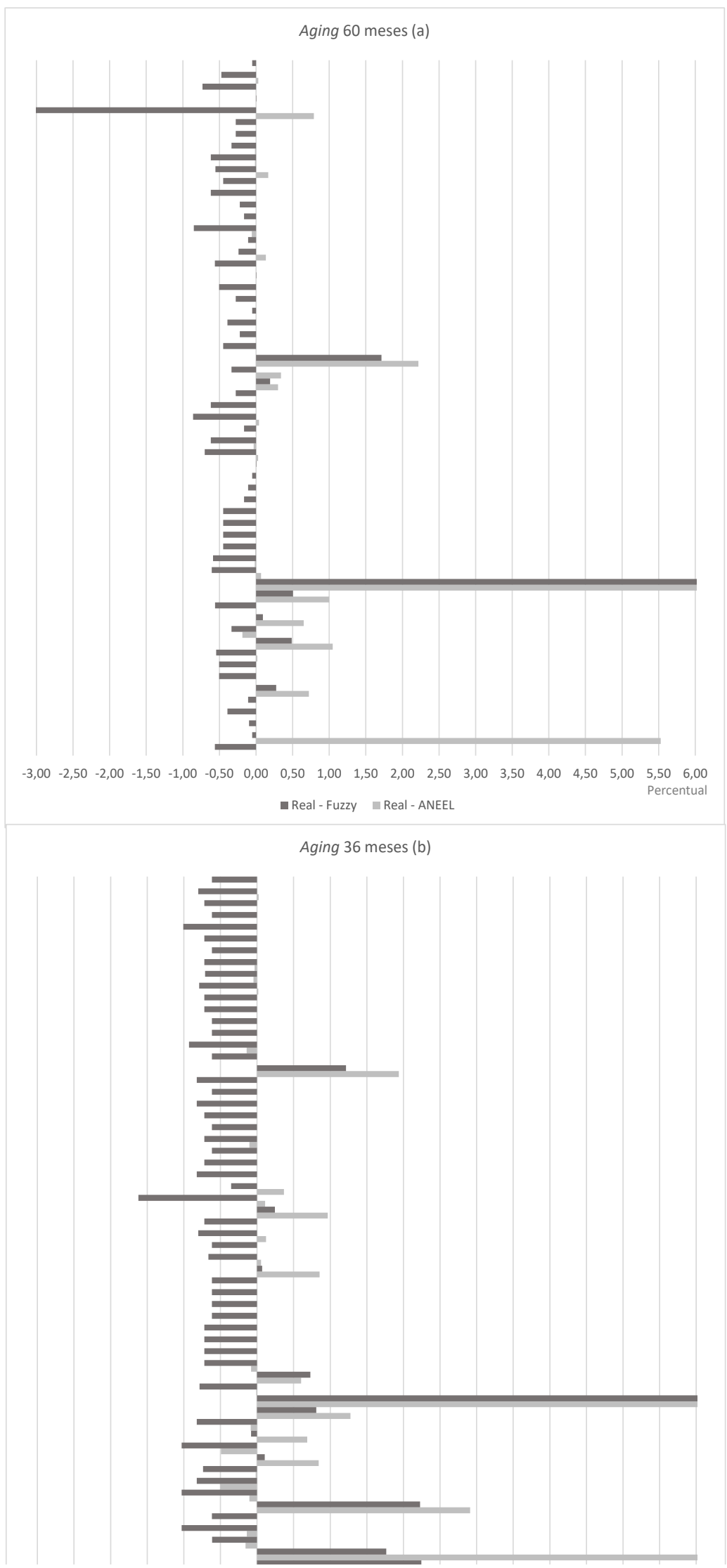

Figura 0.44 - Desvios \% Inadimplência real x fuzzy x ANEEL. Em (a) aging de 60 meses e em (b) aging de 36 meses 
De acordo com a análise qualitativa realizada (Figura 4.45 e 4.46), percebese que, especialmente no que se refere às empresas com taxas de inadimplência mais baixas, como já comentado para a classe rural e poder público, embora os desvios absolutos e especialmente os desvios relativos sejam altos em função da classe apresentar taxas reais muito próximas de zero, a grande maioria das empresas apresentaram previsões dentro das mesmas faixas da inadimplência real. Merece destaque, assim como na classe iluminação pública, o caso da Light, onde a metodologia fuzzy, considerando a curva de aging de 60 meses, indicou um nível moderado para o valor previsto, enquanto o real foi muito baixo. Tal resultado indica que, dado o porte e nível de vulnerabilidade onde essa empresa se insere, a taxa de inadimplência poderia ser superior à verificada, que está em $0,9 \%$.

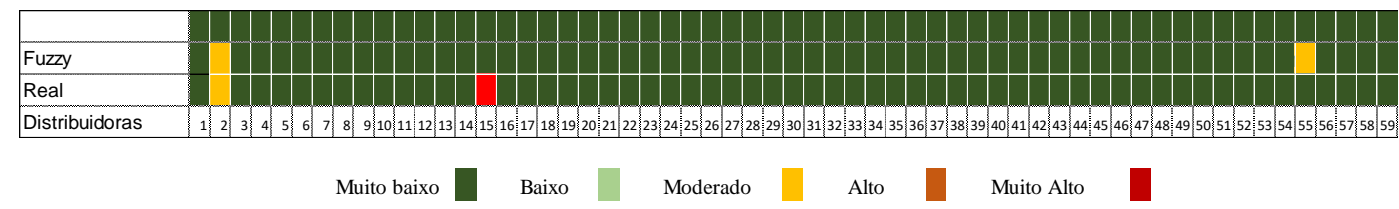

Figura 0.45 - Comparação da meta ANELL, com a meta estabelecida no modelo fuzzy e a inadimplência real declarada pelas distribuidoras de energia elétrica do Brasil - curva de aging de 49 a 60 meses

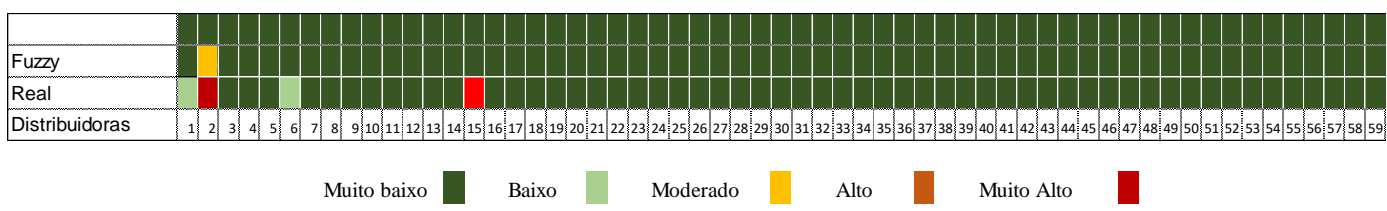

Figura 0.46 - Comparação da meta ANELL, com a meta estabelecida no modelo fuzzy e a inadimplência real declarada pelas distribuidoras de energia elétrica do Brasil - curva de aging de 25 a 36 meses

\subsection{8. \\ Discussão dos resultados}

Os resultados da utilização da Inferência fuzzy para a obtenção das metas regulatórias da inadimplência, especialmente para as classes residencial, industrial comercial e rural, mostraram que é possível persistir nesse caminho, uma vez que a metodologia proposta desvincula-se da metodologia de perdas não técnicas, mantendo os princípios da regulação por incentivo e captando a heterogeneidade das diversas áreas de concessão. A metodologia de Inferência 
fuzzy trouxe resultados diretos, que ficaram muito próximos aos obtidos pela metodologia da ANEEL, sem, contudo, fazer uso de métodos ad hoc, uma das principais críticas à metodologia de perdas não técnicas.

Foram testadas no modelo fuzzy duas curvas de aging: i) de 45 a 60 meses de faturamentos não recebidos em relação à data de referência (dez/2016), que é utilizada na metodologia atual e ii) de 25 a 36 meses de faturamentos não recebidos em relação à data de referência (dez/2016), período sugerido pelos agentes de distribuição durante a realização das Consultas Públicas realizadas pela ANEEL. Observa-se, pelas seções discutidas ao longo do trabalho, que os erros quadráticos médios, que indicam o poder de assertividade do modelo, foram sempre menores no modelo que utilizou a curva de aging de um maior período, ou seja, dos faturamentos não recebidos entre 49 e 60 meses da data de referência.

Ainda no que se refere às curvas de aging, cabe ressaltar que, apesar de haver algumas diferenças significativas entre as duas curvas, entende-se que há outros pontos de melhorias para a adoção do modelo fuzzy que trariam melhores resultados do que a adoção de uma nova curva de aging. Portanto, poder-se-ia manter a curva de aging de 49 a 60 meses, conforme metodologia atual.

Quanto à construção do modelo, merece destaque a utilização de apenas duas entradas na especificação da metodologia de inferência fuzzy. Essas entradas, constituídas por variáveis de extrema importância para a correta classificação das distribuidoras nas diferentes regiões do país, contribuíram para simplificar a implantação do modelo, ao mesmo tempo que garantiram a comparabilidade entre as distribuidoras, bem como permitiram a manutenção da prática da regulação por incentivos.

A escolha das variáveis, que compõe essas duas entradas, é parte fundamental para a eficiência do modelo. Em trabalhos futuros, pode-se discutir o tema com as próprias distribuidoras de energia elétrica, agregando mais valor à análise, visto a experiência acumulada por esses agentes.

No que se refere à definição das regras, a utilização da própria base de dados forneceu uma boa experiência, mas também pode-se avaliar o estabelecimento de regras por meio de pesquisa junto a especialistas das próprias distribuidoras.

Outra questão que merece especial atenção se trata das distribuidoras de energia que possuem taxas de inadimplência real muito próximas de zero. Acredita-se que tais empresas devam ter um tratamento especial, pois já se 
encontram em um patamar muito próximo do nível ótimo de eficiência e, nesse caso, cabe avaliar se serão capazes de reduzir ainda mais seus patamares de inadimplência ou se devem ter o nível atual totalmente reconhecido como incentivo para que outras distribuidoras persigam tais metas. Esse fato ocorre sobretudo nas classes rural, poder público, iluminação pública e serviço público. Para as classes relacionadas ao setor público, poder-se-ia pensar em penalizações maiores para o caso de inadimplência com o objetivo de incentivar o pagamento em tempo real, o que, vindo do setor público, seria o mínimo esperado. Dessa forma, taxas menores de inadimplência (muito próximas de zero) poderiam ser integralmente reconhecidas nas tarifas dos consumidores.

\section{4. Considerações sobre o capítulo}

Os capítulos anteriores trouxeram conceitos da regulação por incentivo, as fragilidades apuradas na metodologia atualmente empregada para a definição das metas regulatórias de inadimplência de energia, deixando clara a necessidade de se buscar uma nova metodologia, desatrelada da metodologia de apuração da Perdas Não Técnicas - PNT. Buscou-se demonstrar que é possível se desenvolver uma nova metodologia em consonância com os princípios da regulação por incentivo por meio de um modelo simples e robusto, específico para a inadimplência, cuja base se estrutura levando-se em consideração o desempenho das próprias distribuidoras no contexto socioeconômico em que se inserem.

O presente capítulo complementa o capítulo 3 , onde foi apresentado o modelo conceitual de inferência fuzzy, na medida em que detalha a aplicabilidade da metodologia desenvolvida para o caso específico das distribuidoras de energia elétrica brasileiras. Nesse cenário, foram discutidos os resultados trazidos pelo modelo proposto em comparação com os dados reais de inadimplência das faturas das distribuidoras em um período de 49 a 60 meses e de 25 a 36 meses da data de referência (2016), bem como em comparação com as metas apuradas pela ANEEL.

Dessa forma, este capítulo permitiu o atendimento ao quarto e último objetivo específico, qual seja, demonstrar a aplicabilidade de um modelo alternativo e seus diferenciais em relação ao modelo atualmente adotado pela ANEEL. 
O próximo capítulo apresentará as principais conclusões do trabalho e algumas propostas de estudos futuros, bem como possíveis soluções de melhorias para a adoção de um modelo com base em inferência fuzzy para o estabelecimento das metas regulatórias de inadimplência das distribuidoras brasileiras. 


\section{5 \\ Conclusão}

A definição de metas regulatórias de inadimplência é um tema de extrema importância para as distribuidoras de energia elétrica, para as agências reguladoras (ANEEL no caso brasileiro) e para todos os consumidores, visto que tem forte impacto sobre as tarifas de energia. Encontrar uma metodologia robusta, de simples implementação e que seja capaz de captar a heterogeneidade existente nas áreas de concessão, mantendo o incentivo à eficiência e à inovação é um grande desafio.

No Brasil, a atual metodologia proposta pela ANEEL para a definição de metas regulatórias de inadimplência está atrelada à metodologia de perdas não técnicas e não considera algumas variáveis importantes no contexto da inadimplência das faturas de energia, sendo alvo de críticas pelas distribuidoras e pelo meio acadêmico. Apesar de aderente aos princípios da regulação por incentivo, a metodologia utilizada provoca situações de desigualdade na comparação entre as distribuidoras ao aplicar uma mediana móvel para a determinação da meta de inadimplência, causando uma diferenciação entre o número de distribuidoras comparadas para composição das metas individuais de cada distribuidora.

Nesse contexto, o presente trabalho buscou encontrar uma metodologia que seguisse premissas fundamentais, sendo capaz de: manter os princípios da regulação por incentivo, que podem ser considerados como um ganho proveniente da evolução das metodologias propostas pela ANEEL; captar a heterogeneidade das áreas de concessão das distribuidoras; fornecer tratamento isonômico para todas as distribuidoras; basear-se em metodologia robusta e de eficácia comprovada; utilizar-se da base de dados de inadimplência das próprias distribuidoras, extraindo aprendizado e padrões observados e; ser de simples implementação.

Diante do exposto, entende-se que uma metodologia independente para a definição das metas regulatórias de inadimplência tende a beneficiar todos os agentes envolvidos. 
A inferência fuzzy, por se tratar de uma metodologia de simples implementação, muito usada em ambientes com algum grau de incerteza e que permite a implementação de regras oriundas do desempenho das distribuidoras em diferentes conjunturas socioeconômicas, se constitui em uma poderosa ferramenta a ser utilizada para a definição das metas regulatórias de inadimplência.

O estudo realizado mostrou que é possível o desenvolvimento de um modelo específico para a determinação das metas regulatórias de inadimplência e que a metodologia de inferência fuzzy pode atender às premissas necessárias para garantir os princípios da regulação por incentivo e o estabelecimento de metas regulatórias de inadimplência coerentes com a realidade de cada distribuidora. $A$ referida metodologia trouxe resultados diretos, que ficaram muito próximos aos obtidos pela metodologia da ANEEL, sem, contudo, fazer uso de métodos ad hoc, uma das principais críticas à metodologia de perdas não técnicas à qual a atual metodologia de apuração das metas regulatórias de inadimplência está atrelada.

Ressalta-se, no entanto, que há diversas melhorias que podem ser implementadas para aumentar a eficácia do uso da inferência fuzzy na determinação das metas regulatórias de inadimplência.

Para trabalhos futuros, tendo em vista a importância da escolha das variáveis na estruturação do modelo, pode-se discutir o tema com as próprias distribuidoras de energia elétrica, agregando mais valor à análise, visto a experiência acumulada por elas. Alternativamente, de forma a tornar a metodologia mais robusta, mantendo-se a simplicidade de implementação e o foco na própria base de dados, pode-se utilizar, no lugar da média simples das variáveis normalizadas para a constituição das entradas do modelo, a análise de componentes principais ou análise fatorial, de forma que cada variável seja ponderada por sua representatividade e não seja necessário fazer uma análise prévia de quais variáveis deveriam ser mantidas para a constituição das entradas do modelo.

No que tange ao processo de formação das regras, no presente trabalho, optou-se por estabelecer as regras somente por meio da base de dados, o que gera algumas lacunas em função de possíveis regras que não encontram representatividade na base de dados. Dessa forma, em trabalhos futuros, podese preencher as lacunas, criando regras fundamentadas na mesma lógica de 
formação das regras oriundas da base, constituindo um modelo híbrido entre os conhecimentos advindos dos próprios dados e aqueles provenientes da intervenção de um especialista.

Ainda no que se refere a trabalhos futuros, pode-se avaliar a construção de fatores específicos para as classes ligadas ao setor público, visto que a vulnerabilidade para estes segmentos passa por questões distintas dos demais. Alternativamente, para todo o segmento público, poder-se-ia pensar em penalizações maiores para o caso de inadimplência com o objetivo de incentivar o pagamento em tempo real, o que, vindo do setor público, seria o mínimo esperado. Dessa forma, taxas menores de inadimplência (muito próximas de zero) poderiam ser integralmente reconhecidas nas tarifas dos consumidores, sem a necessidade do estabelecimento de metas regulatórias de inadimplência.

Por fim, deve-se mencionar o fato de que um modelo para a definição das metas regulatórias de inadimplência tem implicações políticas na medida em que influência direta ou indiretamente na renda disponível da população, especialmente daqueles que tem maior percentual da renda comprometido com o pagamento da conta de energia, que poderá ser impactada pela parcela de receita irrecuperável transferida para as tarifas de todos os consumidores.

Adicionalmente, um modelo bem fundamentado para definição das metas regulatórias de inadimplência pode funcionar como incentivo aos investimentos e eficiência das distribuidoras de energia, sendo, portanto, um tema que merece atenção especial por parte do órgão regulador. 
6

\section{Referências bibliográficas}

AMENDOLA, M; SOUZA, A.L; BARROS, L.C. Manual do uso da teoria dos conjuntos Fuzzy no MATLAB 6.5. São Paulo, 2005. UNICAMP.

ANEEL - AGÊNCIA NACIONAL DE ENERGIA ELÉTRICA. Nota Técnica no 27/SRM/SGT/SPE/SRD-2019/ANEEL. Abertura de Consulta Pública visando coletar subsídios para a Avaliação de Resultado Regulatório (ARR) da regulação por incentivos do segmento de distribuição de energia elétrica, avaliando o ambiente regulatório quanto à utilização de tecnologias na melhoria do serviço, na eficiência energética e no desenvolvimento do negócio (item no 31 da Agenda Regulatória 2018/2019. Consulta Pública 003/2019. Brasília: Superintendência de Regulação de Mercado; Superintendência de Gestão Tarifária ; Superintendência de Pesquisa e Desenvolvimento e Eficiência Energética ; Superintendência de Regulação da Distribuição, 2019.Disponível em http://www.aneel.gov.br/audiencias-publicas >. Acesso em: 22 mar.19.

ANEEL - AGÊNCIA NACIONAL DE ENERGIA ELÉTRICA. Procedimentos de Regulação Tarifária - PRORET - Submodulo 2.2 Custos Operacionais. Disponível em: < http://www2.aneel.gov.br/cedoc/aren2018806_Proret_Submod_2_2_v3.pd f >. Acesso em: 14 jan 21.

ANEEL - AGÊNCIA NACIONAL DE ENERGIA ELÉTRICA. Procedimentos de Regulação Tarifária - PRORET - Submodulo 2.2 A - Custos Operacionais e Receitas Irrecuperáveis. Disponível em: < http://www2.aneel.gov.br/cedoc/aren2018806_Proret_Submod_2_2A_v2.p df $>$. Acesso em: 14 jan 21.

ANEEL - AGÊNCIA NACIONAL DE ENERGIA ELÉTRICA. Nota Técnica no 107/2015-SGT/SRM/ANEEL. Metodologia de tratamento regulatório para receitas irrecuperáveis. Brasília: Superintendência de gestão tarifária, 2015.Disponível em http://www.aneel.gov.br/audiencias-publicas >. Acesso em: 07 nov.18.

ANEEL - AGÊNCIA NACIONAL DE ENERGIA ELÉTRICA. Nota Técnica no 106/2015-SGT/SRM/ANEEL. Metodologia de tratamento regulatório para perdas não técnicas de energia elétrica. Brasília: Superintendência de Gestão Tarifária, 2015. Disponível em http://www.aneel.gov.br/audiencias-publicas. Acesso em: 07 nov.18.

ANEEL - AGÊNCIA NACIONAL DE ENERGIA ELÉTRICA. Nota Técnica no 188/2014-SRE/ANEEL. Atualização do índice de complexidade socioeconômica para definição do nível regulatório de perdas não 
técnicas. Brasília: Superintendência de Regulação Econômica, 2014. Disponível em http://www.aneel.gov.br/audiencias-publicas. Acesso em: 07 abr. 21.

ANEEL - AGÊNCIA NACIONAL DE ENERGIA ELÉTRICA. Nota Técnica no 188/2014-SRE/ANEEL. Resolução Normativa no 414, de 9 de setembro de 2010. Brasília. Disponível em http://www2.aneel.gov.br/cedoc/ren2010414.pdf. Acesso em: 07 nov.18.

ANEEL - AGÊNCIA NACIONAL DE ENERGIA ELÉTRICA. Contribuições ABRADEE. Consulta Pública no 18/2019. Brasília: Superintendência de Regulação Econômica e Estudos de Mercado, 2019. Disponível em https://www.aneel.gov.br/consultas-publicas-antigas. Acesso em: $07 \mathrm{fev}$ 21.

ARAÚJO, A. C. M. Perdas e inadimplência na atividade de distribuição de energia elétrica no brasil. Rio de Janeiro, 2007, 116 p. Tese (doutorado) - Coordenação dos programas de pós-graduação de engenharia - COPPE. Universidade Federal do Rio de Janeiro.

ARAÚJO, R.V; MARTINEZ, L; MOREIRA, F.A. Statistical Analysis of the Relationship Between Payment Behavior Variables and Delinquency in Electricity Consumption. Department of Electrical Engineering Universidade Federal da Bahia Salvador, Brazil. 2014 IEEE.

EPE - EMPRESA DE PESQUISA ENERGÉTICA. Anuário Estatístico de Energia Elétrica 2020 - ano base 2019. Disponível em https://www.epe.gov.br/pt/publicacoes-dados-abertos/publicacoes/anuarioestatistico-de-energia-eletrica. Acesso em: 07 fev 21.

GOMIDE, F.; GUDWIN, R.; TANSCHEIT, R. Conceitos fundamentais da teoria de conjuntos fuzzy, lógica fuzzy e aplicações. In: Proc. 6th IFSA Congress-Tutorials. [S.I.: s.n.], 1995. p. 1-38.

INSTITUTO ACENDE BRASIL. Perdas comerciais e inadimplência no setor elétrico. White Paper. Edição no 18, fevereiro/2017.

INSTITUTO ACENDE BRASIL. Política Tarifária e Regulação por Incentivos. Cadernos de Política Tarifária. \#1 2007.

JAMASB, T; NILESSEM, P; POLLIT, M. Strategic behaviour under regulatory benchmarking. Energy Economics, p 825 -843, 2004.

KUMBHAKAR, S.C.; Lien, G. Yardstick Regulation of Electricity DistributionDisentangling Short-run and Long-run Inefficiencies. Energy Journal, v.38, n.5, p. 17-38, 2017.

LEITE; D. A. Definição das metas regulatórias de perdas não técnicas para as distribuidoras de energia elétrica no Brasil: proposição de um modelo baseado na Análise de Fronteira Estocástica (SFA). Rio de 
Janeiro, 2014, p.147. Dissertação (mestrado). Dissertação de Mestrado Departamento de Metrologia, Pontifícia Universidade Católica do Rio de Janeiro.

LEVY, B; SPILLER, P.T. The institutional foundations of regulatory commitment: a comparative analysis of telecommunications regulation. Jornal of lay, economics, and organization, v.10, n2, p. 201-246, 1994.

MARAJ, A.; SHATRI, B.; RUGOVA, S. Selection of defuzzification method for outingmetrics in mpls network to obtain better crisp values for link optimization. In: proceedings of the 7th WSEAS International Conference on System Science and Simulation in Engineering. Stevens Point, Wisconsin, USA: World Scientific and Engineering Academy and Society (WSEAS), 2008. (ICOSSSE'08), p. 200-205. ISBN 978-960-474027-7. Disponível <http://dl.acm.org/citation.cfm?id=1562259.1562297>.

em:

MEDEIROS, S.F. As Agências Reguladoras e a captura: um ensaio sobre os desvios regulatórios na Agência Nacional de Energia Elétrica. Revista de Direito da Administração Pública, ISSN 2595-5667. A.2 Vol 2. Ed.1. p. $122-143,2017$

RAUEN, Fábio José. Pesquisa científica: discutindo a questão das variáveis. Anais do IV Simpósio sobre Formação de Professores SIMFOP . Campus de Tubarão Tubarão, de 7 a 11 de maio de 2012. Universidade do Sul de Santa Catarina.

SHLEIFER, A. A Theory of yardstick competition. Randon Jornal of Economics, v.16, n.3, p. 319-327, 1985.

SOUZA, R. C.; CALILI, R. F.; SIMÕES, P. F. M. Audiência 095/2016. Termo aditivo ao Contrato de Concessão de Distribuição de Energia Elétrica da Enel Distribuição Rio Energia e Serviços S.A.: contribuições e críticas à metodologia de perdas não técnicas. Rio de Janeiro, 2017. Relatório Técnico. Pontifícia Universidade Católica do Rio de Janeiro.

TANURE, J. E. P. S. Proposta de procedimentos e metodologia para estabelecimento de metas de qualidade (DEC e FEC) para concessionárias de distribuição de energia elétrica através da análise comparativa. São Paulo, 2004, p. 249. Tese (doutorado). Departamento de Engenharia de Energia e Automação Elétricas da Escola Politécnica. Universidade de São Paulo.

VERGARA, S. C. Metodologia do trabalho científico. São Paulo: Cortez, 2002.

VIEIRA, B.F. Regulação por incentivos no setor elétrico brasileiro: Instituições e Eficiência. Belo Horizonte, 2014, p.166. Dissertação (mestrado). Programa de Pós-Gradução em Direito. Universidade Federal de Minas Gerais. 
VISCUSI, W. Kip; HARRINGTON JR., Joseph; VERNON, John M. Economics of Regulation and antitrust. Cambridge: MIT Press, 2005.

ZADEH, L. A. Fuzzy Sets. Information and Control, v. 8, p. 338-353, 1965. 